Portland State University

PDXScholar

$1-1-2011$

\title{
The Technological Role of Bone and Antler Artifacts on the Lower Columbia: A Comparison of Two Contact Period Sites
}

Kristen Ann Fuld

Portland State University

Follow this and additional works at: https://pdxscholar.library.pdx.edu/open_access_etds Let us know how access to this document benefits you.

Recommended Citation

Fuld, Kristen Ann, "The Technological Role of Bone and Antler Artifacts on the Lower Columbia: A Comparison of Two Contact Period Sites" (2011). Dissertations and Theses. Paper 580.

https://doi.org/10.15760/etd.580

This Thesis is brought to you for free and open access. It has been accepted for inclusion in Dissertations and Theses by an authorized administrator of PDXScholar. Please contact us if we can make this document more accessible: pdxscholar@pdx.edu. 
The Technological Role of Bone and Antler Artifacts on the Lower Columbia:

A Comparison of Two Contact Period Sites

by

Kristen Ann Fuld

A thesis submitted in partial fulfillment of the requirements for the degree of

Master of Arts

in

Anthropology

Thesis Committee:

Kenneth M. Ames, Chair

Douglas Wilson

Shelby Anderson

Portland State University

(C) 2012 


\begin{abstract}
$\underline{\text { Abstract }}$
This thesis explore the technological role of bone and antler artifacts from two contact period southern Northwest coast archaeological sites, the Cathlapotle site (45CL1) and the Meier site (35CO5). Technological measures of sedentism are based on lithics, and predict residential sedentism promotes technological expediency in huntergatherers (Parry and Kelley 1987). Cathlapotle and Meier lithic assemblages consist of expedient and opportunistic assemblages and raw material stockpiles, with the exception of highly curated projectile points and endscrapers (Hamilton 1994). The expectation that residential sedentism promotes technological expediency in hunter-gatherers was tested on the Cathlapotle and Meier bone and antler artifact assemblages in two ways. First, curation and expediency were recorded for each artifact by measuring level of energy investment in manufacture or degree of working. Second, a spatial analysis was used to explore methods of artifact storage and disposal.

Results revealed both Cathlapotle and Meier osseous assemblages are highly curated, except for expedient awls and flakers. Specifically, artifact classes related to subsistence procurement, modification including woodworking, and ornamentation were highly curated. Both sites contain stockpiles of unmodified bone and antler. The spatial analysis showed level of curation did not affect artifact disposal method. Despite this, some patterns were evident. At Cathlapotle, curated procurement and modification artifacts, expedient awls as well as worked fragments were concentrated outside the houses, specifically in Sheet Midden. Broken modification artifacts, ornaments, and detritus were randomly distributed. At the Meier site, curated procurement and
\end{abstract}


modification artifacts, as well as expedient awls were randomly distributed. Broken modification artifacts, detritus and worked fragments were concentrated outside the houses. Ornaments were concentrated in the northern segment (elite area) of the house. There were also significantly more curated complete tools recovered from the cellar facility, while significantly fewer curated complete tools were recovered from the midden facility at Meier.

In this thesis, the effects of contact on osseous assemblages were examined. It is an assumption of North American archaeologists that European-introduced metals replace and/or change the character of traditional technologies such as lithic and osseous technologies. Few quantitative studies comparing pre and postcontact artifact assemblages exist (Bamforth 1993, Cobb 2003). In some parts of northeast North America, European contact is followed by a proliferation of osseous tool working, and over time osseous artifacts drop out of the archaeological record (Snow 1995, 1996).

Cathlapotle and Meier were occupied from AD 1400 to AD 1830, spanning European contact. People at Cathlapotle were in direct contact with Europeans and EuroAmericans since 1792 (Boyd 2011). Previously, it was assumed Cathlapotle was more involved in the fur trade than Meier, because Cathlapotle was mentioned several times in ethnohistoric accounts, while Meier was never mentioned. Also Cathlapotle contains far more historic trade items than Meier (Ames 2011). The assumption that Europeanintroduced metals replace and/or change the character of traditional technologies is tested on the Cathlapotle and Meier assemblages by comparing artifact frequency, density, and assemblage diversity of pre and postcontact assemblages. 
Results show contact is reflected in the osseous assemblages at both Cathlapotle and Meier. Contact is evident, but is reflected in different ways. At Cathlapotle, artifact frequencies, densities, and assemblage diversity decreases postcontact. In contrast at Meier, artifact frequencies and densities increase postcontact, with some artifact classes tripling or quadrupling in frequency. The introduction of metal could have enabled people to work osseous materials faster and easier, decreasing manufacture time, cost, and overall energy investment. The gain in efficiency promoted the proliferation of bone working and an abundance of osseous tools at the Meier site. These results encourage a reevaluation of Meier's role in the fur trade. At Cathlapotle, metal objects may have replaced osseous tools resulting in the decline of bone and antler working and/or activity patterns shifted away from activities requiring osseous tools. The results of this thesis deviate from typical Northwest Coast bone and antler assemblages, challenge technological models of sedentism that are based on lithics, and contradict assumptions of lower Columbians involvement in the fur trade. 


\section{$\underline{\text { Acknowledgments }}$}

Many people were supportive during my time in graduate school and especially during the thesis writing process. First and foremost Dr. Kenneth M. Ames, my thesis advisor and mentor, provided the utmost support and guidance over the years. Without your patience and willingness to discuss ins and outs of my research I would not have made it this far. I thank my thesis committee members, Dr. Douglas Wilson and Dr. Shelby Anderson and also Dr. Virginia Butler. A special mention to my undergraduate professors, Dr. R. Lee Lyman, Dr. Todd Vanpool, and Dr. Christine Vanpool of the University of Missouri Columbia. The three of you believed in me, influenced me, and encouraged me to pursue a graduate education. My community college professor and advisor Mr. William Griffin, without your enthusiasm for archaeology I would not be an archaeologist. I thank all of those who have employed me over the years, Bill Roulette, Alexander Gall, and John Fagan and Jo Reese. Thanks to Greg Baker for irreplaceable help with artifact photography.

I thank my cohort, Meris Mullaley. I have fond memories of late night cups of coffee with you. Special thanks to all of my loving and supporting friends, Renee Preslow, Shannon Kolve, Sara Davis, Karla Hambelton, Katie Wynia, Emily Shepard, Megan Wilson, and Juan Esteban Zea. Thanks and love to my family, my mother, Carol, my father, Walter, and my brother, Wally. Finally, I thank my "Portland Family" Dana Holschuch, AnnieMorrill, and Angela Paolucci. I am truly lucky to have you three as classmates and friends. 
Abstract..........................................................

Acknowledgements..............................................iv

List of Tables.................................................. vii

List of Figures.................................................

Chapter 1: Introduction...........................................

Chapter 2: Bone and Antler Technology............................... 7

Raw Materials...............................................

Tool Manufacture...........................................10

Chapter 3: Environmental and Archaeological Background.................19

Environment and Ethnohistory............................. 19

Regional Chronology.......................................22

Contact and the Introduction of Metal...........................23

The Cathlapotle and Meier Sites..............................25

Site Formation Processes......................................30

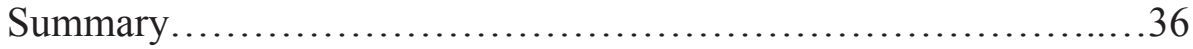

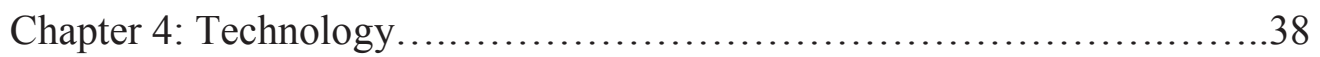

Chapter 5: Formulating Hypotheses and Test Expectations................52

Residential Sedentism Promotes Technological Expediency in Hunter-Gatherers...........................................52

Contact and the Introduction of Metal...........................55

Chapter 6: Methods.............................................. 58

Data Collection.........................................58

Analysis Methodology........................................63

Chapter 7: Results..............................................69 
Table of Contents Continued

Residential Sedentism Promotes Technological Expediency in

Hunter-gatherers........................................69

Whole assemblage......................................71

Procurement artifacts..................................72

Modification artifacts..................................76

Awls..........................................79

Ornaments.......................................... 80

Other artifacts............................................ 81

Contact and the Introduction of Metal.............................84

Chapter 8: Discussion and Conclusions............................... 89

Characterizing assemblages...................................89

Hypothesis 1: Sedentism promotes expediency....................91

Hypothesis 2: Curated complete tools should be stored, broken curated and expedient tools should be discarded....................93

Hypothesis 3: Contact should be reflected within osseous assemblages at Cathlapotle and Meier................................97

Conclusions.............................................. 98

References....................................................... 102

Appendix A: Artifact Classification................................... 120

Appendix B: Observed and Expected Artifact Counts for Significant

Chi Square Tests....................................... 162 


\section{List of Tables}

Table 1

Characteristics of reliable and maintainable systems........................41

Table 2

Durability of bone and antler points versus stone points....................49

Table 3

Lists of artifact classes designated into Raetz's categories.....................53

Table 4

Text expectations of Hypothesis 3 and their possible implications...............57

Table 5

Meier facility volume and percentages................................. 67

Table 6

Meier location volume and percentages................................67

Table 7

Cathlapotle facility volume and percentages.............................68

Table 8

Cathlapotle location volume and percentages.............................6 68

Table 9

Artifact count and frequency per $\mathrm{m}^{3}$ for both sites......................... 70

Table 10

Results of chi squared tests for complete, broken, and all artifacts for Cathlapotle..74

Table 11

Results of chi squared tests for complete, broken, and all artifacts for Meier.......75 


\section{List of Tables Continued}

Table 12

Counts and frequency per $\mathrm{m}^{3}$ of precontact and postcontact assemblages............84

Table 13

Counts and frequency per $\mathrm{m}^{3}$ of Cathlapotle site artifact classes pre and postcontact...86

Table 14

Counts and frequencies per $\mathrm{m}^{3}$ of Meier site artifact classes pre and postcontact.......87 


\section{List of Figures}

Figure 1

Map depicting site locations...............................................

Figure 2

Map of the Meier site plankhouse facilities and excavations........................27

Figure 3

Topographic map depicting Cathlapotle.........................................29

Figure 4

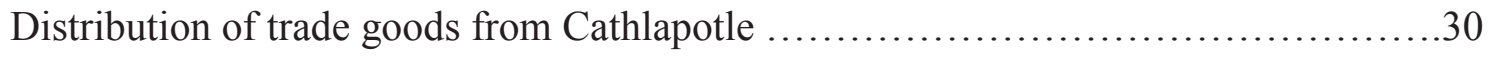

Figure 5

Dorsal and ventral surfaces and attributes recorded.............................60

Figure 6

Osseous artifact elements.................................................61

Figure 7

Illustration of Meier house architectural facilities in systemic context................66 


\section{Chapter 1}

\section{$\underline{\text { Introduction }}$}

Osseous materials, including bone, antler, teeth, and ivory, consistently receive less attention from archaeologists than other raw materials, such as lithics and ceramics. Often, osseous materials are simply counted and described (Clark 1989). Attention is focused on shape and decoration, ignoring technological aspects such as design attributes and production method. This limited attention can be attributed to the fragility and rarity of osseous tools in the archaeological record (LeMoine 1994).

This thesis explores the role of bone and antler tools at two residentially sedentary, contact-period, southern Northwest Coast sites, the Cathlapotle site (45CL1) and the Meier site (35CO5). Technological models of sedentism predict increased residential sedentism promotes expediency in hunter-gatherer lithic assemblages (Hamilton 1994, Parry and Kelly 1987). In this thesis, this expectation is tested on the Cathlapotle and Meier bone and antler assemblages. Results deviate from typical Northwest Coast osseous assemblages, contradict the prediction that sedentism promotes technological expediency, and show that technological measures of sedentism based on lithics do not translate to organic technologies. Additionally, this thesis examines the wide spread informal assumption among archaeologists that European-introduced metals replace and/or influence traditional technologies, such as bone and antler. Based on my review of the available literature, quantitative studies directly comparing late precontact and early postcontact assemblages are rare in general and non-existent for bone and antler tools. To examine the effects of European contact on Cathlapotle and Meier osseous assemblages, the precontact and postcontact assemblages are compared. Results of this 
research questions assumptions of Lower Columbian involvement in the fur trade, and provides a new line of evidence to explore contact at Cathlapotle and Meier.

Technological measures based on lithic tools predict that a sedentary residential pattern promotes the use of expedient tools. Curation and expediency represent poles of a continuum. An expedient strategy anticipates sufficient materials and time to make tools when needed. Expediency is materially wasteful and represents a minimal technological effort where tools are produced when needed, used, and discarded at their use location (Nelson 1991). Sedentary conditions allow past toolmakers the space and time to create a raw material stockpile for expedient chipped stone tool making and use (Hamilton 1994, Nelson 1991, Parry and Kelley 1987). Expediency can be contrasted to tool curation. Curation is a planned strategy, which anticipates future need for materials and tools at use locations (Nelson 1991). Curated artifacts are typically well-made, specialized, formal tools with high levels of investment and maintenance (Binford 1977, Torrence 1989, Weissner 1982). These tools are cared for, transported to their use location, intensively maintained, and stored when not in use. A high technological investment is worthwhile as curated tools are more efficient than expedient tools and have long use lives (Binford 1977); these benefits off-set the increased time and materials needed to manufacture curated tools. This thesis is, at its essence, an exploration of expedient and curated osseous tool technologies among one set of residentially sedentary hunter-gatherers.

A common assumption of North American archaeologists is that Europeanintroduced metal tools replaced traditional technologies (Bamforth 1993). In eastern North America metal replaced many traditional technologies, iron axes replaced ground 
stone ones, copper and ferrous metal points replaced stone and bone points (George and Preston 1987). Snow's research in the Mohawk Valley of New York state suggests the introduction of metal cutting tools coincides with a florescence of elaborate bone work and fine bone carving allowing the manufacture of items or designs impossible to create without metal cutting tools (Snow 1995, Snow 1996). This florescence of osseous tool working is followed by a decline in bone and antler tool frequency and osseous artifacts eventually drop out of the archaeological record.

Cathlapotle and Meier are located about 5.5 miles $(8.9 \mathrm{~km})$ apart on opposite sides of the Lower Columbia River floodplain near Portland Oregon (Figure 1). The region supported some of the densest populations in prehistoric North America (Ames and Maschner 1999, Boyd and Hajda 1987). The sites contain remains of large wooden plankhouses, associated midden(s), and yard deposits. Cathlapotle contains six structures, while Meier just one. Architectural features, artifact analysis, and ethnohistoric records indicate residents of Cathlapotle and Meier were sedentary huntergatherers (Ames 2011, Ames et. al 1999, Smith 2008). 


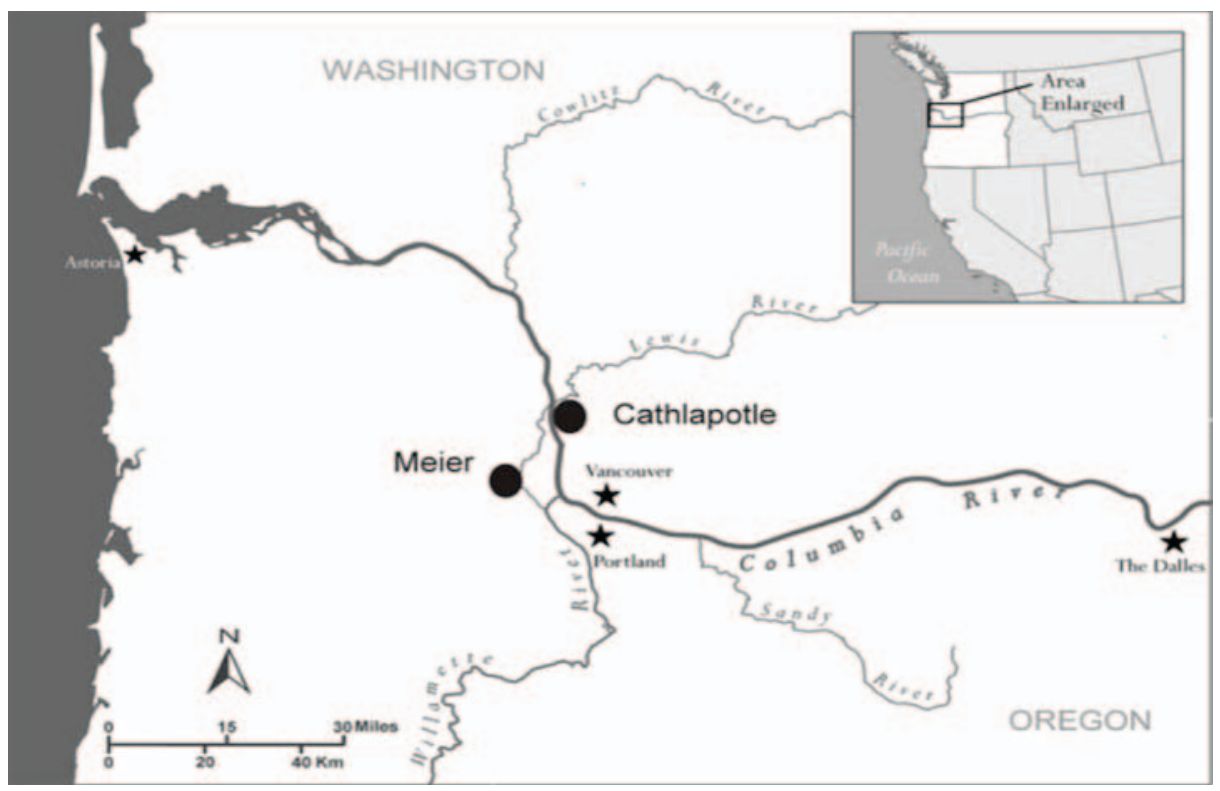

Figure 1: Map depicting site locations.

Cathlapotle and Meier span the contact era dating from AD 1400 to AD 1830 (Ames et. al 1999). Several Europeans observed and described Cathalpotle, including Lewis and Clark, who visited the site in 1806 (Moulton 1999). There are no ethnohistoric accounts of the Meier site (Sobel 2004). Measures of contact, including presence and abundance of beads and metal, suggest Cathlapotle was deeply involved in the fur trade, while Meier was only marginally involved (Ames and Sobel 2009, Ames 2011). However, presence and abundance of ceramics from both sites suggest occupants of each were equally involved in the fur trade (Cromwell 2011).

These two sites provided an opportunity to evaluate the role of bone and antler among sedentary hunter-gatherers and to examine postcontact changes in osseous assemblages. Both sites are geographically close, occupied at the same time, span contact, and are riverine, which contrasts with most Northwest Coast bone and antler studies, which are on coastal sites (Ames 2005, Campbell 1981, Raetz 1989). The lithic 
assemblages are typical of residentially sedentary hunter-gatherers, consisting of an expedient and opportunistic assemblage of used flakes, unstandardized core reduction, and a large raw material stockpile (Hamilton 1994). Lithic tool curation is minimized and is evidenced in few specialized tool types that require expensive raw material or reliable designs, such as projectile points and endscrapers.

For this thesis, the Cathlapotle osseous assemblage was analyzed using a methodology developed by Ken Ames and compared to the previously analyzed Meier assemblage (Ames 1976, Ames 2005, Davis 1998). The expectation that sedentism promotes technological expediency was explored in two ways. First, osseous artifacts were evaluated for how curated or expedient each was. This was achieved by measuring energy investment in artifact manufacture or degree of working. Second, artifact storage and disposal methods were examined using a spatial analysis. Curation/expediency research emphasizes that curated tools should be maintained and stored after use, while expedient tools should be discarded after use (Nelson 1991, Weissner 1982). Chi square tests were used to identify concentrations of artifacts within specific spatial locations. The effects of contact on an osseous assemblage were investigated by comparing precontact and postcontact artifact frequency and density and assemblage diversity. Cathlapotle and Meier precontact and postcontact assemblages were compared as well.

Chapters 2-4 are background chapters and describe the physical properties and durability of bone and antler (Chapter 2), Cathlapotle and Meier site descriptions, formation processes, and effects of European contact (Chapter 3), technological organization and sedentism (Chapter 4). In Chapter 5, I draw from the three background chapters and formulate my hypotheses. Data collection and analysis methodology are 
explained in Chapter 6. I present and describe the results from testing hypotheses in Chapter 7, and discuss their implications in Chapter 8. 


\section{Chapter 2}

\section{Bone and Antler Technology}

Osseous technology is understudied in comparison to other archaeological tool types. Research in lithic technology has shown it is fundamental to understanding the physical properties of stone, lithic fracture mechanics, and reduction sequences of stone tools in order to theorize about technological organization (Andrefsky 1994, Cotterell and Kamminga 1987). Raw material attributes including quality, durability, and accessibility shaped hunter-gatherer mobility and technological choices, and provides a foundation for technological organization studies (Andrefsky 1994, Bamforth 1986, Brantingham 2003, Kelly 1988, Kelly and Todd 1988). It is necessary to understand osseous raw material qualities, tool manufacture time, and reduction techniques to evaluate the role of osseous materials in technological systems. The following outlines bone and antler as raw materials, osseous fracture mechanics, and the steps of osseous tool manufacture.

\section{$\underline{\text { Raw Materials }}$}

Bone and antler are comprised of both mineral and protein, creating raw materials that are rigid and strong, yet flexible and elastic. These properties enable osseous tools to absorb shock, and withstand high levels of force, damage, and wear (Johnson 1982). In other words, bone and antler tools are naturally durable. In addition, osseous tools break infrequently, are easy to repair, and their raw materials can virtually be obtained everywhere (Knecht 1997, Lyman 1984). The flexible nature of bone and antler allows tools to be shaped into a great variety of forms, permitting the manufacture of complex formed tools (Torrence 1989). 
Bone is a viscoelastic composite material, with inorganic and organic components (Johnson 1989). Bone is 70\% mineral (hydroxyapatite) and30\% protein (collagen). Collagen is a soft, fibrous, connective tissue. Collagen fibers intertwine to form a matrix. Hydroxyapatite, a dense crystalline calcium phosphate compound, is embedded within the collagen matrix (White 2000). Hydroxyapatite makes bone strong and rigid, while collagen gives bone resilience and elasticity (Ogle2004). Without a mineral content, bone would be rubberlike. Without protein, bone would be very brittle (White 2000). The combination of the two materials gives bone hardness, rigidity, flexibility, and elasticity required to respond to stress.

Most bone tools are made from terrestrial mammal and bird bone. Bone tools are typically made using cortical bone from the shafts of long bones, such as limb bones and metapodials (Campana 1989). Bone tools are limited in form and size due to original morphology of unmodified bone. Bones which are comprised of mostly cancellous bone, such as vertebrae or innominates, or irregularly shaped bones, such as skull bones, are not typically suitable for tool making. Long bones are anisotropic (Johnson 1989). A long bone consists of a cylindrical diaphysis (the shaft) and two epiphyses (the ends).Bones are comprised of cortical and cancellous bone. The molecular and cellular composition of cortical and cancellous bone tissue is the same; the only difference between the two is porosity (White2000). Cortical bone (also called compact bone) is solid and dense and forms the external surface bone. It grows cylindrically along walls of bone shafts surrounding a cavity containing cancellous bone (also referred to as trabecular or spongy bone). Cortical bone is thickest at the center of the diaphysis, and becomes thinner nearing the epiphyses. Long bone ephiphyses house more cancellous bone than 
diaphyses. Cancellous bone is lightweight, porous, and less dense than cortical bone (Schwartz 1995). In terrestrial mammals, cancellous bone houses red marrow, while cancellous bird bone houses calcium for bird shell production (Campana 1989, Ogle 2004).

In terrestrial mammals, the transition between cortical and cancellous bone is abrupt and easily seen (Petillon 2008). The distinction is not apparent in sea mammal bones. Sea mammal bone is intermediate between cortical and cancellous bone. It is very dense to promote buoyancy, therefore is more difficult to shape than terrestrial mammal bone (Johnson et al. 2000). Sea mammal bone, however, may be preferred for artifact manufacture because they tend to be larger and allow greater elaboration of form and size in artifacts. For example, large clubs from the Northwest Coast are constructed of whale bone (Ames 1976).

Cortical bone is comprised of thin layers of calcitic bone matrix called lamellae. Lamellae are concentrically deposited around a nutrient canal. Collectively, these are known as a haversian system, or osteon. The haversian system is the basic structural unit of bone (White 2000). Haversian systems are oriented parallel to a bone's long axis and provide nutrients to cortical bone (Campana 1989).Cancellous bone receives nutrition from blood vessels in marrow space, and lacks haversian systems. The organization of haversian systems is what gives cortical bone its unidirectional grain along the long axis. The unidirectional grain of cortical bone gives bone resilience and strength.

Bone is highly elastic, flexible, built to absorb shock, and is resistant to breakage. Bone can withstand a great amount of stress. When bone is struck, plastic deformation from stress occurs (Johnson 1989). If a bone is not struck hard enough, without enough 
stress to cause microcracking, irreversible deformation can occur. When stress is too great, microcracking occurs leading to bone fracture. Common bone fractures include longitudinal, transverse, and spiral. Longitudinal fracture is splitting bone with the grain parallel to the long axis. Transverse fracture is breaking bone in half against the grain, perpendicular to the long axis. Spiral fracture is a tensile-shear fracture, and is caused by twisting of bone on impact (Johnson 1989). Spiral fracture is considered characteristic of green fresh bone, but Myers et. al. (1980) suggests weathered bone that is not completely dry will also produce spiral fractures.

Antlers are annual bone growth. Antler is molecularly similar to bone, but has less mineral content, causing it to be more flexible than bone. Similar to bone, antler is comprised of a core of cancellous bone surrounded by cortical bone. Cancellous bone decreases towards the tine tips, which are comprised entirely of cortical bone. During life, bone is surrounded by periosteum, a thin tissue layer. Periosteum coats the outer surface of bones and functions in the attachment of tendons, and carries blood cells, lymphatics, and nerves (Schwartz 1995, White 2000). Antler is surrounded by velvet, which is similar to periosteum. Blood vessels within velvet and antler itself provide nutrients and oxygen to the antler. Velvet is shed when antler growth is complete. Blood vessels within the velvet and antler dry out and are shed at the end of the season.

\section{$\underline{\text { Tool Manufacture }}$}

Bone and antler are extremely accessible raw materials and can be obtained everywhere. Bone and antler acquisition was likely embedded into prehistoric subsistence schedules (Binford 1979). This accessibility frees hunter-gatherers from dependence on lithic resources. Although osseous materials are more accessible than stone materials, 
making formal bone and antler tools can be more time consuming than stone tool manufacture, which may affect choice of raw material. Additional advantageous exist for each raw material and are described in Chapter 4.

Once raw materials are obtained, they must be cleaned of tissues if fresh, or soaked and softened if dry. Fresh bone, also referred to as green bone, is less brittle and more pliable, making it much easier to work than dry bone (Ogle 2004). Stanford et. al's (1981) experimental work on elephant bone demonstrated that green bone is very easy to work and resistant to fracture, while dry bone shattered upon fracture. White (1977) also attests to the ease of working green bone.

Antler becomes dry on living animals prior to shedding, and therefore must always be soaked and softened prior to working. Bone and antler may be simply soaked in boiling water or submerged in another liquid such as saltwater or rainwater (Campana 1989). Experimental studies suggest both soaked bone and antler regain hardness quickly, and repeated softening throughout the tool manufacture process is necessary to maintain softness (Campana 1989).

Once bone and antler have been prepared for tool making by means of cleaning and softening, the next steps are to create blanks to make tools and then to shape the blanks into tools (Newcomer 1974). Tool blanks can be produced by percussion, or the "groove and splinter" method. Percussion is to strike a bone with a percussor or hammer, for example a cobble. Bone percussion will sometimes exhibit hertzian cone patterns, bulbs of percussion, and flake scars, much like lithic fracture patterns. But the unidirectional grain of long bones often causes rough irregular fractures, producing large amounts of small bone fragments and bone splinters that are unsuitable for tool blanks. 
Percussion of osseous materials is an inexact, wasteful process (Ogle 2004). Bone can be flaked, in a similar manner as in the early stages of lithic reduction. Stanford et. al's (1981) experimental work outlines the bone flaking, also referred to as bone quarrying, process. Bone flakes can be detached from a core parallel to the longitudinal axis's unidirectional grain. Stanford et. al also note bone flakes become dull very quickly, and resharpening of bone flakes is difficult, therefore bone flakes were likely created and used expediently (Stanford et al. 1981). Adze work or chopping is considered another type of percussion reduction. Repeated adzing of bone or antler will remove flakes and leave striations and negative flake scars. Other methods used to shape blanks into tools, such as abrasion, will obliterate most signs of percussion and blank manufacture.

Grooving, cutting, or sawing into bone to divide, snap and split it into two is referred to as the "groove and splinter" or "saw and snap" method (Campana 1989, Newcomer 1974). The "groove and splinter "method is often used to remove articular ends, resulting in detritus that consists of a bone fragment with one articular end and a rough opposing end with striations and remains of a groove running around the diaphysis. Replication studies show this method is difficult to start and produces many error strokes (Ogle 2004). Despite these problems, The "groove and splinter" method is the most efficient and least wasteful method of creating bone blanks (Campana 1989, Ogle 2004, Newcomer 1974).

In addition to percussion and the "groove and splinter" method, bone blanks can be obtained by heat as well as the taut cord method. Heating bone to very high temperatures causes it to shrink and split into long thin fragments (Campana 1989). This method was observed being used by Salish speakers to obtain fragments to make needles 
(Ray 1933as cited in Campana 1989). The taut cord method refers to wrapping a wet cord that has been rolled in sand around a long bone, holding it taut, and moving it back and forth. The sand and fibers from the cordage saw into the bone. This is a form of abrasion that effectively and quickly saws through bone. Replicative studies show both the base and the wall of the bone cut using this method are smooth and polished (Campana 1989).

Once a blank of suitable size and shape is created, bone is shaped into tools by scraping and abrasion, and may be finished with perforation or polishing. Scraping involves literally scraping layers of bone using a stone tool such as a scraper, blade, or burin. Scraping leaves many irregularities such as chattermarks that result when a tool digs too deeply into bone (Campana 1989, Newcomer, 1974, Ogle 2004, White 1977). An alternative to scraping is abrasion, which is done with either a hand-held abrader run across bone, or the opposite, running a bone across a large abrasive stone slab. Abrasion produces fewer irregularities and shapes bone faster than scraping. Abrasion or grinding that is parallel to the long axis and grain of a bone is called axial grinding while abrasion that is perpendicular to the long axis of a bone is referred to as cross grinding (or transverse abrasion). Axial grinding is effective when shaping a symmetrical object. It is slow yet produces a surface with even curves and sharp tips. Cross grinding is a faster method because the angle of grinding is not fixed as it is in axial grinding. It is useful for reducing, flattening, and rounding a bone. Replicative studies show that abrasion is much more effective if the working surface is constantly flushed with water, or if abrasion is completed under running water (Newcomer 1974). 
Finishing techniques include perforation and polish. Perforations in bones are created using a stone tool. Perforating bone is time consuming and often results in a biconvex hole surrounded with striations. Polish is observed on many bone tools. Polish is evidenced as a smooth sheen along the bone surface or edge. When bone or antler comes in contact with a soft material, such as hide, polish is produced. If polish is ubiquitous, it is viewed by researchers as intentional and created through manufacture. If it is near the tip or working end, it is assumed to be created through use. In addition, body oils resulting from handling of artifacts post excavation can create a polish-like sheen as well. Ethnographers observed Salish speakers and Aleut polishing finished bone and horn artifacts with both pumice and horsetails (Campana 1989). Polish on bone and antler artifacts eliminates traces of previous reduction methods.

Osseous tool manufacture is a multi-step process involving several reduction techniques. Since each step in bone tool manufacture eliminates traces of previous reduction methods, an osseous tool reflects only the final type of modification. In addition, multiple manufacture methods can achieve the same tool morphology (Newcomer 1974). It is often impossible to tell how an osseous tool was manufactured. Many curated bone and antler tools exhibit heavy abrasion and polish, the final types of modification.

Experimental work indicating manufacture time for osseous tools manufacture is rather ambiguous. Elston and Brantingham (2002) state it takes more time to manufacture an organic point than a stone point. Frison and Zeimens (1980) replicated a large bone projectile point like those found at Folsom levels at Agate Basin sites of the Great Plains and Rocky Mountains. Using stone tools to create a blank and abrasion to 
shape the point, the entire process took over three hours to complete. In contrast, Campana (1989) stated it took him ten to fifteen minutes to complete a simple pointed bone implement using scraping. It took five minutes to complete a bone pointed implement using abrasion, and five to ten minutes to complete a spatulate implement. Lyman (1984) suggests expedient bone tools can be made very rapidly at butchery stations from the bones of the animal undergoing processing. Therefore, bone tool manufacture may or may not take more time than stone tool manufacture. Manufacture time and investment reflects whether bone tools were expedient tools or curated tools. Formed, curated tools have a higher level of investment and take longer to create than expedient tools. Complexity of a tool will increase manufacture time as well.

The methods described to reduce and shape bone into the tools described above, are not always used or needed to produce a workable bone tool. Many bone expedient tools (sometimes called "fracture-based-tools") exhibit no modification other than fracturing prior to use (Johnson 1989). They lack evidence of manufacture modification that results from cutting, grooving, and abrading (Lyman1984). Bones such as these are modified by use, rather than modified for use (Shipman 2001). For example, splinter awls often exhibit no modification other than use on the pointed tip area. Splinter awls are utilized pointed bone splinters that are the numerous byproducts of long bone fracture.

Expedient bone tools are frequently found at butchery sites in the Great Plains, where often only expedient bone tools, functioning as choppers, muscle separators, knives, and scrapers, are recovered. Tools are made from the animals being processed, are used during processing, and are discarded at the butchery site. Some expedient tools 
are simply utilized (unmodified before use) while others are intentionally shaped. In addition, bone flakes are simple to produce and are effective butchery tools. Bone flakes dull quickly and were likely expediently used and discarded once dulled. All one needs is the knowledge to kill an animal and to produce and use bone expediency tools (Johnson 1982). Embedding butchery tool production in the butchery process likely enhanced prehistoric mobility (Stanford et. al 1981).

Naturally modified bones are often mistaken for expedient tools and are termed "pseudo-tools" (Brain 1967). There has been great debate regarding what is and how to identify an expedient bone tool, often related to bone fracture type (Brain 1967, Brain 1981, Fisher 1984, Johnson 1989, Lyman 1984, Myers et. Al 1980). Previously, research identified culturally modified bone tools (later determined to be pseudo-tools) by the presence of a spiral fracture. Taphonomic research has questioned the validity of this criterion and found that spiral fractures are often created during butchery, by carnivores, trampling, and other natural agents including wind, water, sedimentary abrasion, frost action, soil acidity, and falling rock, and are present in very early fossil assemblages where hominid modification is impossible (Lyman 1984,Myers et. Al 1980). Taphonomy is the study of the laws of destruction and burial and the interval between living communities and fossilized communities (Shipman 2001). Taphonomic research considers the processes and conditions that have altered a bone assemblage to the condition upon discovery. Bone is greatly affected by taphonomic agents, and may literally disappear from archaeology sites.

Recent research has focused on characterizing usewear to identify expedient tools (Brain 1967, Bonnichsen 1982, Fisher 1984, Johnson1989, LeMoine, 1980, Lyman 1984, 
Myers et al. 1980, Shipman 2001).Brain (1967) and Bonnichsen (1982) emphasize the importance of identifying patterned wear, which they define as isolated wear on one area of the tool rather than all over wear, when identifying a bone as having been culturally modified. Macroscopic usewear, similar to lithic usewear, such as accidental flaking, pitting/crushing, striations, polish, and edge-rounding are used as indicators of cultural modification (see Johnson 1989 and Semenov 1967 for osseous usewear descriptions).Scanning electron microscopes are used to identify microscopic usewear on osseous artifacts (Shipman et al. 1984, Shipman 2001). LeMoine (1984) utilized the principles of tribiology - the science of friction, lubrication, and wear to characterize microscopic usewear. LeMoine (1984) created experimental tools, used them on various surfaces, studied the resultant wear through the lens of tribiology, and compared the results of the experimental study to archaeological collections. Through this study LeMoine (1984) was able to describe the physics of bone alteration through use as well as the mechanisms underlying the creation of use wear (LeMoine 1984). Experimental work, comparative collections, considering taphonomy and tribiology, and patterned usewear studies all lead towards a greater understanding of expedient and early osseous technologies.

This chapter outlined the physical properties of bone and antler that give each the flexibility, rigidity, and durability necessary for tool manufacture. Experimental research on osseous tool manufacture methods indicate that osseous tool manufacture was a multistep, staged process requiring a greater time investment than stone tool manufacture (Campana 1989, Frison and Zeimens 1980, Newcomer 1974). Curated osseous tool manufacture may have necessitated specialists who were able to invest time into making 
long use life durable tools. Although bone and antler is extremely durable, it is a flexible material and can be easily worked and is often part of simple expedient technologies. 


\section{Chapter 3}

\section{$\underline{\text { Environmental and Archaeological Background }}$}

The following chapter consists of background, including an environmental summary of the Lower Columbia and ethnohistory of Chinookan people living in the Lower Columbia region during European contact. The focus is on the history of European contact in this region and introduction of trade goods, particularly metal, in the Lower Columbia region. Site description, site history, and site formation processes are provided in this chapter as well. A detailed discussion of site formation processes is essential background for the spatial analysis described in Chapter 6.

\section{Environment and Ethnohistory}

The Lower Columbia River region, a 190 mile $(310 \mathrm{~km})$ stretch, from the mouth of the Columbia River to The Dalles, Oregon, encompasses the Columbia River floodplain, inland prairies, the Cascade foothills, and the coastline adjacent to the river's mouth. The Portland Basin, also known as the Wapato Valley, extends along the Columbia River from its confluence with the Sandy River downstream to its confluence with the Cowlitz River and the Willamette River from its confluence with the Columbia River to Willamette Falls at Oregon City (Ames et al. 1999). The Wapato Valley's topography is variable ranging from the steep basaltic ridge known as the Tualatin Mountains paralleling the west bank of the Columbia, to alluvial floodplains with islands and elevated landforms (levees and rock outcrops) interspersed with low wetlands, lakes, and meadows, to interior flat grass prairies and oak savannas broken up by groves of fir trees, to the sloping foothills of the Cascades east of Portland (Pettigrew 1981). Climate in the area is characterized by mild, wet winters and warm, dry summers. Native people 
in the area subsisted on seasonal fish runs, including salmon, sturgeon, eulachon, and resident fresh water fish such as minnows and suckers, terrestrial mammals, primarily deer and elk, and plant foods including berries, roots, and tubers such as wapato and camas. Many resources were found at riverine locations while others were available in the interior and upstream locations (Boyd and Hajda 1987). People migrated to temporary villages at hunting, fishing, and gathering locations based upon seasonal availability of resources, while maintaining permanent winter villages like Cathlapotle and Meier (Silverstein 1990).

At European contact the people who inhabited the Lower Columbia River region spoke Chinookan languages and are collectively known as Chinookans (Thompson and Kinkade 1990). Prehistorically the Portland Basin contained a high density of villages lining the banks of the Columbia and associated water bodies. People occupying this area and the greater Northwest Coast are considered complex hunter-gatherers. Complex hunter-gatherers did not farm and maintained hunter-gatherer subsistence, yet had sophisticated social structures and cultural traditions usually found in agricultural societies. Lower Columbian groups were residentially sedentary occupying large plankhouses, were socially stratified by wealth and ascribed status, and maintained some of the highest population densities in native North America (Ames 2011). Northwest Coast societies were organized by household; plankhouses were a central social, political, and economic institution of the prehistoric Northwest Coast (Ames et al. 1992). The rich and diverse, yet seasonal and patchy environment supported dense populations, in part through bulk harvesting of resources for winter stores. Slave labor and the work of free 
individuals contributed to household production of means necessary to harvest resources in bulk and to maintain plankhouses and complex societies of the Lower Columbia.

In addition to the archaeological record, a rich ethnohistoric and ethnographic record provides important context for this research. European explorers entered the mouth of the Columbia and reached Cathlapolte by 1792 (Gibson 1999). William Broughton, a British naval officer working for George Vancouver, provides the earliest reference of Cathlapotle (Sobel 2004). He traveled to Sauvie Island in 1792 and described Cathlapotle as a large village with a population of about 1,000 individuals. Broughton also states Cathlapotle residents were eager to trade with Euroamericans and attached high values to metal weapons (Ames and Sobel 2009). In addition to Broughton, Lewis and Clark observed and wrote about Cathlapotle. They saw the village twice, once in November of 1805 on their voyage to the coast and again in March of 1806on their return voyage (Moulton 1990). Lewis and Clark noted the presence of fourteen houses, while only six houses were observed and confirmed archaeologically. Additionally, Lewis and Clark noted Cathlapotle residents possessing iron sword-like implements three to four feet in length (Ames et. al 1999, Moulton 1990).

British, Euro-American and Russian fur companies established several trade outposts along the Pacific coast and the interior along major rivers during Cathlapotle and Meier's occupation. Permanent American trading posts such as Fort Astoria were established by 1811 (Silverstein 1990). Occasionally Cathlapotle residents traveled to Fort Astoria to trade with Euro-Americans (Ames and Sobel 2009). Fort Vancouver, the headquarters of the Hudson's Bay Company's Columbia Department was established in 1825 on a bluff overlooking the Columbia. Fort Vancouver was very close to Cathlapotle 
and residents likely had regular contact and trade with the Hudson's Bay Company (Merk 1931).

Prior to European contact, Alaskan copper was traded via long complex trade networks amongst high status individuals (Ames 2011, Banach 2002). Metal was highly valued and a marker of social status, both pre and postcontact (Gibson 1999, Kaehler 2002, Moulton 1990, Plummer 1991). Native Lower Columbians may have been introduced to trade metals through Asian and European shipwrecks centuries prior to direct contact (Ames and Sobel 2008, Plummer 1991). Both Cathlapotle and Meier produced several iron and copper artifacts including: nails, bullets, musket balls, knives, blades, projectile points, Chinese coins, items of adornment, copper sheets and many metal fragments (Ames 2011).

\section{Regional Chronology}

It is thought that prehistoric lifeways of the Northwest Coast were consistent for the last 3,500 years (Ames 2005).Material culture of the Late Pacific (1,800-200 BP) probably differed little from ethnographically observed Northwest Coast cultures. Plankhouses and large winter villages were found along the coast during the Late Pacific. Many Northwest Coast sites are dominated by bone and antler tools and the use of chipped stone declines in places it was previously very important, such as the Gulf of Georgia and the San Juan Islands (Carlson 1960, 1982).

The known archaeological record of the Lower Columbian floodplain begins around 2,500 BP, but projectile points in the uplands suggest a much earlier presence (Sobel 2004). The region contains a multitude of sites, but most are poorly reported 
and/or represent surface remains or eroding cutbanks (Dahnke 2009, Pettigrew 1981).

Sites range from large village sites along the shores of the Columbia River and associated water bodies to small special purpose sites in the foothills of the Cascades. The Vancouver Lake/Lake River Archaeological District (VLLRAD) includes 91 sites surrounding the shores of Vancouver Lake in Clark County, Washington. At least 20 Lower Columbian sites contain house features, including the Bachelor Island site (45CL43), Herzog (45CL11), the Broken Tops site (35MU57), and Cathlapotle (45CL1) and Meier (35CO5) (Sobel 2004).

Occupations at Cathalpotle and Meier, from AD 1400 to AD 1830, fall into Ames and Maschner's (1999) Late Pacific and Modern phases and Pettigrew's (1981) Multnomah 2 and Multnomah 3. The two sites were occupied for approximately 350 years before European contact and then about 40 years postcontact from about AD 1790 to AD 1830. Cathlapotle was described by European and Euro-American observers several times, while Meier was never mentioned (Ames and Sobel 2009, Moulton 1990). By the 1830 's $75-90 \%$ of native populations had died of epidemics brought by Europeans and Euro-Americans, including malaria, measles, influenza, and venereal diseases (Hajda in Ames 1994). By the 1850's most surviving Chinookans were relocated to reservations.

\section{Contact and the Introduction of Metal}

It is a wide spread informal assumption among archaeologists that after European contact indigenous societies quickly abandoned traditional technologies in favor of European-introduced metal objects (Bayman 2003, Silliman 2003). Metal objects are assumed to be technologically superior and more efficient than traditional technologies 
(Bamforth 1993). Traditional technologies are expected to drop out of the archaeological record after contact (Bamforth 1993, 2003, Cobb 2003, Snow 1996). This assumption remains largely untested as quantitative studies directly comparing precontact and postcontact assemblages are rare.

Throughout North America, metal tools were in high demand by native people when the fur trade began. On the east coast of North America, metal cutting tools such as hatchets, axes, arrowheads, sword blades, and knives were popular as well as needles, ice picks, flint and steel for fire starting, kettles, and firearms (George and Preston 1987). Metal was economized and curated, when items reached the end of their use-lives, they were recycled. Copper and brass kettles were cut up and used to manufacture arrowheads, cutting tools, and ornaments. Metal is extremely durable and dulls less quickly than stone or osseous tools. Metal tools came to be universally valued for utilitarian advantages. A growing demand for this new raw material quickly made natives reliant on European metal suppliers (George and Preston 1987, Snow 1995). Metal cutting tools sometimes coincide with a florescence of elaborate bone work and bone carving (George and Preston 1987). In Eastern North America, metal replaces many traditional utilitarian bone and antler tool types while also offering a new material to work bone and antler. In some places traditional technologies disappear completely (Snow 1995, 1996).

Snow's $(1995,1996)$ work in the Mohawk Valley outlines changes in bone and antler tools through time. Prior to contact, sites were rich with bone and antler tools including harpoons, points, flakers, awls, needles, pins, tubes, handles, knives, pendants, combs, and effigies. European trade goods were present on the Mohawk Valley as early 
as 1580 and increased in abundance thereafter. By 1600 metal cutting tools are even more available and bone and antler artifacts are more elaborately worked and engraved in ways impossible prior to contact (Snow 1995). The bone comb provides an example of the availability of metal tools; prior to contact bone combs were worn as decoration and had few large teeth. After contact bone combs have many fine teeth, which would be difficult or impossible to create without metal cutting tools, and were used for grooming in addition to decoration. Wampum, purple or white tubular beads manufactured from hard shell clams (Mercenaria mercenaria) or conch (Stigas strombus), began being produced in the Mohawk Valley after 1624 and would be impossible to manufacture without iron drills (Pena 2001). In the later 1600's bone and antler tool counts decrease. Around 1700 bone and antler tool manufacture (among other traditional technologies) practically disappear from the archaeological record of the Mohawk Valley (Snow 1995, 1996). In sum, Snow's $(1995,1996)$ work describes metal being introduced in an area with a developed bone and antler industry prior to contact, followed by a florescence of osseous tool working and then the eventual decline and disappearance of bone and antler tools. Evidence from the Mohawk Valley is comparable to the Lower Columbia in that both areas had well developed osseous industries prior to contact and peoples were in direct contact with fur trading and exploring Europeans.

\section{The Cathlapotle and Meier Sites}

Cathlapotle and Meier are two contact-era archaeological sites, located close to Portland, Oregon (Figure 1) within the Lower Columbia River region. Research at the Cathlapotle and Meier is part of the Wapato Valley Archaeological Project (WVAP). Since 1987 the WVAP has investigated contact-era household production and 
organization, labor organization in particular, regional systems and trade, as well as site formation processes (Smith 2008). Both Cathlapotle and Meier were excavated by Portland State University as field schools, under the direction of Kenneth M. Ames from 1987-1996. Together the sites yielded over 23,000 artifacts of bone, antler, stone; various contact era materials, as well as a rich faunal and botanical sample (Smith2008).

The Meier site is located near the Scappoose, Oregon and the Multnomah Channel, about two kilometers from the confluence of the Columbia and Willamette Rivers. The site contains evidence of one large plankhouse and associated midden and yard deposits (Figure 2). The site was dated to AD1400-AD1830 (Ames et. al 1992). Historic trade beads suggest Meier was abandoned slightly earlier than Cathlapotle, around AD1815 (Ames and Sobel 2009, Kaehler 2002). The Meier plankhouse is one of the larger archaeologically observed plankhouses on the Northwest Coast and measures about $30 \mathrm{~m}$ long by $14 \mathrm{~m}$ wide and housed about 200 people (Ames 2010). The rear (North) section of the house was the elite area and contained prestige goods, including copper bracelets and an anthropomorphic figurine (Ames 2011). Projectile points were concentrated in the southern section near the door, but were found throughout the house indicating all members of society were terrestrial mammal hunters (Davis 2010, Smith 2008). It seems there was an emphasis on wood working in the southern portion of the 
house as well (Ames 2011).

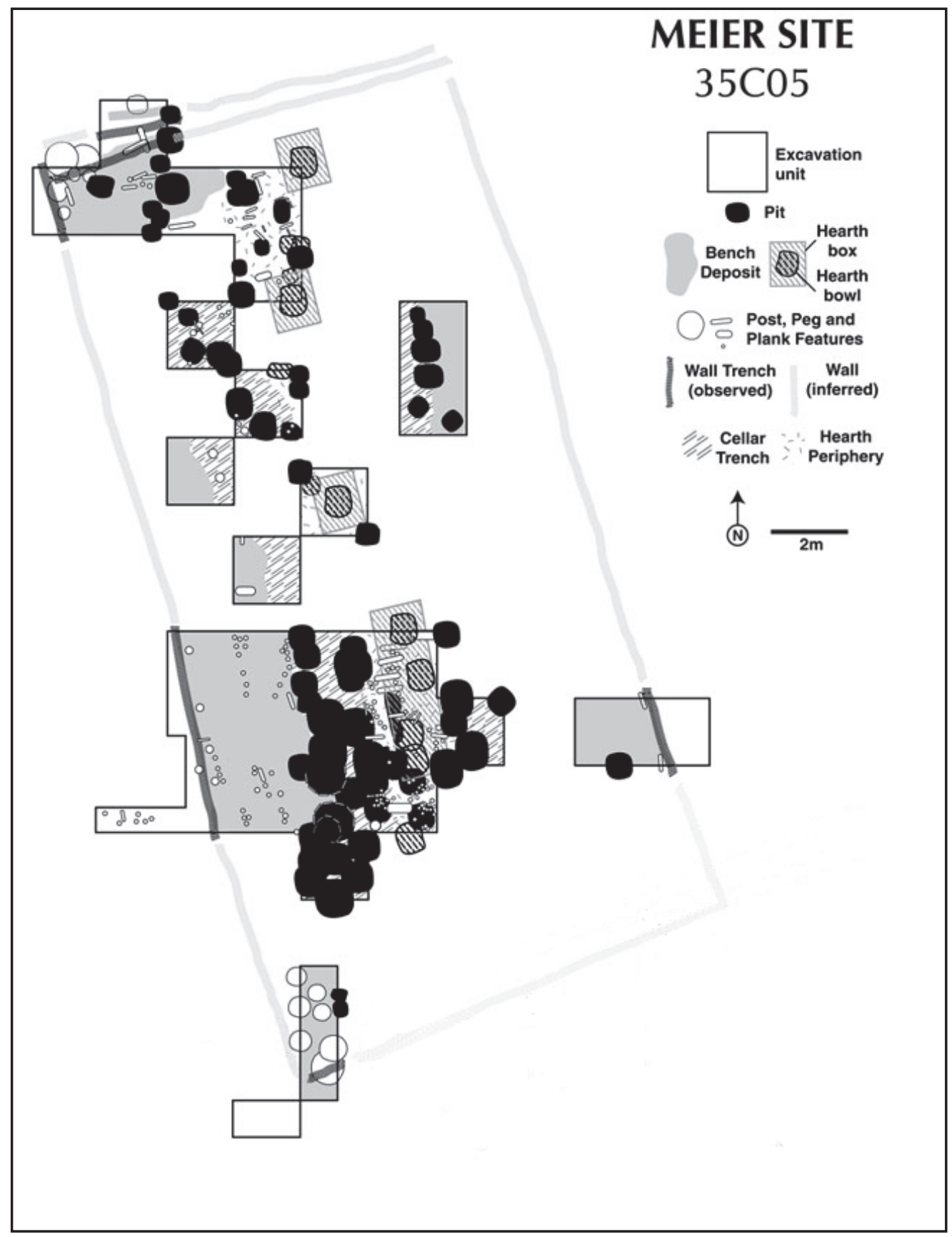

Figure 2. Map of the Meier site plankhouse facilities and excavations.

Courtesy of Cameron Smith. 
The Cathlapotle site is located near the confluence of the Columbia and Lewis Rivers in Ridgefield, Washington within the Ridgefield National Wildlife Refuge. This strategic location of Cathlapotle is likely why this site is mentioned several times in ethnohistoric accounts, while Meier is not mentioned once (Moulton 1990). Meier is located near the Multnomah Channel, a few miles from the Columbia. It is assumed that Cathlapotle was more involved in the fur trade than Meier, since Cathlapotle was mentioned in several ethnohistoric accounts and contains an abundance of historic trade goods. The site itself measures $250 \mathrm{~m}$ long and $70 \mathrm{~m}$ wide. Cathlapotle contains six depressions, evidence of six large semi-subterranean structures, ranging in size from $10 \mathrm{~m}$ wide by $20 \mathrm{~m}$ long to $15 \mathrm{~m}$ wide by $70 \mathrm{~m}$ long (Figure 3 ). A seventh structure was discovered buried beneath one of the six depressions. The houses are aligned in two north-south running rows paralleling Lake River (Ames and Sobel 2009). Cathlapotle housed from 300 to 900 people and varied in population seasonally. The site was dated from AD 1450 and1830 (Ames et. al 2008). 


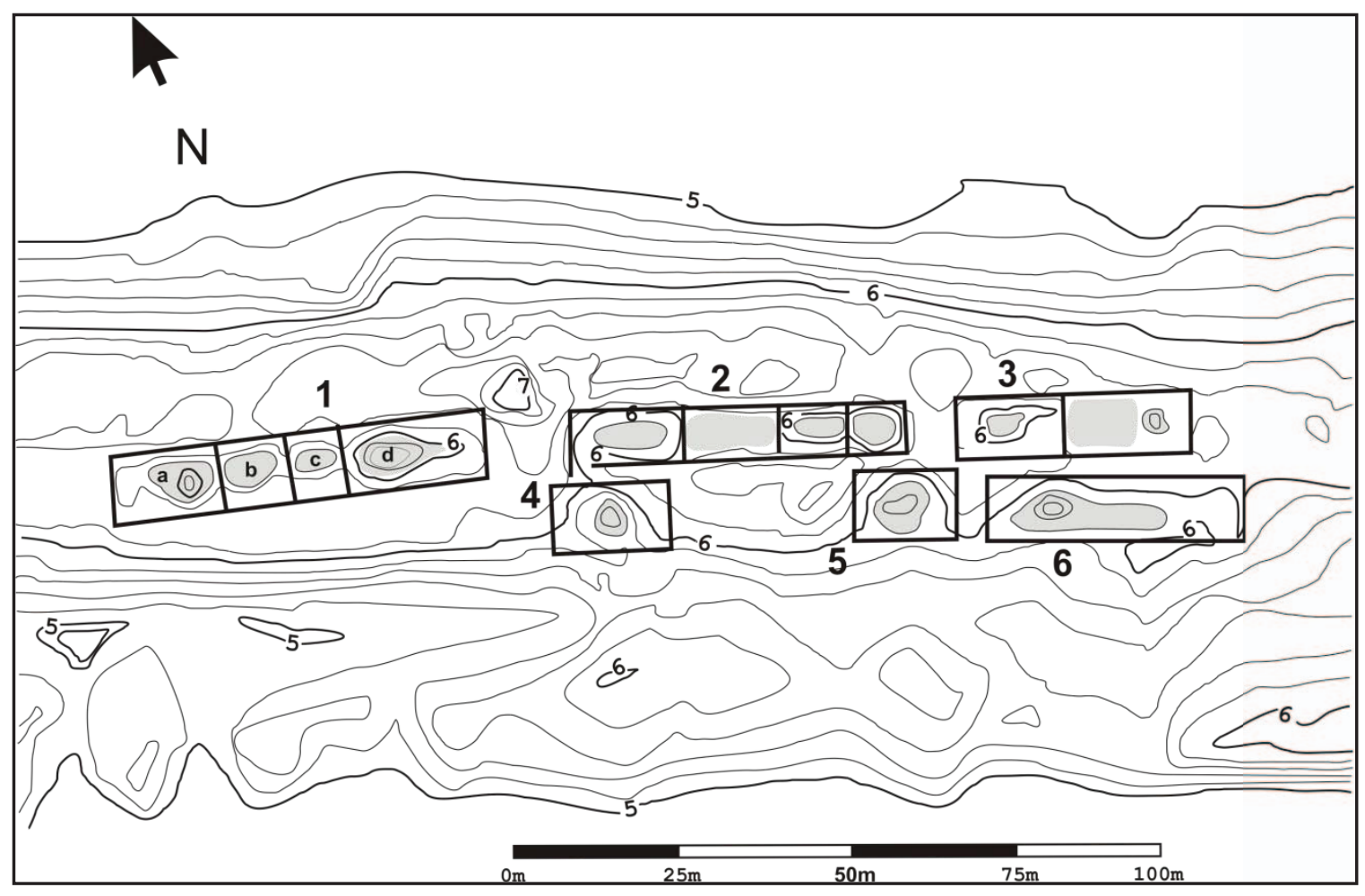

Figure 3. Topographic map depicting Cathlapotle. Courtesy of Ken Ames.

Cathlapotle houses 1 and 4 were extensively sampled, while houses 2 and 6 were tested; houses 3 and 5 were augered only (Ames et. al 2008). House 1 was divided into four compartments, House 1a, House 1b, House 1c, and House 1d. House 1a was not sampled. House 1d, the largest compartment of House 1, is interpreted as the high status end of the house. It contains a cache of high status and prestige goods including iron daggers, elaborately carved net weights, anthropomorphic figures and other elite goods (Ames and Sobel 2009, Daehnke 2005). Projectile points are most common in House 1d as well. A cache of six copper rods, similar to foreshafts made of bone or wood, were found in the bench storage area of House $1 \mathrm{~b}$ (Banach 2002).

Both sites produced a variety of fur trade era artifacts, including copper, iron, glass beads, glass other than beads, and ceramics. Widespread distribution of trade goods 
and their clear stratigraphic order makes it possible to separate precontact and postcontact components in most excavation units (Figure 4). Iron is found in the deepest strata, sometimes in precontact levels, followed by beads, copper, and other materials (Ames and Sobel 2009).

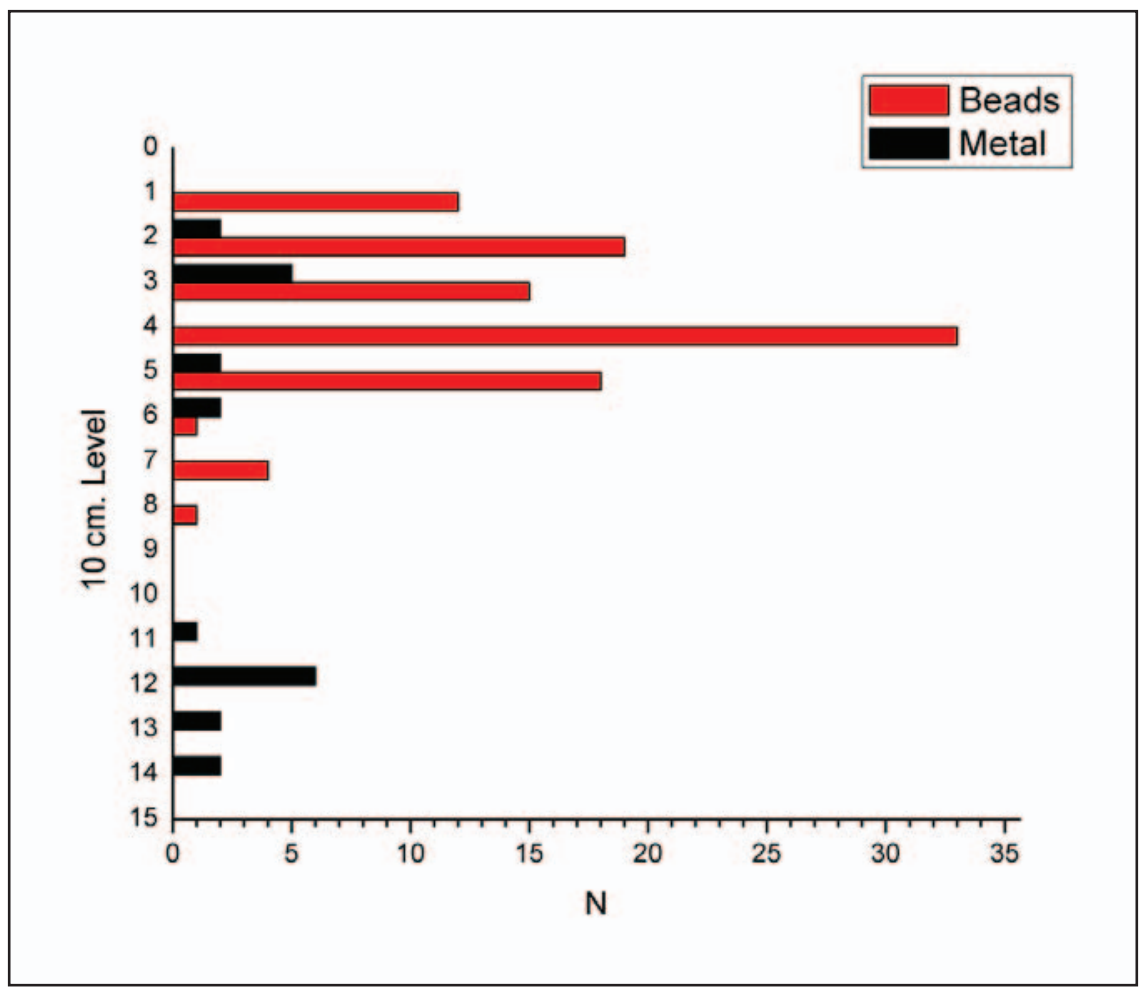

Figure 4. Distribution of trade goods from Cathlapotle. Courtesy of Ken Ames.

\section{$\underline{\text { Site Formation Processes }}$}

The archaeological record is the result of natural and cultural processes. Artifacts and features reflect the behavior, social organization, and structure of a group of people. Site formation processes research aims to understand how cultural materials transition from systemic context to archaeological context. Schiffer (1975) identifies two kinds of formation process, cultural processes, human caused factors that affect artifacts after their initial period of use, and natural or non-cultural processes, processes of the natural 
environment and its effects on artifacts and archaeological deposits. Cultural processes include artifact maintenance and reuse, recycling, and discard including both primary and secondary deposition. Primary deposition is discard of an artifact in its use location, while secondary deposition is discard away from initial use location. Tool loss (accidental discard) is an example of primary deposition, while transport of a broken tool to a midden is an example of secondary deposition. Schiffer (1975) has termed areas where lost artifacts accumulate as artifact traps. Artifact traps might include house entrances, beneath house flooring, or house footings. Other cultural processes include agricultural practices, looting, or archaeological excavation.

Cultural site formation processes of Cathlapotle and Meier were complex, mostly as a result of extensive subterranean storage complexes at both sites (Ames et al. 2008). The Meier site contains no discrete occupational floor that has collected artifacts over time, house floors were planked (Smith 2008). Artifacts were recovered from what is left of architectural features, from pit fill from subterranean storage complexes, and midden or exterior contexts. Primary deposition includes artifacts recovered from architectural features and in activity areas outside the house(s), while secondary deposition includes artifacts recovered from the midden, house cleaning episodes, and pit fill. Subterranean storage complexes, plank molds, and hearths are all artifact traps. The Meier site was plowed and both sites were looted to some degree. The eastern portion of the Meier site was severely looted and is considered extensively disturbed (Kaehler 2002). Natural processes include forces of nature, such as floods, earthquakes, fire, decay and decomposition, cryoturbation, bioturbation, trampling, and carnivore action. Cathlapotle House 1 was flooded and required resetting and rebuilding. This flooding event may 
represent Columbia River flooding associated with the Bonneville Land Slide (Dahnke 2009).

Preservation of bone and antler artifacts is always of concern, and is often why researchers do not take the time to investigate osseous technologies. Overall, bone and antler preservation is very good at both Cathlapotle and Meier. Each site contains a sizeable faunal sample. Smith (2008) describes bone and antler preservation at both sites. The presence of several thousand fish vertebrae and elements much smaller and less dense than the majority of bone and antler artifacts collected from Cathlapotle or Meier indicate that preservation is not an issue. Smith (2008) addresses differential preservation within sites and between sites. He concludes differences in preservation between facilities or sites is trivial.

WVAP archaeologists have divided the Meier house into three $10 \mathrm{~m}$ long analytic units aligned with the long axis of the house, north, central, and south. Deposits outside the house are divided into Midden (formal midden) and Yard (all exterior deposits outside of the midden). This is for ease of analysis and intra-site comparison. Cathlapotle is analyzed by house or house compartment where applicable. Deposits outside of houses are divided into Midden Lobes A and B (areas of formal midden) and Sheet Midden (equivalent to yard deposits).

Architectural facilities (i.e. bench, hearth) are used as analytic units. Smith (2006) outlines architectural facilities at the Meier site. His work is summarized here and modified to accommodate Cathlapotle. Plankhouse interiors were arranged with benches lining the walls, parallel to a central hearth area running the length of the house. Benches were wooden structures used for sleeping and storage, $1 \mathrm{~m}$ to $2 \mathrm{~m}$ wide, bordering walls of 
plankhouses. Space beneath was either used to stack wooden boxes (like Meier) or contained subterranean cellars (like Cathlapotle). Benches have low artifact densities at the Meier site, but have high artifact densities at Cathlapotle (Smith 2006). This is due to the nature of the bench area, which at Meier was a sandy floor used for above ground storage, and at Cathlapotle functioned as the cellar facility. Resetting wall planks near benches may have disturbed the bench area and small, lost, or discarded artifacts may fall into wall trenches or gaps between planks and supporting matrix (Smith 2006).

The cellar area was rarely mentioned in ethnohistoric records, probably because it was not seen by visitors walking in and around the plankhouse. At Meier, the cellar area is a separate architectural feature that is located between the bench area and the central hearths and was covered with a planked floor. At Cathlapotle, the cellar facility is found beneath the benches. Cellars were excavated during initial house construction and were subterranean. The cellar is an area of excavated pits that were straight walled, flat bottomed and about $1 \mathrm{~m}$ in depth (Ames 2010). Cellar matrix is a dark, greasy, distinct, organic composition. After abandonment, cellar pits filled in with a variety of decaying organics, baskets that lined the pits, organic remains within the pits, and planking (Smith 2006). Cellars contained usable artifacts, artifact caches, raw material stockpiles, large artifacts (site furniture), and food resources. The bulk of faunal remains, floral remains and large artifacts were recovered from cellars. When cellars were cleaned out, at both sites, matrix was deposited in middens. At Cathlapotle the bench/cellar is treated as one facility, while at Meier the bench facility and the cellar facility are separate. The two facilities are lumped together when comparing the two sites. Artifacts from the bench/cellar facilities are interpreted as storage related artifacts. 
A row of separated, equally spaced hearths ran down the center of the plankhouse at both sites. They provided areas of warmth, smoke, and light, and spaces surrounding hearths were excellent work places. At Meier, hearths were subterranean boxed hearths, while at Cathlapotle they were not. Hearths were meticulously cleaned and contained very little fire cracked rock, yet hearth peripheries contained a high density of artifacts at both sites. Archaeologically, hearth facilities produce ash, burnt clay, and calcined bone. When hearths were cleaned out they were dumped in the midden, where intact lenses of hearth material were found (Smith 2006). Hearths are classic artifact traps, items are frequently lost in or near the hearth (Schiffer 1975). Social gatherings, food processing, and any activities that require light all took place by the hearth.

Wall facilities include scattered plank molds and clusters of superimposed postmolds in a straight line (Ames 2010). Wall facilities are artifact traps as artifacts likely fell there by mistake from the bench or bench cellar while resetting wall planks (Schiffer 1975). In contrast to hearth facilities which represent the center of household activity, the wall facility is purely architectural and represents construction-related activities. When facility designation was ambiguous during excavation, facility assignments are sometimes combined. The wall/bench/cellar facility at Cathlapotle is a combination of the wall, bench, and cellar facilities. The same is true for the bench/cellar/hearth periphery facility.

Smith (2006) summarizes his work and explains that the bench, cellar, and hearth periphery were identical in the north, central, and southern areas of the Meier house. Plankhouse layout was maintained for centuries, suggesting the interior had one essential plan (Smith 2006).Although the houses were organized by relative status, everyone, both 
elite and commoner, made and used the same sets of tools, but in differing quantities. Therefore, people likely participated in all activities on some level, perhaps to differing degrees. Artifacts were deposited in all areas of the plankhouse from beginning to end of occupation. Functions of facilities did not change radically through time either. Artifacts moved from the hearth periphery (production) to the cellars or benches (storage) to the midden (discard) continually for centuries.

Midden is a formal area of intentional discard. The Meier midden consists of a thin stratum of bivalve shells interbedded with thicker strata of ash, burnt clay, and earth (Ames et al. 1992). At Cathlapotle, there are two formal middens, Lobe Midden A, located between House 1 and House 2, and Lobe Midden B, located between House 5 and House 6 (Figure 3). Middens at both sites contain evidence of multiple hearth cleaning episodes, containing intact lenses of ash, thermal rock, and faunal material. Wapato Valley plankhouses, and their facilities within, were cleaned frequently and materials dumped in the midden. Therefore middens represent areas of intentional discard (a trash heap) and likely contain artifacts that were lost in artifact traps (hearth periphery) or simply thrown out during a house cleaning (storage).

The Yard at the Meier site includes all exterior deposits that are not midden. The Sheet Middens at Cathlapotle are equivalent to the yard at Meier. Yard and Sheet Midden are low density artifact scatters outside the house(s) that are not formal midden and are the predominant activity areas outside the house(s). Yard and Sheet Midden literally were prehistoric front yards between houses and waterways. Therefore artifacts recovered from such facilities are representative of activities taking place in the yard, ranging from nut processing to fish drying and everything in between. Yard and Sheet 
Midden deposits will also be affected by smaller structures built around the house(s) as well as flooding events and alluvial activity. At Meier, the Yard is treated as one facility. At Cathlapotle, Sheet Middens are divided by associated house into Sheet Midden House 1, Sheet Midden House 2, and Sheet Midden House 6.

\section{$\underline{\text { Summary }}$}

Cathlapotle and Meier are similar sites that were occupied contemporaneously and are geographically close, yet the two sites exhibit many differences. An obvious difference is that Cathlapotle is a larger site, with at least six houses, and it supported a larger population than Meier, which is smaller and contains the remains of one large house. Artifact assemblages are generally the same, but differ in proportions. Cervid bone frequencies and projectile points provide the best examples. Overall faunal assemblages are similar between the two sites, both are dominated by cervids, but proportions differ. Deer outnumber elk more than 4 to 1 at Meier, while elk outnumber deer 3 to 1 at Cathlapotle (Lyman2003). Projectile point type frequencies mirror cervid bone frequencies at both sites (Davis 2010). Small-stemmed points greatly outnumber side-notched points at Meier, while at Cathlapotle, side-notched points outnumber smallstemmed points. Davis's (2010) research suggests a correlation between small-stemmed points and deer bones at Meier and side-notched points and elk bones at Cathlapotle. Significant differences in projectile point frequencies were likely attributed to hunting different cervids. Additional differences between the sites include copper and osseous artifacts. Both sites contain similar trade goods, although more than twice as much copper was recovered from Cathlapotle $\left(n=120, n / m^{3}=0.5\right)$ than Meier $\left(n=52, n / m^{3}=0.32\right)$. Copper projectile points were only recovered from Meier, while copper rods were only 
recovered from Cathlapotle (Banach 2002). Bone and antler artifact counts differ greatly between the two sites, Meier contains almost three times as many osseous artifacts $\left(\mathrm{n}=1219, \mathrm{n} / \mathrm{m}^{3}=7.61\right)$ than Cathlapotle $\left(\mathrm{n}=411, \mathrm{n} / \mathrm{m}^{3}=1.71\right)$. Differences in osseous artifact frequencies are not correlated with any other artifact class, are not related to excavated volume, and are unexplained.

Cathlapotle and Meier are unique sites in a unique setting. This chapter provides temporal, spatial, and ethnohistorical context of Cathlapotle and Meier and the artifacts they have produced. European contact was the most significant cultural event in North American history. Although evidenced in Northeast osseous assemblages, there are few examples of contact reflected in North American osseous assemblages (Snow 1995, 1996). 


\section{Chapter 4}

\section{$\underline{\text { Technology }}$}

This thesis investigates the expectation that sedentism promotes expedient technologies (Henry 1989, Hamilton 1994, Parry and Kelly 1987). An overview of the curation/expediency continuum and what factors influence either strategy including mobility, toolkit transportability, raw material availability, and risk, and provides necessary background for hypothesis and test expectation development regarding the relationship between sedentism and expediency. This chapter provides experimental and ethnographic evidence of osseous materials versus stone and builds upon Chapter 2, emphasizing the durability, long uselives, and flexibility of osseous materials.

Technological organization encompasses the strategies used during raw material procurement, manufacture, use, reuse, transport, maintenance, and discard of tools. The strategy here is a problem solving process; people solve problems through technology. Research regarding technological organization focuses on defining technological strategies and the artifact assemblages they produce in an effort to predict assemblage composition and/or to infer technological strategy from artifact assemblages. Technological organization studies explore the economic, environmental, and social factors that influence technological strategy employed (Nelson 1991).

Most studies of technological organization focus on efficiency. Research focusing on efficiency operates under the assumption that efficient technology and tools save time and energy. What is efficient is circumstantial and varies with context. In a given situation, efficient technological systems are those most appropriate to accomplish a task 
quickly with the least amount of effort. Efficiency is an underlying theme of technological organization studies.

Theorizing about hunter-gatherer technological organization began when Lewis Binford introduced the curation/expediency continuum in the 1970's (Binford1977, 1979, 1980). Curation is a planned technological strategy executed in stages where tools are manufactured and stored in anticipation of future use and then transported and used at a different time and/or location. Curation anticipates future need for materials and tools at use locations (Nelson 1991). Curated tools have high levels of investment, are intensively maintained and repaired during downtime when they are not needed (Binford 1977, Torrence 1989, Weissner 1982). People using curated tools frequently schedule downtime to "gear up" and prepare toolkits for later use. Curated tools are cared for and valued. Investing time and labor in the manufacture and maintenance of curated tools increases tool efficiency and extends tool use-life (Binford 1977). Curated assemblages are technologically sophisticated and distinct (Bamforth 1986).

In contrast to curation, an expedient strategy anticipates sufficient materials and time to make tools when needed. Expediency is materially wasteful and represents a minimal technological effort where tools are produced when needed, used, and discarded at their use location. Expedient strategies are only possible with adequate supplies of raw materials. Expediency is appropriate when raw material supply, time, and place of use are predictable (Nelson 1991). Expedient assemblages are technologically simple and less patterned (Bamforth 1986, Binford1979). Nelson (1991) emphasizes the contrast between expediency and opportunistic behavior, which is situational and in response to immediate, unanticipated, unplanned conditions. Curation and expediency should be 
viewed as a continuum, with most technological systems reflecting aspects of both strategies. Andrefsky (1994) explores these concepts referring to curated tools simply as formal tools and expedient tools as informal tools.

Bleed (1986) introduced tool design concepts of reliability, the degree to which design ensures a tool will effectively operate under a range of conditions, and maintainability, the degree to which design emphasizes features that make it easy and quick to return a broken tool to useful condition (Table 1). Reliable designs emphasize dependability. Reliable technological systems work best when used during high risk, highly specialized, repetitive, predictable activities with high failure costs. They are optimal when repair and maintenance can be scheduled during downtime and where bulk and weight of technology is not important (Bleed 1986). Maintainable technology tends to be simpler, and works best when the system is needed continuously and unpredictably and when risk and failure costs are low. Maintainable designs work well for activities that are not time stressed (Nelson 1991).

Technological systems can be reliable, maintainable, both, or neither. Bleed continues that foragers who utilize scattered yet ubiquitous resources tend towards maintainability, while collectors who utilize seasonally abundant resources with scheduled downtime tend towards reliability. Archaeologically, people using reliably designed technology will produce special purpose sites and sites with evidence of caching, storage, and curation as well as effective transportation technology and downtime for gearing up. Reliably designed tools tend to be complex and frequently hafted. Peoples using maintainable technology will produce generalized sites with a 
range of faunal remains and technology that is smaller in size with modular characteristics (Bleed 1986).

Table 1.Characteristics of reliable and maintainable systems.

\section{Adapted from Bleed (1986)}

Reliable Systems:

1) Overdesigned components (parts stronger than minimally need to be)

2) Under stressed (system used at less than full capacity)

3) Parallel subsystems and components (redundant and standby)

4) Carefully fitted well made parts

5) Generalized repair kit to fix any repair

6) Maintained and used at different times, probably in different locations

7) Manufactured and maintained by specialists Maintainable systems:

1) Generally light and portable

2) Subsystem arranged in series (each has one unique function)

3) Specialized repair kit with ready to use extra components

4) Modular design

5) Designed to operate when partially functional

6) Repair and maintenance during use

7) User maintained and easily serviceable

Nelson (1991) expanded on Bleed's concept of maintainability, by adding versatility, in which tools are maintained in a generalized form to meet a variety of needs, and flexibility, when tools are changed in form to achieve multifunctional demands. Using versatile or flexible tools provides many technological options, and also simplifies toolkits. Nelson (1991) also emphasizes transportability. A highly transportable toolkit must anticipate future need and operate within the constraints of a mobile lifestyle. Transportable tools should be lightweight, small, and durable. Flexible or versatile tools can decrease the number of items within a transportable toolkit. Lightweight materials may be used instead of heavier, more durable materials, such as baskets instead of 
ceramics or organics instead of stone (Nelson 1991). Parry and Kelly (1987) suggest transportable toolkits with a variety of portable curated specialized tools were comprised of lightweight organics, and simple expedient lithic flakes used to maintain an organic technology. Factors described below such as mobility patterns, seasonality of resources, and degree of risk influence when specific design features are emphasized.

The curation/expediency continuum and other design aspects that effect the organization of technology are ways of categorizing technological systems and tools. Since the introduction of these concepts researchers have been theorizing as to what drives variation of technological design and organization, specifically along the curation/expediency continuum. Variation in technological systems misattributed to mobility and settlement patterns, seasonality of resources and time budgeting, location and distribution of lithic resources, and risk (Binford 1977, 1979, 1980, Bamforth 1986, Bamforth and Bleed 1997, Chatters 1987, Torrence 1983, 1989).

Mobility is a primary factor in hunter-gatherer technological organization. Much like curation and expediency, residential and logistic mobility (as well as foragers and collectors) are not polar opposites, but rather represent a continuum. Binford (1980) differentiated between residential mobility, moving the entire group from one residence to another, and logistical mobility, moving small groups to and from the residence on logistical forays to retrieve resources. Foragers "map on" to resources and frequently move residences and people to resource locations (Binford 1980, Chatters1987, Kelly 1992). Foragers gather food daily and do not store food. Collectors move residences less frequently, while small groups travel on long logistical forays to procure resources to be brought back to residences. Task groups focus on resources that can be acquired in large 
quantity and stored for future need. Residentially mobile groups are typically found in places where diversity of resources are available for most of the year, while peoples practicing a logistic strategy are found in places where resources are seasonally available, abundant, and geographically dispersed. Chatters (1987)suggests residential mobility requires a generalized technology designed to procure a diversity of resources, while logistic mobility requires a more specialized technology with tools designed for the procurement of specific resources.

Sedentism is relative, not absolute (Kelly 1992). In some places people became more sedentary over time (or less mobile), such as in Midwestern North America and the Natufian in the Levant. In the Plateau region east of the Northwest Coast culture area, archeological data indicate episodic or seasonal sedentism (Ames 2011). The Northwest Coast, including Cathlapotle and Meier, exhibits residential sedentism, where large winter villages were maintained through the year. Northwest Coast subsistence resources were abundant yet seasonal and spatially patchy, requiring logistic forays to obtain bulk subsistence resources to support large populations.

In general, curated strategies are associated with frequent residential or logistical movements, while expediency is favored by sedentary groups or groups with infrequent movements (Kelly 1992). Curated bifacial tools and cores are associated with mobile peoples or logistic forays, while expedient flake tools and bipolar reduction are used at residence locations. From this pattern it is hypothesized that increased increased residential sedentism leads to increased reliance on expedient tool technology (Parry and Kelly 1987). As people spend more time in one place they accumulate and store things, including raw materials. Sedentism allows time and space for raw materials to be 
stockpiled and used expediently (Hamilton 1994, Nelson 1991, Parry and Kelly 1987). A shift towards expedient core technology coincides with a shift in settlement patterns towards sedentism. This shift is seen in the Eastern Woodlands of North America, the Plains, the Southwest, Mesoamerica, as well as on the Lower Columbia (Hamilton 1994, Parry and Kelly 1987). If high quality raw material is abundant, it eliminates the need to manufacture portable curated lithic tools. Parry and Kelly (1987) suggest the use of expedient lithic technology may result from the widespread use of organic materials.

Bamforth (1986) suggests raw material availability rather than mobility dictates which technological strategy groups use. He frames his argument viewing raw materials for tool making as subsistence resources, no different than plants or animals. The nature and distribution of lithic resources condition how they are exploited(Bamforth 1986). When lithic raw materials are local and abundant, technology is more likely to be expedient. When lithic raw materials are exotic and/or scarce, technology is more likely to be curated and conservative. Intensity of tool maintenance and recycling varies with raw material availability. Social forces, such as lithic resource ownership or controlled access to lithic resource locations by elites may condition technological strategy as well.

Kelly (1988) supports Bamforth (1986) when he states there is no direct correlation between mobility and the organization of technology. Kelly suggests instead a combination of raw material availability and mobility strategy dictates technological strategy. He illustrates this using curated bifacial tools as an example and outlines the three main ways biases are used. Bifaces can be used as cores, long use-life tools, and as by-products. Bifaces are used as cores when there is limited raw material availability or when logistic forays are common. They are used as long use-life tools when raw material 
is scarce and residential mobility is low. Finally, bifaces can be by-products of a reliable system, where the focus is on the hafting mechanism of a complex tool whereby the biface must fit and is a by-product of the system (Kelly 1988).

Torrence $(1983,1989)$ took a different approach to hunter-gatherer technological organization. Her initial research proposed time budgeting influences technological organization rather than mobility. Time budgeting is reflected by tool complexity and assemblage diversity. Essentially, creating efficient tools to complete specific tasks saves time. The less time people have to search for, pursue, and capture resources, the more likely they are to invest time in tool manufacture and maintenance to increase tool efficiency and in turn save time during resource procurement. When resources are seasonally available or time is limited, investing and scheduling time to manufacture and maintain a curated technology will increase tool efficiency (Binford 1977, Torrence 1983). Time invested in technological manufacture and maintenance increases as resource diversity and duration of availability decreases. Using specialized tools increases the speed to complete a task and maximizes efficiency, and in turn creates diverse assemblages. Diverse assemblages comprised of specialized tools are found when the range of activities requiring technology is small, while generalized assemblages are found when technology is used for many tasks (Torrence 1983). In addition, Torrence (1983) argues complex tools are time savers because individual parts can be replaced, avoiding the need to make a new tool. Therefore, the more time budgeting required, the more likely technology will be curated, complex, and specialized, all factors increasing assemblage diversity. 
Torrence (1989) builds on her previous research but focuses on risk management in lieu of time stress. Risk is probability of failure. Subsistence risk is the variation in availability or accessibility of subsistence resources. Risk increases when people are dependent on mobile resources, especially those which are aquatic, seasonal, and available for short durations. Referring to an activity as high risk indicates probability of succeeding at an activity (a positive outcome) is low and probability of failing to complete the activity (a negative outcome) is high, while low risk indicates probability of succeeding at an activity is high and probability of failure is low. A positive or successful outcome reaps rewards, while a negative outcome, or failure, has associated consequences. Bamforth and Bleed (1997) refer to these consequences as failure costs. Failure costs are context dependent and condition severity of risk. Failure costs during resource procurement increase when there are no alternative food resources. Severity of risk increases when failure costs are high. For example, hunting large game while there are abundant small mammals and plant resources has lower failure costs than hunting large game with few or no alternative resources. High risk activities often have severe failure costs but also reap the greatest rewards if a positive outcome is the result. Risk also has many social effects: successful individuals engaging in high risk activities may be rewarded with social prestige, while failure may damage one's reputation (Bamforth and Bleed 1997).

Risk theory operates under the assumption that specialized tools and complex tools are more efficient and effective at completing a given task, making a resource more available in time and/or space. Risk type, severity, and associated failure costs determine level of technological investment, tool reliability, tool complexity, and assemblage 
diversity. The degree to which tools are designed to be reliable reflects increasing risk (i.e.: the more severe the risk the more reliable the technology). Bamforth and Bleed (1997) add that designing tools that are transportable and durable with long use-lives can help minimize risk. In addition, technological costs must be considered, as people must have sufficient downtime to manufacture and maintain such complex tools. Therefore hunter-gatherers can effectively manage risk in the face of high failure costs by investing time in to manufacture, maintain, and use reliable, complex, specialized tools.

All of these theories about hunter-gatherer technological organization are based on and empirically tested on lithic assemblages. In contrast to this theory building focusing on lithic technology, there has been little to no theory building around bone and antler artifacts. This is despite the abundance of bone and antler artifacts in many places, including the Northwest Coast, where bone and antler artifacts are often the most common artifacts recovered. The physical properties and accessibility of bone and antler as raw materials, as well as experimental and ethnographic evidence, offer an interesting perspective on the role of osseous technologies in technological organization and challenges precedents set by stone tool analysts. Experimental and ethnographic work done is in regards to projectile points of stone, bone, antler, and wood. This research offers invaluable insight into the advantages of organic projectile points and osseous tools over all.

The physical properties, accessibility, and transportability of osseous raw materials suggest bone and antler artifacts were essential and likely crucial components of hunter-gatherer toolkits. The factors that shape osseous tool kit composition are likely different than those (discussed above) that shape lithic tool kit composition. As described 
in Chapter 2, bone and antler are extremely durable, they are rigid and strong yet flexible and elastic (LeMoine 1994, Ogle 2004). These physical properties enable osseous tools to withstand high levels of force, stress, damage, and wear. Bone and antler are highly accessible as they are extremely easily obtained through scavenging or embedding in butchery practices (Knecht1997, Lyman 1984). Using osseous raw materials frees hunter-gatherers from dependence on lithic quarries. Bone is also naturally lightweight, an advantage to mobile groups. When transportability is an issue, lightweight materials were likely favored: baskets instead of ceramics and wood or osseous tools rather than stone tools (Nelson1991).This combination of physical properties and accessibility makes for a unique material, with many technological options and advantages. Experimental studies conducted by Elston and Brantingham (2002), Frison and Zeimens (1980),Knecht (1997), and Lyman (1984) found that bone and antler points are extremely durable and have many advantages over stone points (Table 2). Binford's (1979) ethnographic observations of the Nunamiut support these findings. Organic points penetrate more deeply, are more easily repaired, and break less frequently than stone points (Knecht 1997 and various references therein). Lyman et al.'s (1998) experiments using antler, bone, and wooden projectiles indicate that antler penetrates even deeper than bone, and both perform better than wood. Organic points penetrate deeper, but stone points are more lethal as during use they fracture inside prey causing intense hemorrhaging. In all of Knecht's experiments, bone and antler points were rarely damaged during repeated use, even when bone was struck. Osseous points can be easily repaired by sharpening through abrasion or quickly manufactured into an expedient tool in this manner. Osseous materials can be worked into more specific tools and parts of tools than can stone 
(Torrence 1983). The flexible nature of bone and antler allows for detailed engraving designs as well.

Table 2. Durability of bone and antler points versus stone points.

\begin{tabular}{|c|c|c|}
\hline Durability & Bone and Antler & Stone \\
\hline Use & Rarely damaged & $\begin{array}{l}\text { Shatter penetrating prey: } \\
\text { Invariably break on missed shot }\end{array}$ \\
\hline Transport & Rarely damaged & Easily damaged \\
\hline $\begin{array}{l}\text { Cold } \\
\text { Temperatures }\end{array}$ & Unaffected & Become brittle \\
\hline Use-life & Long & Short \\
\hline
\end{tabular}

Ellis (1997) evaluated factors influencing choices of using organic points over stone points for over 100 ethnographic cases. His results show that stone spear and arrow points are used in pursuit of large dangerous game and in warfare. Thrusting spears with stone points were only used in situations of little danger or when replacement weapons were available. Thrusting spears with organic points were used against smaller herd animals and against dangerous animals when no replacement weapons were available. Organic points were preferred to arm arrows in cold weather, as stone tends to become more brittle and break easier in cold weather. These comparisons of organic points to stone points show that organic points are stronger, durable, have longer use-lives and are reliable, while stone points are more lethal and deadly (Bleed 1986, Knecht 1991, Knecht 1997, Ellis 1997, Elston and Brantingham 2002). Their durability and reliability make osseous materials ideal for the manufacture of specialized, curated tools with long uselives. Their availability, accessibility, and ease of sharpening make osseous materials 
great candidates for expedient tools. In addition, Knecht's experiments suggest bone points need not be sharp as even a dull bone point will perform well (Knecht 1991). This suggests a quickly manufactured osseous expedient tool will likely last during the entirety of the task at hand possibly without needing resharpening.

Bone and antler tools are extremely advantageous to prehistoric hunter-gatherers for several reasons. Osseous materials can be obtained virtually everywhere (anywhere there are mammals or birds), freeing people from dependence on lithic quarry locations and providing raw materials available for expedient tool making at any time in most places. They are lightweight and are unaffected by temperature. Bone and antler are durable in nature, able to withstand great force, perform well when dull, and are quickly resharpened (Knecht 1991). Ellis's (1997)ethnographic research indicates that when reliability is a concern organic materials are almost always chosen. Curated osseous tools require a greater time investment in manufacture, have longer uselives, break less frequently and are more easily repaired than stone tools. Tools constructed of bone and antler can be shaped into a greater variety of forms than stone, allowing for manufacture of complex formed tools. Osseous materials can be quickly sharpened, durable, and perform well when dull, allowing for manufacture of proficient expedient tools.

The durability of osseous materials is likely their most advantageous trait. It is assumed European-introduced metal tools are more efficient than traditional technologies since metal is durable and dulls less quickly than stone or bone. Formal metal tools may have been more advantageous since they have no manufacture costs, while formal curated osseous tools have high manufacture costs, although metal likely had high procurement costs. Using metal tools to work osseous materials will decrease 
manufacture time for curated osseous tools, make expedient osseous tool manufacture extremely fast, and also decrease osseous tool repair and resharpening time.

This chapter outlines the curation/expediency continuum, several technological organizational and design strategies and their causational factors. Sedentism promotes expediency in lithic tool assemblages, but others have shown mobility does not dictate the technological strategy employed (Kelly 1988, Bamforth 1986). Ethnographic and experimental work of osseous materials versus stone provides evidence supporting the durability and advantages of osseous technologies in high risk situations of those requiring an extremely durable, reliable tool with a long use-life and in situations requiring a durable expedient tool manufactured rapidly. Both osseous tools and metal tools are extremely durable. Metal tools likely enhanced osseous technology manufacture by decreasing manufacture costs. 


\section{Chapter 5}

\section{Formulating Hypotheses and Test Expectations}

\section{$\underline{\text { Residential sedentism promotes technological expediency in hunter-gatherers. }}$}

This expectation was based upon and empirically texted upon lithic assemblages. In this thesis, this expectation was texted in two ways with two hypotheses. First, the expectation that sedentism promotes expediency was tested as a formal hypothesis, Hypothesis 1: sedentism promotes expediency. This was tested by evaluating where each artifact falls within the curation/expediency continuum. Essentially this is measuring energy investment in artifact manufacture and degree of working. This is described in detail in Chapter 6. Second, this expectation is further explored using a spatial analysis, Hypothesis 2: curated complete tools should be stored, while expedient and broken curated tools should be discarded. This was achieved by using chi square tests for each arbitrary analytic unit, architectural facility, as well as inside and outside the houses.

Hamilton (1994) tested Hypothesis 1, sedentism promotes expediency, on the Meier site lithic assemblage. He concluded the lithic assemblage is mostly expedient, with the exception of highly curated arrow points and endscrapers. The Cathlapotle lithic assemblage is similar to Meier, an expedient assemblage with highly curated arrow points and endscrapers (Ames 2011). However, Davis (1998) concluded the Meier site osseous assemblage was highly curated, but did not speculate why. Possible reasons for a highly curated osseous assemblage include: durability and longevity of curated osseous tools, a need for complex formed tools, and an expedient lithic industry that allowed more time for a developed organic industry (Elston and Brantingham 2002, Knecht 1997, Parry and Kelly 1987). The durability of bone and antler tools makes them reliable when risk is 
high and failure costs are severe (Torrence 1989, 1983). Additionally, osseous tool making requires a great time investment, so it may only be worthwhile to manufacture curated tools. Davis (1998) did not attempt a spatial analysis to explore the expectation that sedentism promotes expediency.

Ames (2005) describes Northwest Coast osseous assemblages as having aspects of both curation and expediency. Based on previous research and on inferences made on the sites and their environments described below, osseous assemblages from Cathlapotle should be have aspects of both curation and expediency (Ames 2005, Davis 1998, Hamilton 1994, Parry and Kelly 1987). Test expectations are described in terms designated by Doria Raetz (1989) (Table 3). Raetz (1989)divides osseous tools on the Northwest Coast into three functional groups: procurement, modification, and ornaments. Procurement refers to artifact types that were used for the primary procurement of resources. Modification refers to artifact types that were used to modify, process, manufacture, and repair resources, materials, and other items. Ornaments refer to artifact types that were used for personal adornment and did not function as procurement or modification tools. I add a residual "other" category, including pegs, crescents, worked fragments, and detritus.

Table 3. Lists of artifact classes designated into Raetz's categories.

\begin{tabular}{|c|c|c|c|}
\hline Procurement & Modification & $\underline{\text { Ornaments }}$ & Other \\
\hline Bipoints & Blades & Beads & Crescents \\
\hline Points & Flakers & Pendants & Pegs \\
\hline Harpoon parts & Handles & Pins & Worked Fragments \\
\hline \multirow[t]{4}{*}{ Foreshafts } & Chisels & Tubes & Detritus \\
\hline & Wedges & & \\
\hline & Awls & & \\
\hline & Punches & & \\
\hline
\end{tabular}


Text expectations for Hypothesis 1 are as follows. Artifacts related to subsistence procurement, should be highly curated at Cathlapotle. Arrowheads are highly curated at both sites (Hamilton 1994). Hunting and fishing likely took place away from the site, possibly requiring logistic forays. Task groups on logistic forays are more likely to use curated tools (Binford 1980). Northwest coast subsistence resources are highly seasonal, mobile, and many are aquatic. Acquiring seasonal resources for large populations while potentially facing competition with other households coupled with the need to create food stores, adds time stress and increases failure costs associated with high risk. Using durable, complex, curated, reliable osseous tools would help manage risk and increase subsistence returns (Bamforth and Bleed 1997, Torrence 1989). Most activities requiring modification tools took place at residential sites. With sufficient stockpiles, curation would not be necessary. Therefore modification tools should be expedient. Ornaments are used for personal adornment and should be curated. The category other will likely be both curated and expedient as worked fragments and detritus represent the manufacture of osseous tools.

There are large numbers of curated endscrapers at both Meier and Cathlapotle (Hamilton 1994, Ames 2010). It is thought this reflects an increased demand for furs at Meier and Cathlapotle during the postcontact period (Hamilton 1994, Smith 2008).Awls are the osseous hide working counterpart to endscrapers. Since, endscrapers are one of the two highly curated lithic artifact classes at both sites, awls should be curated as well. Additionally, if Hypothesis 1 is supported, there should be sufficient raw material stockpile of bone and antler at both sites. 
Test expectations for Hypothesis 2, curated complete tools should be stored, while expedient and broken curated tools should be discarded, are as follows. Curated tools are cared for and should be found in storage facilities. Complete curated tools should be concentrated in storage facilities within the house(s), specifically the bench/cellar facility at Cathlapotle and the cellar facility at Meier. Broken or exhausted tools should be concentrated outside of the house in middens and not randomly distributed. Used and discarded expedient artifacts should be recovered from middens and not randomly distributed as well.

\section{$\underline{\text { Contact and the Introduction of Metal }}$}

The assumption that European-introduced metal objects will influence and/or cause traditional technologies to disappear from the archaeological record has been only tested on lithic assemblages (Bamforth 1993, Cobb 2003). Snow's $(1995,1996)$ work provides evidence that contact is reflected in osseous assemblages. Hypothesis 3: contact should be reflected within osseous assemblages at Cathlapotle and Meier, was formulated from Snow's work.

European contact was among the most significant events to cause major cultural and technological change on the Northwest Coast. Contact at Meier and Cathlapotle was probably swift. Residents of these sites likely had both knowledge of Europeans and possessed European trade goods prior to contact. From 1792 on, Lower Columbians were in direct contact with Europeans (Boyd 2011). Foreign disease decimated native populations and a mere forty years later both villages were abandoned. In this short amount of time, metal became a popular trade item, especially in the form of cutting tools such as axes, knives, and blades, as well as, needles, copper kettles, and firearms (George 
and Preston 1987). Farther north along the coast in Prince Rupert Harbor, there had been no significant changes in precontact bone and antler assemblage for over 2,000 years (Ames 2005). Slight changes are subtle trends and involve minor differences such as haft shape and variations in artifact frequency. Overall, bone and antler assemblages on the Northwest Coast were characterized by profound continuity (Ames 2005).

On the East Coast of North America metal replaced many traditional technologies, for example, iron axes replaced ground stone axes, copper points replaced both stone and bone points (Snow 1995, 1996). On the Northwest Coast metal projectile points and harpoon points are present, but do not completely replace stone points (Ames 2010). Snow's $(1995,1996)$ provides evidence of contact reflected in an osseous assemblage. His work describes precontact assemblages rich in bone and antler artifacts. The introduction of metal was followed by an initial proliferation of bone and antler artifacts, followed by a decline, and finally bone and antler fall out of use completely in favor of European tools.

The Cathlapotle and Meier sites offer excellent opportunities to examine the possible technological effects of contact on osseous assemblages also to test whether significant social change is reflected in the osseous assemblage. If the Lower Columbia assemblages are consistent with those in the Northeast, Snow's work, bone and antler artifacts should reflect contact. Contact should be reflected or not in one of three ways (Table 4). If contact is not reflected and Hypothesis 3 fails, artifact frequency and diversity will remain consistent. If Hypothesis 3 is supported, and contact is reflected, osseous artifact frequencies and densities will change, and either increase or decrease. An increase could indicate a proliferation of osseous artifacts, while a decrease could 
indicate replacement by metal tools. Of course other factors could influence changes in osseous tool frequency and density, these are described in Chapter 8 .

Table 4. Text expectations of Hypothesis 3 and their possible implications.

\begin{tabular}{|cc|}
\hline Artifact Frequency and Diversity & Could reflect: \\
Increase & Proliferation \\
Decrease & Replacement \\
Remain consistent & Contact not reflected \\
\hline
\end{tabular}

The results of Hypothesis 3 will provide more information on Cathlapotle and Meier's involvement in the fur trade. If Cathlapotle is more involved in the fur trade than Meier, Meier assemblages should reflect contact less than Cathlapotle, artifact frequencies and densities should change little. If Cathlapotle and Meier are equally involved in the fur trade, artifact frequencies and densities should vary in similar ways. 


\section{Chapter 6}

\section{$\underline{\text { Methods }}$}

\section{$\underline{\text { Data Collection }}$}

I analyzed the Cathlapolte osseous artifact assemblage. The Meier site osseous assemblage was analyzed by Davis (1998). The methodology used for this artifact analysis was developed by Ames for his analysis of bone and antler tools from the Garden Island site in Prince Rupert Harbor (Ames 1976), and then used again in analysis of nine additional Prince Rupert Harbor sites as part of the North Coast Prehistory Project, the Hatwai site in Idaho, and by Davis for the Meier site (Ames 2005, Ames et. al 1982, Davis 1998). Much of the terminology used to describe artifact shape and orientation was derived from Binford's1963 attribute list for describing and classifying projectile points and from Loy and Powell's 1977 Archaeological Data Recording Guide(Binford 1963, Loy and Powell 1977). Terminology derived from Binford (1963) and Loy and Powell (1977) were modified to accommodate osseous artifact assemblages. To ensure consistency and comparability between assemblages analyzed by myself and Davis, and to reduce observer error, I began data collection by analyzing 100 specimens from the Meier site. I checked my work and compared it to Davis. I continued this until our descriptions of attributes matched. Using Ames's method ensured consistency and comparability between the two sites, enabled me to reach my goals of this thesis, and provided a complete dataset for future research.

This method records both qualitative and quantitative attributes which can be used to construct either hierarchical taxonomies or paradigmatic classifications (Dunnell 1981). The approach is a standard and simple typology that is at the same time detailed 
and thorough. Here, various qualitative and quantitative attributes are described, including several attributes of artifact shape and size as well as manufacture modification, usewear, and other artifact treatments. Although some attributes are not directly relevant to this thesis, they were recorded so one can track formal variability at several scales and create a complete record useful to other researchers. Qualitative and quantitative attributes are described in Appendix A.

Artifacts were measured in three orientations; dorsal, longitudinal, and transverse. The dorsal outline is when the artifact is viewed from the top with the tip pointed to the recorder's left. The longitudinal cross-section is when the artifact is viewed from the side with the tip pointed to the recorder's left. The transverse crosssection is when the artifact is viewed dead on with the tip pointed directly at the recorder. Artifacts were divided into four surfaces, dorsal, ventral, and lateral(2) (Figure 5). The dorsal surface is the top of the artifact in plan view, and the ventral surface is the bottom of the artifact and includes the marrow cavity. The two lateral surfaces are the artifact's sides. Ventral edges are the junction of the marrow cavity and cortical bone on an artifact's ventral surface. Ventral edges were not present on every artifact. 


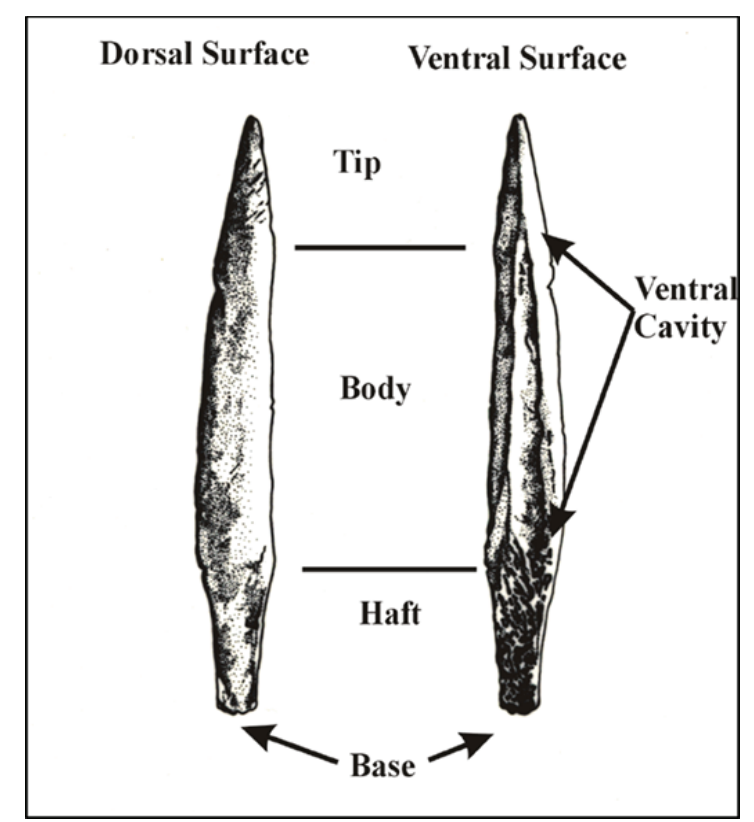

Figure 5. Dorsal and ventral surfaces and attributes recorded.

An artifact's tip, the working end including the point, is considered the distal end, and an artifact's base, opposite from the tip, is considered the proximal end. This methodology uses the terms distal and proximal in reference to the artifact's orientation, rather than the anatomical orientation used in faunal analyses. Artifacts were divided into four elements, tip, body, haft, and base (Figure 6). The point is the angle formed by the lines forming the dorsal outline of the artifact in plan. The body is proximal to the tip, and is noted by a change in the artifact's dorsal and longitudinal outlines. The haft may or may not be present on each artifact. Artifacts that did not possess a haft consist of a body element and a base element. The haft is proximal to the body, and is also noted by an obvious change in the artifact's dorsal and longitudinal outlines for the purpose of affixing a handle or shaft. The base is often the element which is held while the artifact is in use or may be shielded by a handle or shaft. In cases where an artifact was bipointed and the tip and base were not discernable and were not fractured or missing, the tip and 
base were arbitrarily assigned (for example: a complete bipoint). If an artifact possessed an articulatory end, then that end is designated the base or proximal end.

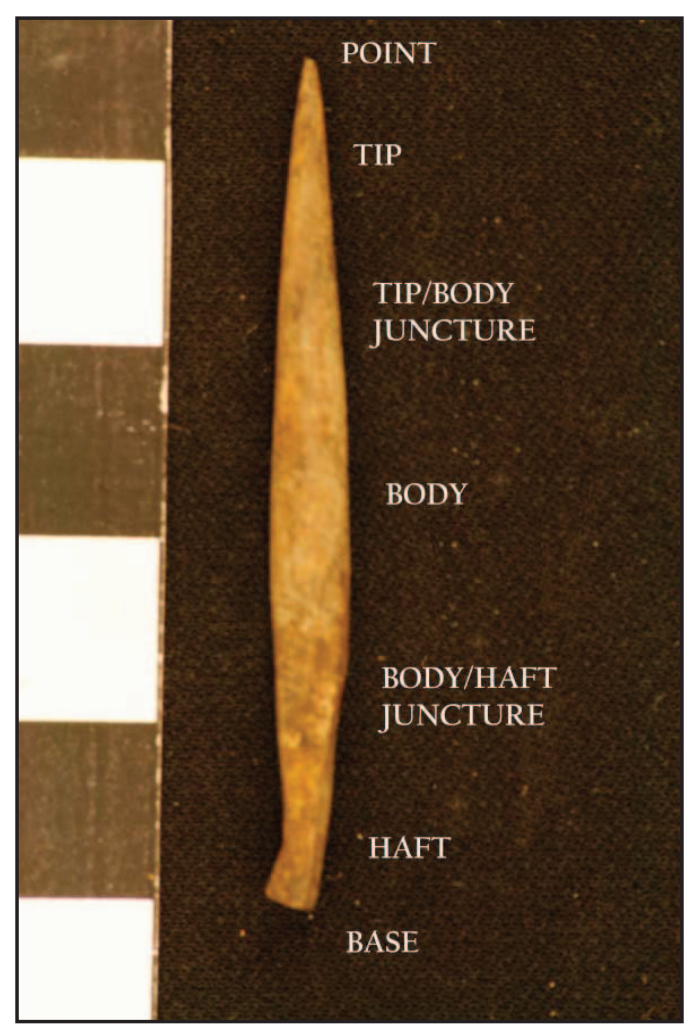

Figure 6. Osseous artifact elements.

Artifact type designation here follows a morpho-functional classification that was derived from ethnographic analogy. Fortunately, Northwest Coast ethnographic records are extremely detailed, making ethnographic analogy possible for this classification, particularly because the assemblages date to the ethnographic/historic period. Such ethnographic analogs were derived from the work of Drucker and Stewart (Drucker 1943, Stewart 1981).

The morpho-functional classification used here is a hierarchical taxonomy (Appendix A). Artifacts were first classed by general functional category or tip shape in 
longitudinal cross section (i.e. adornment, detritus, beveled tool, pointed tool, etc) with unique inclusion criteria for each category. Beyond this, smaller categories are specific to each functional category. For example, the category adornment contains subcategories bead, pendant, pin, or tube; whereas the category beveled tool contains subcategories based on tip shape in plan, point, round or square. Categories based on tip shape in longitudinal cross section are typically sub-classed into tip shape in plan view and then sub-sub-classed by possession of hafting element or base. Categories not based on tip shape in longitudinal cross section are each sub-classed differently, specific to the functional categories themselves. Some categories make distinctions based on completeness or raw material type, while others do not. Fragmented pieces that could not be assigned an artifact type were recorded as worked bone or worked antler fragments. Worked fragments without a discernibly worked tip or base were classed as body fragments. Worked fragments were described in as much detail as possible.

Aside from qualitative and quantitative attributes, other information was noted. Artifact number, field designation, provenience, and any other information written on the bag or bag tag was recorded. A simple sketch of both the dorsal and ventral surfaces of each artifact was drawn with any interesting attributes or treatments shown. Notes include a simple description (i.e. ovate fragment of abraded antler), as well as anything unusual or extraordinary.

Data collection included all modified bone and antler from Cathlapotle and Meier. Unmodified mammalian assemblages were analyzed by Lyman (Ames 2011, Lyman 2003). Any modified bone or antler within the unmodified faunal assemblage was noted and removed by Lyman. Upon completion of data collection, I reanalyzed many artifacts 
to check consistency. All attributes described were recorded by hand on bone tool forms by the author and then entered into Microsoft Excel.

\section{Analysis Methodology}

Davis (1998) described and analyzed the Meier assemblage using the morphofunctional classes (i.e.: adornment, beveled tools, piercing tools) described above and in Appendix A. Artifacts were class each artifact following Ames' $(1976,2005)$ and Davis' (1998) morpho-functional taxonomic classification in Appendix A and classes were put into Raetz's categories, with the addition of a residual “other" category. Using Raetz's categories (and the residual "other") eases analysis by providing larger sample sizes for statistical analyses.

In Chapter 5, test expectations for Hypothesis 1 outlined that procurement artifacts, ornaments, and awls should be curated, while modification tools should be expedient. First, artifacts were designated as more curated or more expedient. Davis (1998) devised an energy scale, measuring energy expenditure by the degree of modification exhibited by each tool. Her energy scale was based on the assumption that curated artifacts were heavily worked, while expedient artifacts were not as extensively worked. Artifacts were assigned energy ranks based on number of worked sides or elements, where four worked sides was considered completely modified, three highly modified, two or less low modification. Artifacts with worked tip, body, haft, and base and an absence of a marrow cavity represent the most curated artifacts, while artifacts that do not possess a haft but are worked on the tip, body, and base were considered curated artifacts. Heavily worked tip/body fragments were considered curated artifacts as many tip/body fragments are the remains of heavily utilized broken tools. Expedient 
artifacts were those that are worked only on the tip, or the tip and body and have nonworked or anatomical bases.

For my analysis of the Cathlapotle bone and antler artifacts I use Davis' energy scale as a guide to determining curation versus expediency. Artifact class frequency and degree of energy investment for Raetz's categories (and “other") are discussed. Results are then compared to Davis' analysis of the Meier site bone and antler artifacts.

The assemblage was analyzed spatially by comparing the distribution of complete and broken artifacts throughout site locations and architectural facilities. Complete curated tools should be concentrated inside the house(s) in the storage facilities, the cellar or bench/cellar. Broken curated tools and discarded expedient tools should be concentrated outside the house(s) in the midden.

The simplest coarse-grained spatial analysis was to compare what was located inside the house(s) with what was located outside the house(s). Both sites are divided both arbitrarily and architecturally into analytic segments (locations) and facilities. The interior of the Meier site house is simply divided into $10 \mathrm{~m}$ segments, North, Center, and South. Portions of the site outside of the Meier house are divided into Midden (east of the house) and Exterior (yard). At Cathlapotle, each house or house compartment is treated as an analytic segment, House 1B (H1B), House 1C (H1C), House 1D (H1D), House 2 (H2), House 4 (H4), House 6 (H6), and House 7 (H7). Portions of the site outside of the houses are divided into Midden and Sheet Midden. Cathlapotle middens are located between houses, Midden Lobe A (MA) is located between Houses 1 and 2, and Midden Lobe B (MB) located between Houses 5 and 6. The sheet midden is separated into three analytic segments based on which house it is associated with, Sheet 
Midden House 1 (SMH1), Sheet Midden House 2 (SMH2), and Sheet Midden House 6 (SMH6).

Assemblages were analyzed spatially in terms of both Raetz's categories and the specific artifact classes. The assemblages were also analyzed in terms of facilities. Facilities are architecturally defined areas that denote specific human behaviors (Kaehler2002). For example, cellars denote storage activities and hearths denote food processing and cleaning activities. Ames et al. (2000) divide (both arbitrarily and architecturally) the Cathlapotle houses into Bench Cellar (BC), Bench Cellar Hearth Periphery (BCHP), Hearth Periphery (HP), Wall (W), Wall Bench (WB), Wall Bench Cellar (WBC), and Wall Bench Cellar Hearth Periphery (WBCHP). The Meier house is divided into Bench (B), Cellar (C), Cellar Bench (CB), Hearth Periphery (HP), and Wall (W). Figure 7 illustrates architectural facilities in systemic context. Using house location designation and facility designation together, one can pinpoint the location of an artifact. For example, an artifact may be recovered from the hearth periphery of House 1D at Cathlapotle, or the cellar in the south end of the Meier house. 


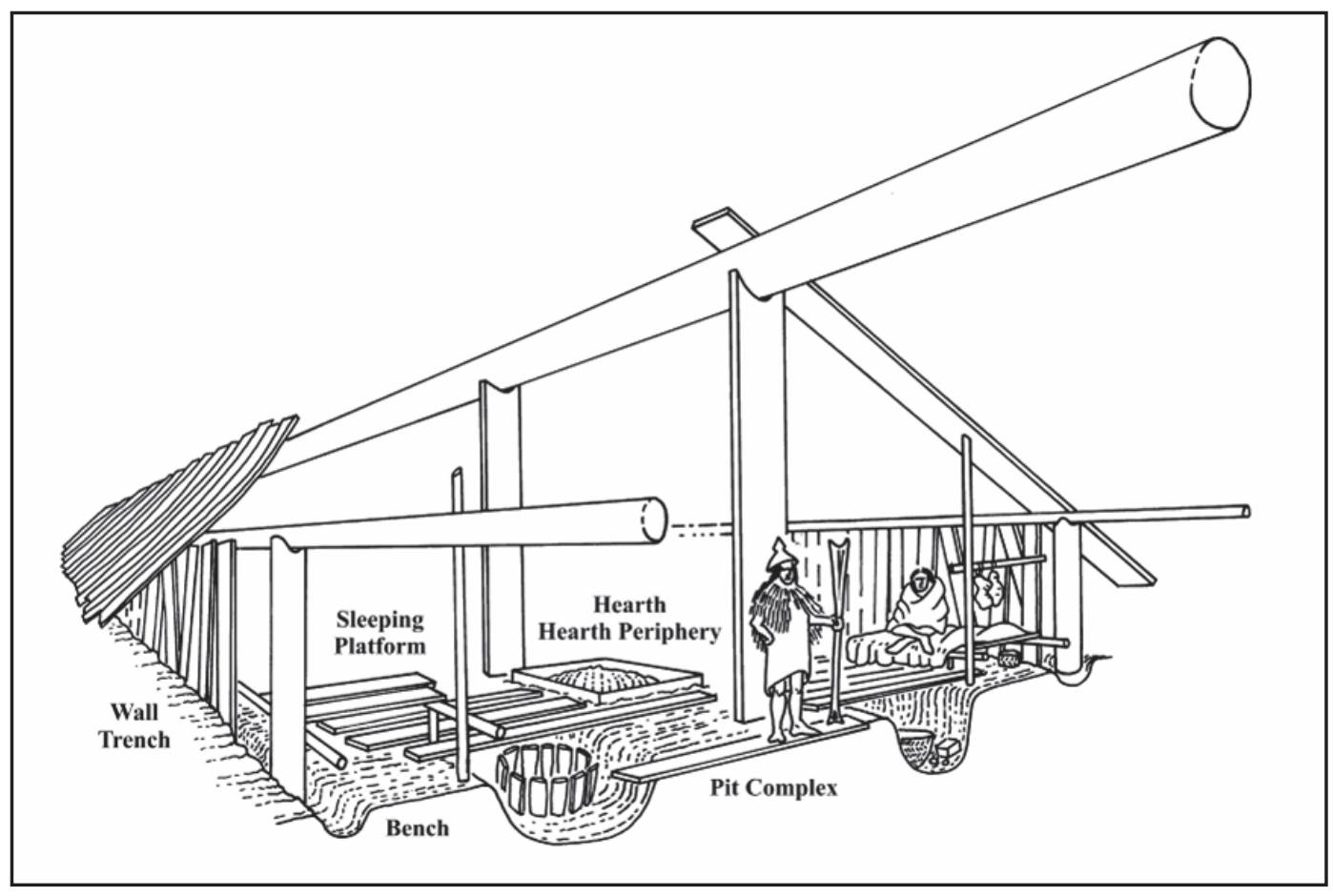

Figure 7. Illustration of Meier house architectural facilities in systemic context.

Courtesy of Cameron Smith.

Test expectations for Hypothesis 3 suggest the introduction of metal tools will alter bone and antler artifact frequencies. To test this hypothesis I compared changes in assemblage composition and artifact frequency between the precontact and postcontact assemblages at either site and then compared differences between sites. One-sample and two-sample chi-square tests were used frequently. I only accepted chi-square tests as statistically significant if the p-value is less than 0.05 . Therefore when I state a chi square test produced significant results, it is at least 95\% likely that differences in observed and expected values are not by chance. Standardized residuals were then calculated to find out which categories influenced the chi-square. A standardized residual is calculated by dividing chi square values (before they are summed) for each 
category by the standard deviation of all chi square values (Fletcher and Lock 2005). The closer the standardized residual is to 2 , the more that category influenced the chi square. Any standardized residuals equal or greater than 2 I termed significant.

When pre and postcontact assemblages were compared, I calculate expected values based on the precontact assemblage of the site in question. To analyze artifact counts within facilities and locations within the house(s) and site, I calculated expected values based on percentage of volume excavated. Excavation volume per $\mathrm{m}^{3}$ and percentages are listed in Tables 5-8.

Table 5. Meier facility volume and percentages.

\begin{tabular}{|c|c|c|}
\hline Facility & $\underline{\mathrm{m}^{3}}$ & $\underline{\%}$ \\
\hline Bench & 25.13 & 16 \\
\hline Cellar & 40.36 & 25 \\
\hline Cellar/Bench & 12.33 & 8 \\
\hline Exterior & 20.45 & 13 \\
\hline Hearth Periphery & 22.9 & 14 \\
\hline Midden & 25.16 & 16 \\
\hline Wall & 13.9 & 9 \\
\hline
\end{tabular}

Table 6. Meier location volume and percentages.

\begin{tabular}{|c|c|c|}
\hline Location & $\underline{m}^{3}$ & $\underline{\%}$ \\
\hline Central & 21.55 & 13 \\
\hline Exterior & 20.9 & 13 \\
\hline Midden & 25.16 & 16 \\
\hline North & 29.8 & 19 \\
\hline South & 62.8 & 40 \\
\hline
\end{tabular}


Table 7. Cathlapotle facility volume and percentages

\begin{tabular}{|lrr|}
\hline \multicolumn{1}{|c}{ Facility } & \multicolumn{1}{c|}{$\mathrm{m}^{3}$} & $\underline{\%}$ \\
Bench/Cellar & 20.42 & 9 \\
Bench/Cellar/Hearth Periphery & 3.83 & 2 \\
Hearth Periphery & 40.44 & 17 \\
Midden Lobe A & 9.13 & 4 \\
Midden Lobe B & 10.02 & 4 \\
Midden Lobe B/Basal & 3.61 & 2 \\
Sheet Midden (H1) & 40.31 & 17 \\
Sheet Midden (H2) & 13.68 & 6 \\
Sheet Midden (H6) & 7 & 3 \\
Wall & 22.04 & 9 \\
Wall/Bench & 5.35 & 2 \\
Wall/Bench/Cellar & 44.44 & 18 \\
Wall/Bench/Cellar/Hearth Periphery & 18.68 & 8 \\
Sheet Midden Unknown & 1.28 & 0.5 \\
\hline
\end{tabular}

Table 8. Cathlapolte location volume and percentages.

\begin{tabular}{|lrr|}
\hline \multicolumn{1}{|c}{ Location } & \multicolumn{1}{c|}{$\mathrm{m}^{3}$} & \multicolumn{1}{c|}{} \\
House 1B & 6.68 & 3 \\
House 1C & 12.6 & 5 \\
House 1D & 68.7 & 29 \\
House 2 & 7.1 & 3 \\
House 4 & 43.31 & 18 \\
House 6 & 14.01 & 6 \\
House 7 & 2.8 & 1 \\
Midden Lobe A & 9.13 & 4 \\
Midden Lobe B & 10.02 & 4 \\
Midden Lobe B/Basal & 3.61 & 2 \\
Sheet Midden (H1) & 40.31 & 17 \\
Sheet Midden (H2) & 13.68 & 6 \\
Sheet Midden (H6) & 7 & 3 \\
Sheet Midden Unknown & 1.28 & 0.05 \\
\hline
\end{tabular}




\section{Chapter 7}

\section{$\underline{\text { Results }}$}

\section{$\underline{\text { Residential sedentism promotes technological expediency in hunter-gatherers }}$}

The Cathlapotle bone and antler assemblage is a highly curated assemblage, an exception to this are awls and flakers, which are expedient tools. Osseous artifacts are nearly three times as frequent at Meier than at Cathlapotle (Meier n=1219, Cathlapotle $\mathrm{n}=411$ ). When the number of tools per $\mathrm{m}^{3}$ of excavation volume is considered, osseous artifacts are five times more frequent at Meier than at Cathlapotle (Table 9). Worked fragments are the most numerous at both sites while ornaments are the least numerous. Table 7 lists artifact types, counts, and densities for both sites. 
Table 9. Artifact count and frequency per $\mathrm{m}^{3}$ for both sites.

\begin{tabular}{|c|c|c|c|c|}
\hline \multirow[t]{2}{*}{ Artifact class } & \multicolumn{3}{|c|}{ Cathlapotle } & \multirow{2}{*}{$\frac{\text { Meier }}{\mathrm{N} / \mathrm{m}^{3}}$} \\
\hline & $\underline{N}$ & $\mathrm{~N} / \mathrm{m}^{3}$ & $\underline{N}$ & \\
\hline \multicolumn{5}{|l|}{ Procurement } \\
\hline Bipoints & 5 & 0.02 & 42 & 0.26 \\
\hline Harpoons & 11 & 0.05 & 24 & 0.15 \\
\hline Points & 22 & 0.09 & 68 & 0.42 \\
\hline Foreshafts & 4 & 0.02 & 0 & 0 \\
\hline Total Procurement & 42 & 0.17 & 134 & 0.84 \\
\hline \multicolumn{5}{|l|}{ Modification } \\
\hline Blades & 0 & 0 & 9 & 0.06 \\
\hline Flakers & 4 & 0.02 & 3 & 0.02 \\
\hline Handles & 7 & 0.03 & 2 & 0.01 \\
\hline Chisels & 15 & 0.06 & 22 & 0.14 \\
\hline Wedges & 40 & 0.17 & 102 & 0.64 \\
\hline Awls & 30 & 0.12 & 143 & 0.89 \\
\hline Punches & 0 & 0 & 60 & 0.37 \\
\hline Total Modification & 96 & 0.4 & 341 & 2.13 \\
\hline \multicolumn{5}{|l|}{ Ornaments } \\
\hline Beads & 7 & 0.03 & 11 & 0.07 \\
\hline Pendants & 3 & 0.01 & 39 & 0.24 \\
\hline Pins & 2 & 0.01 & 1 & 0.01 \\
\hline Tubes & 0 & 0 & 32 & 0.2 \\
\hline Total Ornaments & 12 & 0.05 & 83 & 0.52 \\
\hline \multicolumn{5}{|l|}{ Other } \\
\hline Crescent & 1 & 0.004 & 3 & 0.02 \\
\hline Peg & 1 & 0.004 & 4 & 0.25 \\
\hline Worked & & & & \\
\hline Fragments & 177 & 0.74 & 650 & 4.06 \\
\hline Detritus & 82 & 0.34 & 4 & 0.02 \\
\hline Total Other & 261 & 1.09 & 661 & 4.13 \\
\hline Total Artifacts & 411 & 1.71 & 1219 & 7.61 \\
\hline
\end{tabular}




\section{Whole Assemblage}

The Cathlapotle assemblage consists mostly of artifacts with unknown condition $(n=127,30 \%)$ or broken artifacts $(n=124,30 \%)$, while complete artifacts $(n=77,19 \%)$ and detritus ( $\mathrm{n}=82,20 \%)$ were less frequent. Regardless of completion, significantly more bone and antler artifacts from Cathlapotle were recovered outside the houses $\left(\mathrm{x}^{2}=66.54, \mathrm{p}<0.01\right)$. Specifically, there were significantly more unknown artifacts, complete artifacts, and broken artifacts recovered outside the houses (see Table 10 for $\mathrm{x}^{2}$ values). Detritus was randomly distributed between inside and outside the houses. Significantly more bone and antler artifacts were recovered from the $\mathrm{SM}(\mathrm{H} 2)$ facility than expected $\left(\mathrm{x}^{2}=87.9, \mathrm{p}<0.01\right)$. Inside the houses, artifacts are densest in $\mathrm{H} 7$ and most numerous in H1D. Bone and antler artifacts at Cathlapotle are densest and most numerous in the BC facility.

At Meier, most artifacts are broken $(n=957,79 \%)$, with some complete $(n=179$, $15 \%)$ and artifacts with unknown condition $(n=75,6 \%)$ represented in the assemblage. Regardless of completeness, Meier bone and antler artifacts are randomly distributed inside and outside the house, but more were recovered inside the house. Chi squared tests reveal there are more artifacts, regardless of completion, than expected in both the Cellar and the Midden facilities $\left(\mathrm{x}^{2}=58.63, \mathrm{p}<0.01\right)$. When completeness is considered, patterns are evident. There are significantly fewer complete artifacts outside the house than expected $\left(x^{2}=5.94, p=0.02\right)$ and significantly fewer complete artifacts than expected in the Exterior facility $\left(\mathrm{x}^{2}=10.6, \mathrm{p}=0.03\right)$. Complete artifacts are most numerous and densest in the cellar and there are significantly more complete artifacts recovered from 
the cellar facility $\left(x^{2}=23.04, p<0.01\right)$. In contrast to complete artifacts at Meier, there are significantly more broken artifacts recovered outside the house than expected $\left(\mathrm{x}^{2}=6.36\right.$, $\mathrm{p}=0.01)$ and significantly more broken artifacts recovered in the Midden $\left(\mathrm{x}^{2}=24.1\right.$, $\mathrm{p}<0.01)$. Artifacts with an unknown condition at Meier are randomly distributed inside and outside the house.

\section{$\underline{\text { Procurement Artifacts }}$}

Procurement artifacts at Cathlapotle and Meier include bipoints, harpoons (represented by toggling harpoon valves and one barbed self-arming harpoon head), points (differing from bipoints as they are unipoints), and foreshafts/rods. At both sites bipoints are extremely well worked, exhibiting extensive abrasion and polish. Cathlapotle harpoon valves represent various stages of manufacture, including a valve blank. Two artifacts (826a and 826b) are a pair found in situ. Harpoon valves at Cathlapotle and Meier are curated artifacts. All Cathlapotle and Meier points, including fragments, are extremely well worked and are heavily abraded and polished. A variety of morphological types are represented including small delicate points that were probably hafted in multiples to arm leister spears and larger points with internal hafts or line notches that probably armed composite harpoons. There are more hafted points at both sites than any other type of point, followed by fixed points. There are no foreshafts/rods recorded at the Meier site, and only four recorded at Cathlapotle. Foreshafts/rods were probably present in the Meier artifact assemblage, but not recorded as such. These are well worked on all sides, exhibiting grinding and polish, curated artifacts that were part of larger more complex weapon systems. 
Half of Cathlapotle procurement artifacts are complete $(\mathrm{n}=21,50 \%)$ and half are broken $(\mathrm{n}=21,50 \%)$. Both complete and broken procurement artifacts are concentrated outside the houses, mostly in $\mathrm{SM}(\mathrm{H} 2)$. Table 10 lists chi squared test results for complete, broken, and all procurement artifacts, awls, modification artifacts, ornamental artifacts, other artifacts and for the whole assemblage at Cathlapotle. A chi squared test shows there are both significantly more complete procurement artifacts outside the houses $\left(\mathrm{x}^{2}=9, \mathrm{p}=0.01\right)$ and significantly more procurement artifacts, regardless of completeness, outside the houses $\left(\mathrm{x}^{2}=23, \mathrm{p}<0.01\right)$. Within the houses, procurement artifacts are scattered between $\mathrm{H} 1 \mathrm{C}, \mathrm{H} 1 \mathrm{D}, \mathrm{H} 4$, and $\mathrm{H} 7$, with one or two specimens in each location. Within facilities, complete procurement artifacts are scattered between the $\mathrm{BC}, \mathrm{HP}, \mathrm{W}$, and $\mathrm{WBC}$ facilities, represented by one or two specimens each. Broken procurement artifacts are found in the $\mathrm{BC}, \mathrm{HP}$, and $\mathrm{WBCHP}$ facilities, represented by one or two specimens each. Sample sizes are too small to permit chi squared analysis of locations or facilities for procurement artifacts regardless of completion, but they appear to be scattered across houses and facilities. 


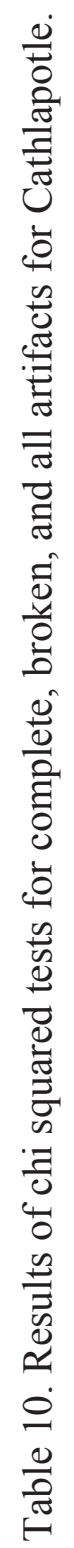

\begin{tabular}{|c|c|c|c|c|c|c|c|c|c|c|c|c|c|c|c|c|c|c|}
\hline$\vec{z}$ & 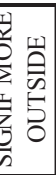 & 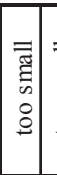 & 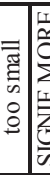 & $\frac{1}{0}$ & 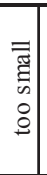 & 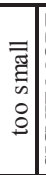 & 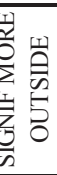 & 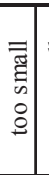 & $\begin{array}{l} \\
\overline{\mathbf{g}} \\
\vdots \\
\vdots\end{array}$ & 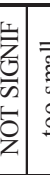 & & 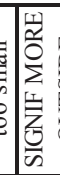 & & 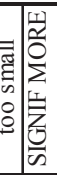 & 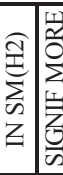 & 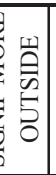 & & 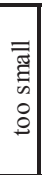 \\
\hline ¿ & $\begin{array}{l}\overrightarrow{\vec{b}} \\
\dot{\vec{v}} \\
\vec{a}\end{array}$ & & & $\overline{\overrightarrow{\dot{\vec{\theta}}}}$ & & & $\begin{array}{l}\overrightarrow{\vec{v}} \\
\dot{\vec{v}}\end{array}$ & & & & & & \begin{tabular}{l|}
$\vec{b}$ \\
$\dot{\vec{v}}$ \\
$\vec{c}$
\end{tabular} & & \begin{tabular}{l|} 
\\
$\overrightarrow{\hat{v}}$ \\
$\overrightarrow{0}$
\end{tabular} & $\begin{array}{l}\vec{b} \\
\overrightarrow{\hat{b}} \\
\mathrm{a}\end{array}$ & & \\
\hline : & $\begin{array}{r}\pi_{\pi}^{\pi} \\
\tilde{x}\end{array}$ & & & $\underset{\pi}{\pi}$ & & & 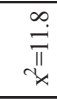 & & & & & & 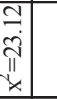 & & 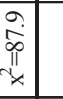 & 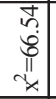 & & \\
\hline 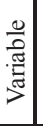 & $\begin{array}{l}\overrightarrow{\mathbf{z}} \\
\vdots \\
\vdots\end{array}$ & 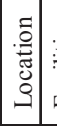 & 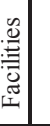 & 引 & 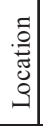 & 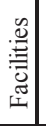 & $\begin{array}{l}\bar{\Xi} \\
\Xi\end{array}$ & 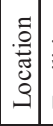 & 总 & $\begin{array}{ll}\vec{\vdots} \\
\vdots \\
\Xi\end{array}$ & 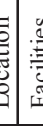 & & 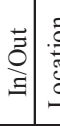 & & 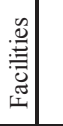 & $\begin{array}{l}\vdots \\
\vdots \\
\vdots\end{array}$ & & 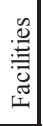 \\
\hline ঊ & 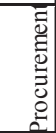 & & & $\frac{n}{3}$ & & & 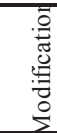 & & & 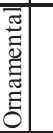 & & & $\begin{array}{l}: \overrightarrow{\mathrm{z}} \\
\overline{\tilde{z}}\end{array}$ & & & च & & \\
\hline $\begin{array}{l}\vec{z} \\
\stackrel{\vec{g}}{0} \\
\approx\end{array}$ & 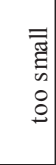 & 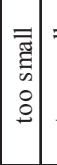 & 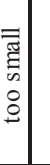 & 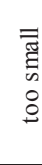 & $\begin{array}{l}\bar{\Xi} \\
\text { : } \\
0 \\
0 \\
\vdots\end{array}$ & 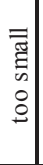 & 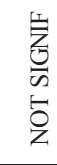 & 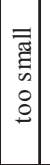 & 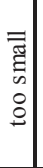 & 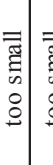 & $\begin{array}{l}0 \\
0 \\
0 \\
0\end{array}$ & & 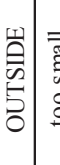 & & 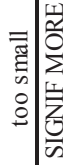 & 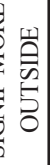 & & 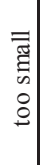 \\
\hline$z$ & & & & & & & & & & & & & $\begin{array}{l}\mathbf{8} \\
0 \\
0\end{array}$ & & & $\begin{array}{l}\overrightarrow{0} \\
\dot{0} \\
\mathrm{i}\end{array}$ & & \\
\hline ีㅣ & & & & & & & & & & & & & 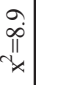 & & & 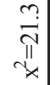 & & \\
\hline 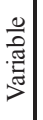 & $\begin{array}{l}\overrightarrow{\bar{o}} \\
\equiv\end{array}$ & 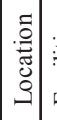 & 造 & 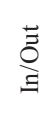 & 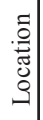 & 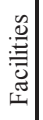 & $\begin{array}{l}\vec{\Xi} \\
\Xi\end{array}$ & 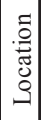 & 童: & 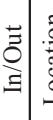 & 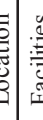 & & 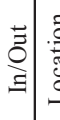 & & 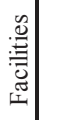 & $\begin{array}{l}\bar{\Xi} \\
\equiv\end{array}$ & & 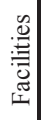 \\
\hline 童 & 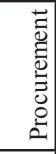 & & & $\frac{n}{3}$ & & & 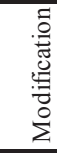 & & & 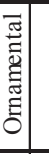 & & & $\begin{array}{l}\stackrel{\breve{g}}{\bar{z}} \\
\overline{0}\end{array}$ & & & ऐ & & \\
\hline 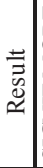 & 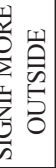 & 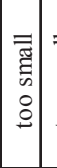 & $\begin{array}{l}\overline{\widetilde{z}} \\
\bar{z} \\
0 \\
\vdots \\
\vdots\end{array}$ & 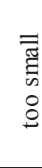 & 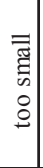 & 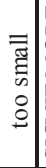 & 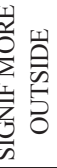 & 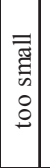 & 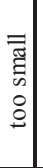 & 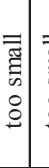 & & & 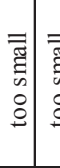 & & & 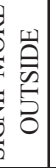 & & 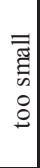 \\
\hline 3 & $\begin{array}{l}\overrightarrow{0} \\
\dot{\vec{v}} \\
\underline{a}\end{array}$ & & & & & & $\begin{array}{l}\overline{\vec{D}} \\
\dot{\vec{v}} \\
\stackrel{0}{2}\end{array}$ & & & & & & & & & $\begin{array}{l}\overrightarrow{0} \\
\dot{0} \\
0 \\
\end{array}$ & & \\
\hline 리 & $\begin{array}{l}\pi \\
x \\
x\end{array}$ & & & & & & 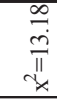 & & & & & & & & & 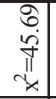 & & \\
\hline 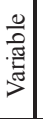 & $\begin{array}{l}\overrightarrow{0} \\
\vdots \\
\vdots\end{array}$ & 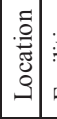 & : & 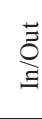 & 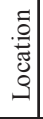 & 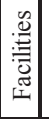 & $\begin{array}{l}\overrightarrow{\bar{\Xi}} \\
\vdots\end{array}$ & 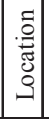 & 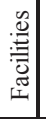 & 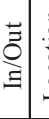 & 象 & & 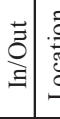 & 密 & 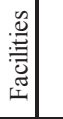 & $\begin{array}{l}\overline{0} \\
\vdots \\
\vdots\end{array}$ & 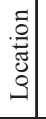 & 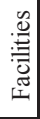 \\
\hline 离 & $\stackrel{2}{2}$ & & & $\frac{3}{3}$ & & & 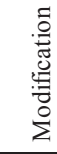 & & & 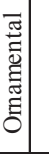 & & & ठ̃ँ & & & « & & \\
\hline
\end{tabular}




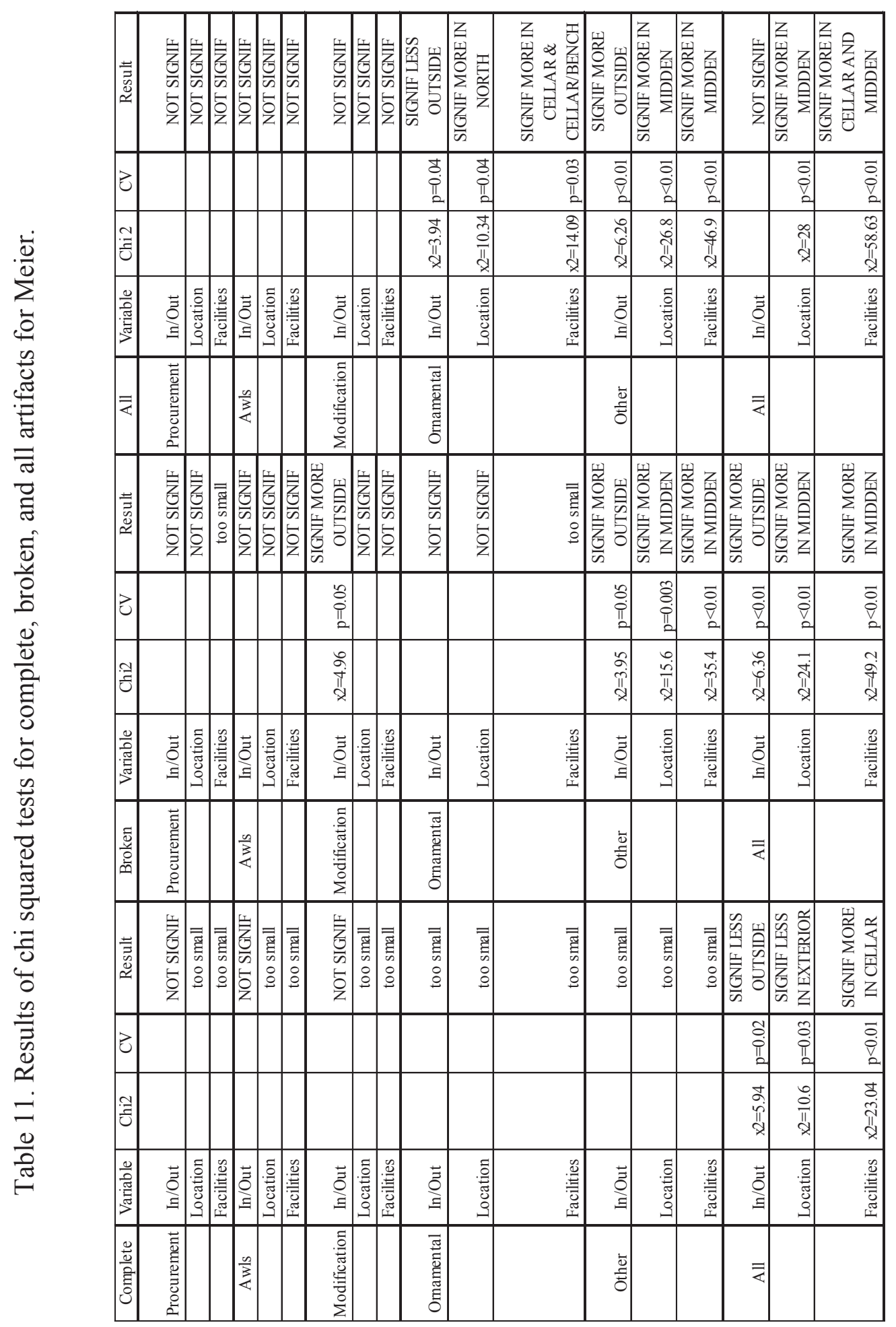


At Meier there are slightly more broken procurement artifacts $(n=72,54 \%)$ than complete $(\mathrm{n}=62,46 \%)$. Most complete and broken procurement tools are located inside the house, although broken procurement tools have higher artifact densities outside of the house. Procurement artifacts are randomly distributed across the site and within facilities (Table 11). Table 11 lists chi squared test results for complete, broken, and all procurement artifacts, awls, modification artifacts, ornamental artifacts, other artifacts and for the whole assemblage at Meier.

\section{$\underline{\text { Modification artifacts }}$}

Modification artifacts include awls, blades, flakers, handles, chisels, wedges, and punches. Awls are discussed separately below. Bone blades could function as hafted knives or as expedient cutting tools. A total of nine blades were recovered from Meier. Davis (1998) ranks seven out of nine blades as curated, and two as expedient. No blades were found at Cathlapotle.

Flakers were used to manufacture stone tools, specifically during pressure flaking. Flakers are not easily recognizable artifact types, many antler flakers are probably classed as worked antler tip fragments or unmodified antler tines (Raetz 1989). Flakers from Cathlapotle exhibit damage from use and little other modification. Flakers from both sites are more expedient than curated, all possess marrow cavities, are not hafted, and are worked on few sides.

Handles are inherently curated artifacts. Handles are often the osseous component of complex compound tools. Handles from Cathlapotle and Meier are extremely well worked, shaped, curated tools. Most handles lack marrow cavities, and are worked on all sides. 
Chisels are beveled pointed tipped tools used for fine work on soft substances. Chisels are interpreted as woodworking tools used during as late stage finishing and artistic carving. Chisel morphology ranges from fixed chisels with worked bases, metapodial chisels, and beaver incisor chisels. At Cathlapotle, fixed chisels are very well worked, with double beveled tips, exhibiting abrasion and polish. Although not hafted, these are curated artifacts. Metapodial chisels are extremely well worked, exhibiting abrasion, grinding, beveling, and polish, with the articulatory end of the metapodial retained to be used as a handle. Four complete metapodial chisels were part of a cache in $\mathrm{SM}(\mathrm{H} 1)$. One metapodial chisel in the cache is a chisel preform that is well worked, but the tip is not yet formed. The artifact retains a girdled end resulting from the girdle and snap method of bone blank manufacture. Beaver incisor chisels are ventrally beveled, polished, and exhibit grinding and abrasion. Chisel tip fragments are very well worked and are broken remains of curated artifacts. Davis (1998) ranks Meier chisels as curated artifacts. Chisels at both sites are curated, cared-for tools.

Wedges are large, wedge-shaped objects with beveled round or square tips. Wedges were used for heavy duty woodworking including felling trees, splitting wood, and hollowing out canoes. There are more round tipped wedges than square tipped wedges at both sites and more wedges overall at Meier. Cathlapotle wedges are very well made exhibiting abrasion, polish, and grinding. Several wedge tips were recovered that are small and appear to be wedge bits. The presence of wedge bits or tips indicates wedge maintenance. Davis (1998) describes Meier wedges as primarily curated artifacts, although some expedient specimens are present. Wedges at Cathlapotle and Meier are highly maintained, well worked, curated artifacts. 
Punches are blunt pointed tools. They were used during stone tool manufacture, specifically indirect percussion. Punches may have also been used as blunt points to stun prey. Like flakers, punches are not easily recognizable artifacts and some were likely misclassed within other artifact classes, such as worked fragments. Meier produced 60 punches, 42 round tipped and 18 square tipped while Cathlapotle produced no punches. Davis (1998) ranks punches as highly curated artifacts.

Modification tools at Cathlapotle and Meier are both curated and expedient. Blades, handles, chisels, wedges, and punches are all very well made, well worked curated tools. These artifacts are generally worked on all sides and many are hafted. Awls and flakers are primarily expedient tools. They are not hafted, evidence of modification is limited to use, and polish is confined to the tip area.

Most Cathlapotle modification tools are broken $(n=42,64 \%)$ rather than complete $(n=24,36 \%)$. There are significantly more complete modification tools recovered outside the houses $\left(\mathrm{x}^{2}=13.18, \mathrm{p}<0.01\right)$ and significantly more modification tools (regardless of completeness) recovered outside the houses $\left(x^{2}=11.8, p<0.01\right)$. These complete modification tools are most numerous in $\mathrm{SM}(\mathrm{H} 2)$, but equally as dense in $\mathrm{SM}(\mathrm{H} 1)$ and $\mathrm{M}(\mathrm{A})$. Inside, Cathlapotle modification tools are found in $\mathrm{H} 1 \mathrm{C}$ and H1D and located in the $\mathrm{BC}, \mathrm{HP}$, and $\mathrm{W}$ facilities. Chi squared tests show broken modification tools are randomly distributed inside and outside the houses (Table 8). Broken modification tools are most numerous in the BC facility in $\mathrm{H} 1 \mathrm{D}$ and $\mathrm{H} 7$. Outside, they are found in $\mathrm{M}(\mathrm{A})$, $\mathrm{M}(\mathrm{B}), \mathrm{SM}(\mathrm{H} 1)$, and $\mathrm{SM}(\mathrm{H} 2)$ and are most numerous in $\mathrm{M}(\mathrm{B})$ and densest in $\mathrm{SM}(\mathrm{H} 2)$.

Like Cathlapotle, most Meier site modification artifacts are broken $(\mathrm{n}=155,78 \%)$ than complete $(n=43,22 \%)$. Most Meier modification artifacts are found inside the 
house. Complete modification artifacts and all modification artifacts, regardless of completeness, are randomly distributed inside and outside the house. There are significantly more broken modification tools found outside the house $(\mathrm{x} 2=4.96, \mathrm{p}=0.05)$, although, broken modification tools are randomly distributed across site locations and throughout facilities.

Awls

Awls are frequently interpreted as expedient tools. Splinter awls, anatomical awls, and expedient awl fragments are abundant at both sites. Meier contains bird bone awls and antler tine awls, both of which are consistent with the pattern of expediency shown on other Meier awls. While the majority of Cathlapotle awls are expedient, three awls recovered from Cathlapotle are well worked curated awls exhibiting abrasion and polish over the entirety of the artifact (one is hafted as well). Davis (1998) ranked half of Meier worked awls as somewhat curated and the other half as expedient.

Most Cathlapotle awls are complete $(\mathrm{n}=21,70 \%)$ rather than broken $(\mathrm{n}=9,30 \%)$. Most complete Cathlapotle awls are found outside the houses, within $\mathrm{SM}(\mathrm{H} 1)$ and $\mathrm{SM}(\mathrm{H} 2)$. Half of broken awls are located outside the houses and half inside. Broken awls are found in H1D, H4, and H7, represented by one or two specimens each. Both complete and broken awls are found in the $\mathrm{BC}, \mathrm{HP}$, and $\mathrm{WBC}$ facilities, represented by one or two specimens each. Although sample sizes were too small to calculate chi squared tests on the distribution of complete or broken awls, a chi squared test of the distribution of all awls revealed there are significantly more awls outside of the house than expected $\left(x^{2}=36, p<0.01\right)$. 
In contrast to Cathlapotle, most Meier awls are broken $(\mathrm{n}=107,75 \%)$ rather than complete $(n=35,25 \%)$. There are more complete awls within the house, but a higher density of awls outside the house. Sample sizes were too small to calculate chi squared tests on the distribution of complete awls throughout the site and facilities, although complete Meier awls are most numerous and densest in the Center of the house within the Cellar and Cellar/Bench facilities. Broken awls and all awls regardless of completion are randomly distributed throughout the site and facilities (Table 9).

\section{Ornaments}

Ornaments were used for personal adornment, are frequently decorated, and include: beads, pendants, pins, and tubes. Beads are perforated objects, suitable for threading with others (Loy and Powell 1977). Cathlapotle and Meier beads are extremely well worked artifacts, exhibiting abrasion and polish. Davis (1998) ranks Meier beads as curated artifacts. Some specimens are completely covered in abrasion, while others are decorated with incised geometric patterns. All have finished ends and all are constructed of bird bone.

Pendants include items that could have been suspended. Pendants were worn as jewelry, or attached to clothing or regalia via a hole, groove, or notch. Cathlapotle pendants are all well worked, polished, and have holes drilled into each. Davis (1998) ranks Meier pendants as curated artifacts. Pins are objects used to fasten or secure something. Often pins resemble ethnographic blanket pins used to secure blankets wrapped around shoulders, while others resemble ethnographic hair pins that are often decorated and used to secure hair. Cathlapotle contained two pins, both decorative. One resembled a toggle, and was likely used as a blanket pin, or to secure clothing. The 
second is anthropomorphic and seems to be the top of a hair pin. Meier contained one pin that Davis described as curated and well worked.

The function of tubes is unknown. Tubes may be objects of personal adornment, decorating clothing or functioning as beads. Tubes may also be used as whistles, drinking tubes, or as underwater breathing devices (Raetz 1989). Cathlapotle contains no tubes, while Meier contains 32 tubes. Davis ranks 23 of 32 tubes as curated and 9 as expedient.

At Cathlapotle, half of the ornaments are complete $(n=6,50 \%)$, while half are broken $(n=6,50 \%)$. Chi squared tests show all ornaments, regardless of completion, are randomly distributed between the inside and outside of the houses. Sample sizes are too small to calculate chi squared tests for complete and broken artifact distribution.

At Meier, there are more broken ornaments $(n=48,58 \%)$ than complete $(n=35$, 42\%). Broken ornaments are randomly distributed inside and outside the house, throughout the site, and throughout facilities. Complete ornaments are mostly found inside the house and the highest densities are in the North end of the house, in the Cellar and Cellar/Bench facilities. There are significantly fewer ornaments, regardless of completion, recovered outside the houses $\left(x^{2}=3.94, p=0.04\right)$ and significantly more ornaments, regardless of completion, in the northern portion of the house $\left(\mathrm{x}^{2}=10.34\right.$, $\mathrm{p}=0.04)$. There are significantly more ornaments, regardless of completion, in the Cellar and Cellar/Bench facilities $\left(\mathrm{x}^{2}=14.09, \mathrm{p}=0.03\right)$.

\section{$\underline{\text { Other Artifacts }}$}

Other artifacts include crescents, pegs, detritus, and worked fragments. Crescents are small bipointed bone objects in the shape of a crescent or a bell curve. Crescents are 
not usually described in Northwest Coast Site Reports, or sometimes are included with bipoints (Ames 2005). One crescent was recovered from Cathlapotle, and three crescents were recovered from Meier. All are extremely well worked curated artifacts. All are very small and delicate, lack marrow cavities, and are worked on all sides. Davis (1998) ranks Meier crescents as curated artifacts. Pegs resemble wooden pegs, and were likely used in house construction and/or construction of other wooden materials. One peg was recovered from Cathlapotle, while four pegs were recovered from Meier. The Cathlapotle peg was very well worked and shaped on all sides. Davis ranks Meier pegs as curated artifacts as well.

Detritus is waste from osseous tool production and is neither curated nor expedient. Many pieces of detritus are metapodials that display evidence of the girdle and snap technique of creating osseous blanks for tool making. Typically specimens have one end that is heavily modified with girdling marks surrounded by saw, cut, and adze marks, while the opposite end (the articulatory end) is otherwise unmodified. A chisel preform recovered from Cathlapotle retains girdling near the tip, which was yet to be formed. The chisel was very well made and recovered from a cache. Detritus also includes modified elk scapula, as well as all other bone and antler detritus that has not been girdled and snapped. Several large antler cores were recovered from Cathlapotle as well. The presence of detritus reflects the manufacture of curated tools, and stockpiling bone and antler blanks and/or cores for future tool production. Cathlapotle yielded 82 pieces of detritus, while Meier yielded 4. Either the two sites have radically different osseous tool making strategies, or more likely, Davis and I differed on classification of detritus. Davis likely classed many pieces of detritus as worked fragments. 
Worked fragments include items that are too fragmentary to be classed in any category. They are divided by identifiable characteristics including material, element, or treatment (Appendix A). Some may be unidentifiable detritus from tool manufacture or butchery, and some are broken tools. A total of 177 worked fragments were recovered from Cathlapotle, and 650 from Meier. The majority of worked fragments from both sites are simply worked bone or antler body fragments.

Crescents and pegs are curated artifacts, while detritus and worked fragments represent the remains of both curated and expedient artifacts as well as general modification of osseous materials. At Cathlapotle, there are 5 (2\%) complete other artifacts and $63(24 \%)$ broken other artifacts. The majority of the other artifact assemblage ( $\mathrm{n}=111,42 \%)$ is designated as unknown condition, meaning it is unknown whether or not the object is complete or broken and may not be a formal tool whatsoever. Detritus $(\mathrm{n}=82,31 \%)$ is designated as such and completeness is not evaluated. Four out of five complete other artifacts are located outside in $\mathrm{M}(\mathrm{B}), \mathrm{SM}(\mathrm{H} 1), \mathrm{SM}(\mathrm{H} 2)$, and $\mathrm{SM}(\mathrm{H} 6)$ facilities. The one complete other artifact is in the HP facility of H4. There are significantly more broken other artifacts outside of the houses at Cathlapotle $\left(\mathrm{x}^{2}=8.9\right.$, $\mathrm{p}<0.01)$. Outside, most broken other artifacts are located in $\mathrm{SM}(\mathrm{H} 2)$. There are significantly more other artifacts designated unknown outside of the houses at Cathlapotle $\left(\mathrm{x}^{2}=9.3, \mathrm{p}<0.01\right)$, mostly in $\mathrm{SM}(\mathrm{H} 1)$ and $\mathrm{SM}(\mathrm{H} 2)$. There are significantly more detritus outside the houses at Cathlapotle $\left(\mathrm{x}^{2}=3.6, \mathrm{p}=.05\right)$. Outside, detritus is most numerous and densest in $\mathrm{SM}(\mathrm{H} 1)$. Regardless of completeness, there are significantly more other artifacts outside than expected $\left(\mathrm{x}^{2}=147, \mathrm{p}<0.01\right)$ and in the $\mathrm{SM}(\mathrm{H} 2)$ facility $\left(\mathrm{x}^{2}=87.9, \mathrm{p}<0.01\right)$. 
At the Meier site, Davis designated the majority of other artifacts as broken $(\mathrm{n}=580,89 \%)$, some unknown $(\mathrm{n}=70,11 \%)$ and few as complete $(\mathrm{n}=4,0.6 \%)$. All complete specimens are located inside the house in the cellar and wall facilities. There are significantly more broken other artifacts located outside the house $\left(x^{2}=3.95, p=0.05\right)$ and in the midden $\left(\mathrm{x}^{2}=15.6, \mathrm{p}<0.01\right)$. Broken other artifacts are randomly distributed within house facilities. There are significantly more other artifacts designated unknown located outside the house $\left(\mathrm{x}^{2}=6.26, \mathrm{p}=0.01\right)$. Outside the house, most unknown other artifacts are located in the midden. Within the house, most unknown other artifacts are located in the south end.

\section{$\underline{\text { Contact and the Introduction of Metal }}$}

Contact is reflected in both the Cathlapotle and Meier osseous artifact postcontact assemblages (Table 12). At Cathlapotle artifact count decreases after contact by 29 artifacts and artifact frequency drops to 1.1 artifact per $\mathrm{m}^{3}$. The Meier site is the opposite, artifact counts increase after contact by 656 artifacts and artifact frequency per $\mathrm{m}^{3}$ increases considerably.

Table 12.Counts and frequency per $\mathrm{m}^{3}$ of precontact and postcontact assemblages.

\begin{tabular}{|lrrrrr|} 
& \multicolumn{1}{c}{ Precontact } & & \multicolumn{2}{c|}{ Postcontact } & \\
& $\underline{\mathrm{N}}$ & $\frac{\mathrm{N} / \mathrm{m}^{3}}{2}$ & $\underline{\mathrm{N}}$ & $\mathrm{N} / \mathrm{m}^{3}$ \\
Cathlapotle & 199 & 2.2 & & 170 & 1.1 \\
Meier & 269 & 5.4 & 925 & 8.4 \\
\hline
\end{tabular}

The two precontact assemblages are similar. At Meier there are more precontact bipoints, points, awls, flakers, wedges, and pendants (Tables 13 and 14). The Meier 
precontact assemblage contains blades and tubes, while these are absent at Cathlapotle. There are more harpoons, pins, and chisels at Cathlapotle, although chisels have a higher artifact frequency per $\mathrm{m}^{3}$ at Meier. Handles and crescents are found in similar frequencies at both sites. 
Table 13.Counts and frequency per $\mathrm{m}^{3}$ of Cathlapotle site artifact classes pre and postcontact.

\begin{tabular}{|c|c|c|c|c|}
\hline Cathlapotle & Precontact & & Postcontact & \\
\hline & $\mathrm{N}$ & $\mathrm{N} / \mathrm{m}^{3}$ & $\mathrm{~N}$ & $\mathrm{~N} / \mathrm{m}^{3}$ \\
\hline \multicolumn{5}{|l|}{ Procurement } \\
\hline Bipoints & 1 & 0.01 & 1 & 0.006 \\
\hline Harpoons & 9 & 0.1 & 2 & 0.01 \\
\hline Points & 10 & 0.1 & 9 & 0.07 \\
\hline Foreshafts & 1 & 0.01 & 3 & 0.02 \\
\hline Total Procurement & 21 & 0.2 & 15 & 0.1 \\
\hline \multicolumn{5}{|l|}{ Modification } \\
\hline Blades & 0 & 0 & 0 & 0 \\
\hline Awls & 21 & 0.2 & 7 & 0.05 \\
\hline Flakers & 1 & 0.01 & 3 & 0.02 \\
\hline Handles & 1 & 0.01 & 6 & 0.04 \\
\hline Chisels & 11 & 0.1 & 2 & 0.01 \\
\hline Wedges & 14 & 0.2 & 22 & 0.1 \\
\hline Total Modification & 48 & 0.5 & 40 & 0.3 \\
\hline \multicolumn{5}{|l|}{ Ornaments } \\
\hline Beads & 4 & 0.04 & 3 & 0.02 \\
\hline Pendants & 2 & 0.02 & 1 & 0.006 \\
\hline Pins & 1 & 0.01 & 1 & 0.006 \\
\hline Total Ornaments & 7 & 0.07 & 5 & 0.03 \\
\hline \multicolumn{5}{|l|}{ Other } \\
\hline Crescent & 1 & 0.01 & 0 & 0 \\
\hline Peg & 0 & 0 & 1 & 0.007 \\
\hline Detritus & 47 & 0.5 & 32 & 0.2 \\
\hline Worked Fragments & 82 & 0.9 & 69 & 0.5 \\
\hline Total Other & 130 & 1.4 & 102 & 0.7 \\
\hline All & 199 & 2.2 & 170 & 1.1 \\
\hline
\end{tabular}


Table 14. Counts and frequencies per $\mathrm{m}^{3}$ of Meier site artifact classes pre and postcontact.

\begin{tabular}{|c|c|c|c|c|}
\hline Meier & Precontact & & Postcontact & \\
\hline & $\mathrm{N}$ & $\mathrm{N} / \mathrm{m}^{3}$ & $\mathrm{~N}$ & $\mathrm{~N} / \mathrm{m}^{3}$ \\
\hline \multicolumn{5}{|l|}{ Procurement } \\
\hline Bipoints & 13 & 0.26 & 28 & 0.25 \\
\hline Harpoons & 3 & 0.06 & 21 & 0.2 \\
\hline Points & 16 & 0.32 & 52 & 0.48 \\
\hline Foreshafts & 0 & 0 & 0 & 0 \\
\hline Total Procurement & 32 & 0.64 & 101 & 0.92 \\
\hline \multicolumn{5}{|l|}{ Modification } \\
\hline Blades & 4 & 0.08 & 5 & 0.05 \\
\hline Awls & 35 & 0.7 & 106 & 0.96 \\
\hline Flakers & 3 & 0.06 & 0 & 0 \\
\hline Handles & 1 & 0.02 & 0 & 0 \\
\hline Chisels & 4 & 0.08 & 21 & 0.2 \\
\hline Wedges & 21 & 0.42 & 76 & 0.7 \\
\hline Punches & 20 & 0.4 & 39 & 0.35 \\
\hline Total Modification & 86 & 1.71 & 248 & 2.25 \\
\hline \multicolumn{5}{|l|}{ Ornaments } \\
\hline Beads & 2 & 0.04 & 9 & 0.08 \\
\hline Pendants & 10 & 0.2 & 27 & 0.24 \\
\hline Pins & 0 & 0 & 1 & 0.009 \\
\hline Tubes & 7 & 0.1 & 25 & 0.23 \\
\hline Total Ornaments & 18 & 0.36 & 62 & 0.56 \\
\hline \multicolumn{5}{|l|}{ Other } \\
\hline Crescent & 1 & 0.02 & 2 & 0.02 \\
\hline Peg & 0 & 0 & 4 & 0.04 \\
\hline Detritus & 1 & 0.02 & 3 & 0.03 \\
\hline Worked fragments & 131 & 2.6 & 504 & 4.58 \\
\hline Total Other & 133 & 2.63 & 513 & 4.66 \\
\hline All & 269 & 5.4 & 924 & 8.4 \\
\hline
\end{tabular}

The postcontact assemblages differ more than the precontact assemblages. At Cathlapotle, there is a slight decrease in artifact counts and frequency per $\mathrm{m}^{3}$ of bone and antler tools postcontact. At Cathlapotle, most postcontact artifact classes decline in 
counts and frequency per $\mathrm{m}^{3}$, except for foreshafts, flakers, and handles, which increase. Wedge count increases after contact but wedge frequency per $\mathrm{m}^{3}$ decreases. Harpoons and chisels decrease to only one or two specimens each. Awls are three times less frequent after contact. In contrast to Cathlapotle, all Meier artifact classes increase in counts and in frequency per $\mathrm{m}^{3}$ postcontact. Harpoons, points, awls, chisels, wedges, tubes, pendants, and worked fragment counts and frequency per $\mathrm{m}^{3}$ triple or quadruple after contact. There are no postcontact flakers or handles at Meier, while both are present at Cathlapotle. Although contact is reflected differently at both sites, chi square tests comparing precontact to postcontact assemblage composition at either site have the same results. There are significantly fewer modification artifacts and significantly more other artifacts than expected in postcontact assemblages at both sites $\left(C: x^{2}=8.9, p=0.02 ; M\right.$ : $\left.\mathrm{x}^{2}=16.3, \mathrm{p}<0.01\right)$. Implications of these results are discussed in Chapter 8 . 


\section{Chapter 8}

\section{$\underline{\text { Discussion and Conclusions }}$}

Hypothesis 1,sedentism promotes expediency, failed for both Cathlapotle and Meier osseous assemblages. Hypothesis 2, curated complete tools should be stored, expedient and broken curated tools should be discarded, failed at Cathlapotle and was supported at Meier. Hypothesis 3, contact should be reflected with in osseous assemblages at Cathlapotle and Meier, was supported at both sites, but in different ways. The following chapter characterizes the assemblages and discusses these results and their implications.

\section{$\underline{\text { Characterizing Assemblages }}$}

Bone and antler were worked more intensively at Meier than at Cathlapotle and there are considerably more osseous artifacts at Meier than at Cathlapotle. Cathlapotle has more houses, a larger population, and a higher excavated volume than Meier $\left(\mathrm{C}=240.22 \mathrm{~m}^{3}, \mathrm{M}=160.24 \mathrm{~m}^{3}\right)$. Despite this, most osseous tool classes are more frequent per $\mathrm{m}^{3}$ at Meier. The assemblages are similar in terms of composition and degree of curation with some exceptions. Meier contains blades, punches, and tubes, while Cathlapotle does not. There are considerably more procurement artifacts, wedges, awls, and pendants at Meier than Cathlapotle. Flakers, beads, pins, crescents, handles, and pegs are similar in frequency per $\mathrm{m}^{3}$ at both sites. Worked fragments are three times as frequent per $\mathrm{m}^{3}$ at Meier than at Cathlapotle, although this may reflect analytical differences. 
Although the two sites are very similar they do have several differences namely proportions of projectile point styles and deer and elk proportions (Davis 2010). Both sites contain similar types of historic trade goods, although there are more at Cathlapotle (Kaehler 2002).Lithic assemblages are similar as well (Ames 2011, Hamilton 1994).

Differences between these two sites were likely functional and may reflect task specialization. The abundance of osseous artifacts at the Meier site could indicate residents specialized in osseous tool manufacturing. Osseous tool specialists could produce durable, curated tools and trade them up and down the Columbia and its tributaries. Meier's abundance of osseous artifacts could reflect residents specialized in tasks that require osseous tools. The abundance of procurement tools, wedges, awls, and worked fragments at Meier relative to Cathlapotle may reflect Meier residents engaging in these activities more frequently or specializing in sea mammal hunting and fishing, woodworking, hide working, or basketry.

Woodworking and some high risk subsistence pursuits are associated with elite activities. An overall abundance of osseous artifacts, specifically those associated with woodworking and subsistence procurement, as well as the high numbers of tubes and pendants at Meier may indicate the Meier household was a higher status house than Cathalpotle households. This abundance of bone and antler working at Meier may reflect relative status differences between the two sites. 


\section{Hypothesis 1: Sedentism promotes expediency.}

This hypothesis failed at both sites. The bone and antler assemblages from both Cathlapotle and Meier are highly curated assemblages with the exception of two expedient tool classes, awls and flakers. At both sites osseous artifact classes related to subsistence, woodworking, and adornment consist of highly curated artifacts. A raw material stockpile of bone and antler was maintained at both sites, consisting of caches of raw material and an abundance of detritus and worked fragments providing blanks for formal tool manufacture or for use as expedient tools.

As expected, procurement tools from both sites are highly curated. The presence of curated, specialized tools may be a response to manage risk. Many of the resources procured using bone and antler artifacts are seasonal, mobile, and aquatic. These subsistence pursuits necessitating bone and antler tools, such as sea mammal hunting, are high risk activities with severe failure costs. Acquiring sufficient food stores to survive tough winters and to feed some of the largest populations in native North America added to the climate of risk and increased failure costs. Chinook yearly cycles included ample downtime for the time-consuming manufacture and maintenance of specialized, curated osseous tools. Maintaining a reliable, specialized, curated assemblage of procurement tools increased efficiency of subsistence pursuits and helped minimize risk (Bamforth and Bleed 1997, Torrence 1989). Additionally, competition between households and individuals may have encouraged engagement in high risk activities. 
Hamilton (1994) described Cathlapotle and Meier endscrapers as curated artifacts. An abundance of curated endscrapers postcontact at Cathlapotle may reflect an increased demand for hides during the contact era. Awls are the osseous counterpart to endscrapers, therefore awls were expected to be curated tools. Awls are expedient at both sites, although some curated awls are present. Awls might be multifunctional tools used for activities additional to hide working, such as basketry. Curation may not affect awl performance as it would for other artifact classes, and with a sufficient raw material stockpile, awl curation might not be necessary. It is worthy to note that Cathlapotle contains more endscrapers than Meier, while Meier contains more awls. After contact, endscrapers increase at Cathlapotle, while awls decrease in frequency. This is intriguing, and perhaps suggests a complementary relationship between awls and endscrapers. This is an interesting avenue for future research.

Modification tools were expected to be expedient. Most modification tools are highly curated including blades, handles, chisels, wedges, and punches, while flakers are more expedient than curated. Much like awls, flaker form likely did not affect flaker performance, making curation unnecessary. All woodworking tools are highly curated. Northwest Coast groups had extremely developed woodworking industries. Woodworking requires a strong, durable, shock absorbent tool, making it worthwhile to manufacture curated woodworking tools. Woodworkers likely maintained a curated woodworking toolkit comprised of wedges and chisels of differing sizes, bit shape (round, square, pointed), and raw materials. Cathlapotle and Meier ornaments are all highly curated as expected. 
The assemblages include an abundance of worked fragments and detritus from bone tool manufacture, specifically girdled and snapped metapodial fragments (bone blanks). Both sites have stockpiles and caches of unmodified bone and antler. Maintaining a raw material stockpile is likely the result of sedentism. People have the space and time to maintain a raw material stockpile, allowing for the option of expediency and perhaps encouraging expediency, but not ensuring expediency. Ultimately, it seems Cathlapotle and Meier osseous artifact assemblages support Parry and Kelly's (1987) suggestion that an expedient chipped lithic assemblage allows time to invest in a curated organic industry.

Hypothesis 2: Curated complete tools should be stored, broken curated tools and expedient tools should be discarded.

This hypothesis failed at Cathlapotle and was supported at Meier. Complete curated tools, were expected to be concentrated in storage facilities (cellars) within the house(s) while broken curated and expedient tool were expected to be concentrated outside of the house in middens and not randomly distributed. Artifact distribution at Cathlapotle and Meier differs greatly.

Cathlapotle procurement artifacts, modification artifacts, awls, and other artifacts are concentrated outside the houses, while broken modification artifacts, ornaments, and detritus are randomly distributed. When the entire assemblage is considered, there are significantly more complete, broken, and all artifacts regardless of completion recovered outside the houses, most in the $\mathrm{SM}(\mathrm{H} 2)$ facility. Contrary to my hypothesis, complete 
curated artifacts are not concentrated in storage facilities and broken curated and expedient artifacts are not concentrated in middens. Sheet Midden at Cathlapotle was the predominant activity area (predominately primary deposition), as well as an area of refuse disposal consequence of house cleaning (some secondary deposition). Although Sheet Midden was an area of both primary and secondary deposition at Cathlapotle, it was the focus of many activities at Cathlapotle. Therefore, the concentration of artifacts outside of the houses in the Sheet Midden at Cathlapotle likely reflects the primary deposition of procurement and modification tools, awls, and other artifacts being used and perhaps stored (recall the chisel cache in $\mathrm{SM}(\mathrm{H} 1)$ ) or disposed of (expedient awls) outside of the houses in the sheet midden. The random distribution of detritus suggests early stage osseous tool manufacture (blank making) occurred throughout the site. The random distribution of broken modification artifacts is intriguing and seemingly unexplainable. It is also possible these trends are coincidental and the concentration of artifacts outside the houses reflects secondary deposition resulting from house cleaning episodes.

In contrast, at Meier, procurement artifacts, modification artifacts, and awls are randomly distributed while broken modification artifacts and other artifacts are concentrated outside the house. When the entire assemblage is considered, there are significantly less complete artifacts recovered outside the house and in the exterior facility and significantly more in the cellar facility. These results support my hypotheses that complete curated artifacts will be stored in cellar and storage facilities, while broken artifacts will be discarded in middens. Random distribution of procurement artifacts, 
awls, and modification artifacts along the long axis of the Meier house supports Smith's (2008) conclusion that peoples of all statuses engaged in all the same activities throughout the household.

Some patterns at Meier are nearly opposite of those at Cathlapotle. At Cathlapotle, procurement and modification tools and awls are concentrated outside, while at Meier procurement and modification tools and awls are randomly distributed. At Meier, broken modification tools and other artifacts were concentrated outside the houses. Sheet Midden deposits at Cathlapotle were well sampled $\left(66.27 \mathrm{~m}^{3}\right)$ and are not comparable to partially sampled Exterior (Yard) deposits at Meier $\left(22.76 \mathrm{~m}^{3}\right)($ Ames 2011). It is assumed Sheet Midden and Exterior deposits functioned similarly at both sites, but this spatial analysis suggests the Sheet Midden at Cathlapotle may have functioned as an activity area (primary deposition), while the Exterior at Meier may have functioned as refuse disposal (secondary deposition).

Additionally, Meier ornaments are concentrated in the northern segment of the house and in the Cellar and Cellar/Bench facilities. The northern segment of the Meier house is the rear and is interpreted as the elite area of the household. This concentration of ornaments artifacts at Meier within storage facilities in the elite area contrasts the random distribution of ornaments artifacts at Cathlapotle. This concentration and the abundance of pendants and tubes at Meier supports the notion that the Meier house was a higher status household than the Cathlapotle households. This could also reflect access to raw materials. Perhaps people of all statuses at Cathlapotle had access to bone and antler 
and were able to decorate their bodies and clothing with bone and antler ornaments, while at Meier such access was controlled by elites.

These spatial patterns could reflect differences in house maintenance and cleaning episodes. Cathlapotle had earthen floors. Frequent floor cleaning and debris removal simply out the front door (secondary deposition) could have created a concentration of artifacts outside the houses in the Sheet Midden at Cathlapotle. Meier house floors were planked and would be less likely to reflect cleaning episodes as Cathlapotle would. Instead Meier artifacts could slip through floorboards and be lost within the subterranean cellar complexes. Spatial distribution of artifacts could reflect site abandonment. The retention of curated complete artifacts in Meier cellars and ornaments in the elite house segment could indicate un-planned site abandonment, whereas the absence of a concentration of curated artifacts within Cathlapotle houses could indicate planned site abandonment, where curated valuable tools were intentionally removed from the site.

Both Cathlapotle and Meier produced highly curated osseous assemblages. This analysis showed curated and expedient artifacts were stored and disposed of in a similar manner. Awls were randomly distributed at Meier and concentrated in the Sheet Midden at Cathlapotle. Expedient awls may have been discarded in their use location in the Cathlapotle Sheet Midden as well as all over the site at Meier. While this may be true, awls were not a special case, several other curated artifact classes were found in Cathlapotle Sheet Midden and randomly distributed at Meier. This spatial analysis brought up a multitude of questions about site formation processes, site use, and osseous artifact use. 


\section{Hypothesis 3: Contact should be reflected within osseous assemblages at}

\section{Cathlapotle and Meier}

Hypothesis 3 was supported at both sites, but in different ways. Osseous artifact frequency and density and assemblage diversity decline after contact at Cathlapotle. At Meier, osseous artifact frequency and density and assemblage diversity increase after contact. The precontact assemblages at both sites are alike, while the postcontact assemblages are similar in terms of composition and curation, but differ in terms of assemblage organization and structure. The Meier site osseous assemblage reflects contact more than Cathlapotle, and is consistent with Snow's work (Snow 1995, 1996). At Meier, all tool class counts and frequencies per $\mathrm{m}^{3}$ increase. Harpoons, points, awls, chisels, wedges, tubes, pendants, and worked fragment counts and frequencies per $\mathrm{m}^{3}$ triple or quadruple. The introduction of metal likely enabled people to work osseous materials faster and with ease, decreasing manufacture time, cost, and overall energy investment. The gain in efficiency promoted the proliferation of bone working and an abundance of osseous tools.

In contrast at Cathlapotle osseous artifacts decrease postcontact. Artifact classes such as harpoons, awls, and chisels, decrease to few specimens postcontact. This decline may reflect replacement of osseous tools by metal ones. Metal awls, chisels, or sharp metal cutting tools could have replaced bone and antler awls and chisels after contact at Cathlapotle. The decline of harpoons postcontact is less explicable, and likely reflects 
changes in fishing and sea mammal hunting patterns with the introduction of metal fishhooks, projectile points, and firearms.

Changes in artifact frequency and density and assemblage diversity could reflect effects of European-introduced metal objects. This would be consistent with Snow's $(1995,1996)$ description of Mohawk Valley assemblages. Postcontact changes in Cathlapotle and Meier assemblages could reflect changes in native lifeways and the frequency certain activities requiring osseous tools are participated in. Some factors (among others) which could have caused such changes in Cathlapotle and Meier osseous assemblages include: population loss and shifts, social, political, or economic realignments, changing labor demands and production patterns, shifts in trade networks, accessibility to resource patches, finite access to metal goods and/or elite control of metal access (Bamforth 1993, Bamforth 2003, Silliman 2003). It is apparent that European contact is reflected in both assemblages in different ways.

\section{$\underline{\text { Conclusions }}$}

Bone and antler artifacts are understudied and underappreciated. Osseous assemblages at Cathlapotle and Meier are highly curated and technologically unique for sedentary hunter-gatherers. I offer three conclusions with regards to Hypothesis 1, sedentism promotes expediency. First, in some circumstances it may only be worthwhile to manufacture curated bone and antler artifacts, regardless of settlement pattern. Osseous materials have high manufacture costs with the benefit of a naturally durable, long lasting tool. Second, many activities requiring osseous tools necessitate curation, 
for example, high risk subsistence pursuits, and woodworking. Third, an expedient and opportunistic lithic technology may have allowed more time to invest in a curated organic industry (Parry and Kelly 1987). The Lower Columbia and Northwest Coast had advanced woodworking and fiber industries. Northwest Coast osseous assemblages with high numbers of opportunistic and expedient bone and antler tools often lack chipped lithics (Ames 2005, 2011). An expedient and opportunistic lithic assemblage probably was the result of such a developed organic industry. The technological system at Cathlapotle and Meier was likely a highly curated organic system with an emphasis on wood, fiber, bone, and antler that was easily supplemented by an expedient and opportunistic lithic assemblage (using flakes to manufacture and maintain osseous tools). Such highly curated osseous assemblages deviate from technological organization predictions that sedentism promotes expediency. This hypothesis was based on lithic technology and holds true for lithic assemblages at both Cathlapotle and Meier but was not supported by the highly curated osseous assemblages. To understand technological systems archaeologists should consider tools of various raw material types, both lithic and organic, and how they relate to one another within the technological system.

The results of Hypothesis 2, curated complete tools should be stored, while broken curated and expedient tools should be discarded. The spatial analysis showed curated and expedient tools have similar disposal methods. At Cathlapotle, most artifacts, regardless of degree of curation or completeness are concentrated outside the houses, while at Meier broken artifacts are concentrated outside, while more complete artifacts are concentrated in the cellar facilities. Evaluating storage and disposal of 
complete and broken curated tools brought up many issues for future research regarding site formation processes, site use, facility function and osseous artifact use.

Precontact Northwest Coast bone and antler technologies change little in 2500 years (Ames 2005, 2010). Yet here, bone and antler reflect European contact and track major social change. It is thought that Cathlapotle was more involved with the fur trade than Meier due to the presence and abundance of beads and other trade goods, although ceramic evidence suggests both sites were equally involved (Cromwell 2011, Kaehler 2002). Additionally, Cathlapotle was mentioned several times in ethnographic accounts and is visible from the Columbia River, while Meier was never mentioned and is less visible and located on the Multnomah Channel. Contact is reflected more in the Meier osseous assemblage, which proliferates. These results challenge assumptions regarding contact on the Lower Columbia and encourage a reconsideration of Meier's role in the fur trade.

This research has several implications with regards to the Wapato Valley Archaeological Project and what we know about the similarities and differences between the Cathlapotle and Meier sites. Bone and antler were worked more intensively at Meier. More volume was excavated at Cathlapotle, and Cathlapotle contains six houses, while Meier contains one. This abundance of osseous artifacts at the Meier site could be explained in three ways (or likely a combination of both). First, Meier may have been the residence of osseous specialists, functioning as an osseous tool manufacture center for the Lower Columbia. Second, Meier residents were more intensively engaged in woodworking, hunting and fishing, and hide working than Cathlapotle residents. Third, 
the Meier household may have been a higher status household than Cathlapotle households. Changes following European contact should be evaluated at other contact period sites with osseous assemblages on the West Coast of North America. A comprehensive study of contact at the two sites would be beneficial.

In conclusion, this thesis has shown the value of studying osseous materials. Bone and antler are unique materials: they are naturally durable and extremely available. Studying the osseous assemblages at Cathlapotle and Meier challenges the hypothesis that sedentism promotes expediency, and provides a more accurate description of technological systems along the Lower Columbia. This research encourages a reconsideration of Meier's role in the fur trade and contact on the Northwest Coast. 


\section{$\underline{\text { References }}$}

Ames, Kenneth M.

1976 The Bone Tool Assemblage From the Garden Island Site, Prince Rupert Harbor, British Columbia: An Analysis of Assemblage Variation Through Time. PhD Dissertation, Washington State University, Pullman.

1994 The Northwest coast: Complex Hunter-Gatherers, Ecology, and Social Evolution. Annual Review of Anthropology 23 Pp. 209-220.

2001 Slaves, Chiefs, and Labour on the Northern Northwest Coast World Archaeology 33(1): $1-17$

2002 Going by Boat: The Forager-Collector Continuum at Sea. In. Beyond Foraging and Collecting: Evolutionary Change in Hunter-Gatherer Settlement Systems. Edited by Ben Fitzhugh and Junko Habu, Pp. 17-50. New York, Kluwer/Plenum Press.

2005 The North Coast Prehistory Project Excavations in Prince Rupert Harbour, British Columbia: The Artifacts BAR International Series 1342, Archaeopress, Oxford

2011 Personal Communication

Ames, Kenneth M., James. P. Green, and Margaret Pfoertner

1981 Hatwai (10NP143): Interim Report. Archaeological Reports No. 9, Boise State University, Boise. 
Ames, Kenneth M. and Herb Maschner

1999 Peoples of the Northwest Coast: Their Archaeology and Prehistory. London, Thames and Hudson Ltd.

Ames, Kenneth M., Doria F. Raetz, Stephen Hamilton, and Christine McAfee

1992 Household Archaeology of a Southern Northwest Coast Plank House Journal of Field Archaeology 19(3):275-290

Ames, Kenneth M., Cameron McPherson Smith, Alexander Bourdeau

2008 Large Domestic pits on the Northwest Coast of North America Journal of Field Archaeology 33(1) 3-18

Ames, Kenneth M., Cameron McPherson Smith, William L. Cornett, Elizabeth A. Sobel, Stephen C. Hamilton, John Wolf, and Doria Raetz

1999 Archaeological Investigations at 45CL1, Cathlapotle (1991 - 1996), Ridgefield Wildlife Refuge, Clark County, Washington: A Preliminary Report. US Department of Interior, Fish and Wildlife Service, Region 1. Cultural Resource Series Number 1.

Ames, Kenneth M. and Elizabeth A. Sobel

2009 Finding and Dating Cathlapotle Archaeology in Washington 15 
Andrefsky, William

1994 Raw-Material Availability and the Organization of Technology Raw-Material Availability and the Organization of Technology. American Antiquity 59(1): 2134

Banach, Patricia Kathryn

2002 Copper on the Pacific Northwest coast Unpublished MA thesis Portland State University, Portland

Banning, E.B.

2000 The Archaeologist's Laboratory: The Analysis of Archaeological Data, Plenum Press, New York

Bamforth, Douglas B.

1986 Technological Efficiency and Tool Curation. Amerian Antiquity 51(1) 38-50

1993 Stone Tools, Steel Tools: Contact Period Household Technology at Helo' in Ethnohistory and Archaeology, Approaches to Postcontact Change in the Americas Edited by J. Daniel Rogers and Samuel M. Wilson. Pp. 49-69, Plenum Press, New York

2003 Discussion. In Stone Tool Traditions in the Contact Era Edited by Charles R. Cobb Pp. 165-172, The University of Alabama Press, Tuscaloosa 
Bamforth, Douglas B. and Peter Bleed

1997 Technology, Flaked Stone Technology, and Risk in Rediscovering Darwin:

Evolutionary Theory and Archaeological Explanation Edited by C.M. Barton and G.A. Clark, pp. 109-139. Arlington, VA.

Bayman, James M.

2003 Stone Adze Economies in Post-Contact Hawai'i. In Stone Tool Traditions in the Contact Era Edited by Charles R. Cobb Pp. 94-108, The University of Alabama Press, Tuscaloosa

Binford, Lewis

1963 A Proposed Attribute List for the Description \& Classification of Projectile Points. In Miscellaneous Studies in Typology and Classification. Edited by A.M. White, L.R. Binford, and M.L. Papworth Pp. 193-221 University of Michigan, Museum of Anthropology, Anthropological Papers 19, Ann Arbor.

1977 Forty-seven Trips: A Case Study in the Character of Archaeological Formations Processes in Stone Tools as Cultural Markers: Change, Evolution and Complexity Edited by RVS Wright, pp. 24-36. Canberra: Australian Institute of Aboriginal Studies.

1979 Organization and Formation Processes: Looking at Curated Technologies. Journal of Anthropological Research 34(5) 255-273 
1980 Willow Smoke and Dogs' Tails: Hunter-Gatherer Settlement Systems and Archaeological Site Formation. American Antiquity 45(1) 4-20

Bleed, Peter

1986 The Optimal Design of Hunting Weapons: Maintainability or Reliability American Antiquity 51(4) 737-747

Bonnichsen, Robson

1982 Bone Technology as a Taphonomic Factor: An Introductory Statement Canadian Journal of Anthropology 2(2) 137-144

Boyd, Robert T. and Yvonne P. Hajda

1987 Seasonal Population Movement along the Lower Columbia River: The Social and Ecological Context American Ethnologist 14(2) pp. 309-326

Brantingham, P. Jeffrey

2003 A Neutral Model of Stone Raw Material Procurement American Antiquity 68(3) pp. $487-509$

Brain, C.K.

1967 Hottentot Food Remains and Their Bearing on the Interpretation of Fossil Bone Assemblages, Pretoria

1981 The Hunters or the Hunted? An Introduction to African Cave Taphonomy The University of Chicago Press, Chicago and London. 
Campana, Douglas V.

1989 Natufian and Protoneolithic Bone Tools: the Manufacture and Use of Bone Implements in the Zagros and the Levant British Archaeological Reports, Oxford

Campbell, Sarah K.

1981 The Duwamish No. 1 site: a lower Puget Sound shell midden. University of Washington, Seattle

Carlson, Roy L.

1960 Chronology and Culture Change in the San Juan Islands, Washington American Antiquity 25(4) 562-586

1982 Prehistory of the Northwest Coast pages 13-32 in Indian Art Traditions of the Northwest Coast edited by Roy Carlson pp. 13-32 Simon Fraser University, Burnaby BC.

Chatters, James C.

1987 Hunter-Gatherer Adaptations and Assemblage Structure Journal of Anthropological Archaeology (6) 336-375

Clark, Cherie

1980 Bone Tool Manufacture and Use by Prepottery Occupants of the McCutchanMcLaughlin Site Bulletin of the Oklahoma Anthropological Society, Vol. XXIX 
Cobb, Charles C.

2003 Introduction: Framing Stone Tool Traditions after Contact. In Stone Tool Traditions in the Contact Era Edited by Charles R. Cobb Pp. 1-13, The University of Alabama Press, Tuscaloosa

Cotterell, Brian and Johan Kamminga

1987 The Formation of Flakes American Antiquity 52(4) 675-708

Cromwell, Robert J.

2010 A Typological Analysis of the Historic Ceramic Ware Sherds Recovered from the Cathlapotle (45CL1) Site and The Meier (35CO5) Site. Report on File, Portland State University

Daehnke, Jon

2005 Cathlapotle: Catching Time's Secrets US Fish and Wildlife Service, Sherwood OR

Davis, Deborah

1998 Bone Tool Technology: Measurements of Curation and the Spatial Distribution of Bone and Antler Artifacts from a Pacific Northwest Coast Plankhouse Site. Unpublished M.A. Thesis, Portland State University, Portland. 
Davis, Sara J.

2010 Projectile Point Variation at the Meier (35CO5) and Cathlapotle (45CL1) Archaeological Sites. Unpublished M.A. thesis, Department of Anthropology, Portland State University, Portland.

Drucker, Phillip

1943 Archaeological Survey on the Northern Northwest Coast. Bureau of American Ethnology, 133(20), Smithsonian Institution, Washington D.C.

Dunnell, Robert C.

1981 Seriation, Groups, and Measurement. In Manejo de Datos y Metodos Matematicos de Arqueologia, Edited by George L. Cowgill, Robert Whallon, and Barbara S. Ottaway. Union Internacional de Ciendias Prehistoricas y Protohistoricas, Mexico.

Ellis, Christopher J.

1997 Factors Influencing the Use of Stone Projectile Tips in Projectile Technology edited by H. Knecht, pp. 37-74 Plenum, New York

Elston, Robert G. and P. Jeffrey Brantingham

2002 Microlithic Technology in Northern Asia: A Risk-Minimizing Strategy of the Late Paleolithic and Early Holocene. Archaeological Papers of the American Anthropological Association 12(1):103-116 
Fletcher, Mike and D.R. Lock

2005 Digging Numbers: Elementary Statistics for Archaeologists Oxford University, Oxford

Frizon, George C.and George M. Zeimens

1980 Bone Projectile Points: An Addition to the Folsom Cultural Complex, American Antiquity, 45(2) 231-237

Fisher, Daniel C.

1984 Taphonomic Analysis of Late Pleistocene Mastodon Occurrences: Evidence of Butchery by North American Paleo-Indians. Paleobiology 10(3) 338-357

George, Peter J, and Richard J. Preston

1987 "Going in Between": The Impact of European Technology on the Work Patterns of the West Main Cree of Northern Ontario The Journal of Economic History $47(2) 447-460$

Gibson, James R.

1999 Otter Skins, Boston Ships, and China Goods: The Maritime Fur Trade of the Northwest Coast, 1785-1841 University of Washington Press, Seattle, Washington. 
Hamilton, Stephen C.

1994 Technological Organization and Sedentism: Expedient Core Reduction, Stockpiling, and Tool Curation at the Meier Site (35CO5). MA Thesis, Department of Anthropology, Portland State University, Portland.

Henry, D.O.

1989 Correlations Between Reduction Strategies and Settlement Patterns. In Alternative Approaches to Lithic Analysis edited by D.O. Henry and George Odell Pp. 139-212 Westview Press, Boulder.

Johnson, Eileen

1982 Paleo-Indian Bone Expediency Tools: Lubbock Lake and Bonfire shelter Canadian Journal of Anthropology/Revue Canadienne d'anthropologie 2(2)

1989 Human Modified Bones from Early Southern Plains Sites in Bone Modification edited by Robson Bonnichsen and Marcella H. Sorg Pp. 431-471 University of Maine, Orono, ME

Johnson, Eileen and Gustavo Politis, and Maria Gutierrez

2000 Early Holocene Bone Technology at the La Olla 1 Site, Atlantic Coast of the Argentine Pampas Journal of Archaeological Science (27) 463-477 
Kaehler, Gretchen Anne

2002 Patterns in glass : the interpretation of European glass trade beads from two protohistoric sites in the greater Lower Columbia region MA thesis Portland State University, Portland.

Kelly, Robert L.

1988 The Three Sides of a Biface American Antiquity 53(4) 717-734

1992 Mobility/Sedentism: Concepts, Archaeological Measures, and Effects Annual Review of Anthropology 21: 43-66

Kelly, Robert L. and Lawrence C. Todd

1988 Coming into the Country: Early Paleoindian Hunting and Mobility American Antiquity 53(2) 231-244

Knecht, Heidi

1993 Early Upper Paleolithic Approaches to Bone and Antler Projectile Technology. In Hunting and Animal Exploitation in the Later Paleolithic and Mesolithic of Eurasia edited by G.L. Peterkin, H. M. Bricker, and P. Mellars pp. 33-47.

1997 Projectile Points of Bone, Antler, and Stone: Experimental Explorations of Manufacture and Use. In Projectile Technology edited by H. Knecht pp 191212, Plenum, New York NY. 
LeMoine, Genevieve M.

1994 Usewear on Bone and Antler Tools from MacKenzie Delta, Northwest Territories. American Antiquity 59(2) 316-334

Loy, Thomas and G. R. Powell

1977 Archaeological Data Recording Guide. Heritage Record No. 3, British Columbia Provincial Museum, Victoria

Lyman, R. Lee

2003 Mammalian Zooarchaeology of Cathlapotle (45CL1): Descriptive Paleontology and Taphonomic Analyses. Report to Department of Anthropology, Portland State University, Portland

1984 Broken Bones, Bone Expediency Tools, and Bone Pseudotools: Lessons from the Blast Zone Around Mount St. Helens, Washington. American Antiquity 49(2):315-333

Lyman R. Lee and Michael J. O’Brien

1999 Prehistoric Osseous Rods from North America: Arguments of Function North American Archaeologist. 20(4) 347-364 
Lyman, R. Lee, Michael J. O'Brien, and Vance Hayes

1998 A Mechanical and Functional Study of Bone Rods from the Richey-Roberts Clovis Cache, Washington, U.S.A. Journal of Archaeological Science 25:887906

Merk, Frederick

1931 Fur Trade and Empire, George Simpson's Journal 1824-1825 Cambridge: Harvard University Press

Myers, Thomas P. and Michael R. Voorhies, and R. George Corner

1980 Spiral Fractures and Bone Psuedotools at Paleontological Sites Reports, American Antiquity, 45(3) 483-490

Moulton, Gary E.

1990 The Definitive Journals of Lewis and Clark: Down the Columbia to Fort Clatsop. University of Nebraska Press, Lincoln.

Nelson, Margaret

1991 The Study of Technological Organization. In Archaeological Method and Theory, edited by Michael B. Schiffer, Pp. 57-100. University of Arizona Press, Tucson. 
Newcomer, Mark H.

1974 Study and Replication of bone tools from Ksar Akil (Lebanon), World Archaeology 6(2) Pp. 138-153

Ogle, Todd B.

2004 Morphological and Functional Analysis of a Late Prehistoric Artifact Assemblage from the Walan Point Site, Jefferson County, Washington, Unpublished M.A. thesis, Washington State University, Pullman

Parry, William J. and Robert L. Kelley

1987 Expedient Core Technology and sedentism, in The Organization of Core Technology edited by Jay K. Johnson and Carol A. Morrow Westview Press, Boulder, Co Pp. 285-304

Pena, Elizabeth S.

2001 The Role of Wampum at the Albany Almshouse. International Journal of Historical Archaeology, 5(2) 155-174

Petillion, Jean-Marc

2008 First Evidence of a whale-bone industry in the western European upper Paleolithic: Magdalenian artifacts from Isturitz (Pyrenees-Atlantiques, France) Journal of Human Evolution (54) 720-726 
Pettigrew, Richard M.

1981 A Prehistoric Cultural Sequence in the Portland Basin of the Lower Columbia Valley. Unpublished PhD Dissertation. University of Oregon, Eugene

Plummer, Catherine

1991 The Shogun's Reluctant Ambassadors: Japanese Sea Drifters in the North Pacific. Portland: Oregon Historical Society.

Raetz, Doria

1989 Bone Tool Assemblages as an Aid to Shell Mound Site Typologies on the Northwest Coast Unpublished M.A. thesis, Portland State University, Portland Semenov, S.A.

1967 Prehistoric Technology: An Experimental Study of the Oldest Tools \& Artifacts from Traces of Manufacture and Wear. Redwood Press Limited, London.

Schiffer, Michael

1975 Archaeology as behavioral science. American Anthropologist 77:836-848

Schwartz, Jeffrey H.

1995 Skeleton Keys: An Introduction to Human Skeletal Morphology, Development, and Analysis, Oxford University Press, New York 
Silliman, Stephen

2003 Using a Rock in a Hard Place: Native-American Lithic Practices in Colonial California. In Stone Tool Traditions in the Contact Era Edited by Charles R. Cobb Pp. 127-150, The University of Alabama Press, Tuscaloosa

Silverstein, M.

1990 Chinookans of the Lower Columbia. In Handbook of North American Indians, Vol. 7 Northwest coast, edited by W. Suttles, Pp. 533-546. Smithsonian Institution, Washington D.C.

Shipman, Pat

2001 What Can You Do with a Bone Fragment? Proceedings of the National Academy of Sciences of the United States of America 98(4) 1335-1337

Shipman, Pat, Daniel C. Fisher, Jennie J. Rose

1984 Mastodon Butchery: Microscopic Evidence of Carcass processing and bone tool use Paleobiology 10(3) Pp. 358-365

Sobel, Elizabeth A.

2004 Social Complexity and Corporate Households on the Southern Northwest Coast of North America, A.D. 1450-1855, PhD dissertation, University of Michigan 
Snow, Dean

1995 Mohawk Valley Archaeology: The Sites Occasional Papers in Anthropology (23) Matson Museum of Anthropology, Pennsylvania State University, University Park.

1996 The Iroquois Blackwell, Oxford

Smith, Cameron McPherson

2006 Formation Processes of a Lower Columbia River Plankhouse Site in Household Archaeology on the Northwest Coast edited by Elizabeth Sobel, Ann Trieu, and Ken Ames Archaeological Series 16, International Monographs in Archaeology, Ann Arbor.

2008 The Organization of Production among Sedentary Foragers of the Southern Pacific Northwest Coast BAR International Series 1741, Archaeopress, Oxford

Stanford, Dennis, Robson Bonnichsen, Richard E. Morlan

1981 The Ginsberg experiment: Modern and prehistoric evidence of a bone-flaking technology. Science, 212(4493) Pp 438-440

Stewart, Hilary

1981 Artifacts of the Northwest Coast Indians Big Country Books

Thompson, Laurence C and M. Dale Kinkade 
1990 Languages In Handbook of North American Indians, vol. 7: Northwest edited by Wayne Suttles

Torrence, Robin

1983 Time Budgeting and Hunter-gatherer Technology. In Pleistocene Hunters and Gatherers in Europe. Edited by G. Bailey, pp. 11-22, Cambridge University Press, New York.

1989 Retooling; Toward a Behavioral Theory of Stone Tools. In Time, Energy, and Stone Tools edited by Robin Torrence. Pp 57-66. Cambridge: Cambridge University Press

Weissner, Polly

1982 Beyond Willow Smoke and Dog's Tails: a Comment on Binford's Analysis of Hunter-Gatherer Settlement Systems. American Antiquity 47: 171-178

White, Randall

1977 The Manipulation of Burins in Incision and Notation in Bone Technology Experimentation, Assemblage, and Non-Human Modification A Symposium Organized for the Annual Meeting of the Society of American Archaeology, New Orleans.

White, T.D.

2000 Human Osteology Academic Press, San Diego 
Appendix A:

Artifact Classification 


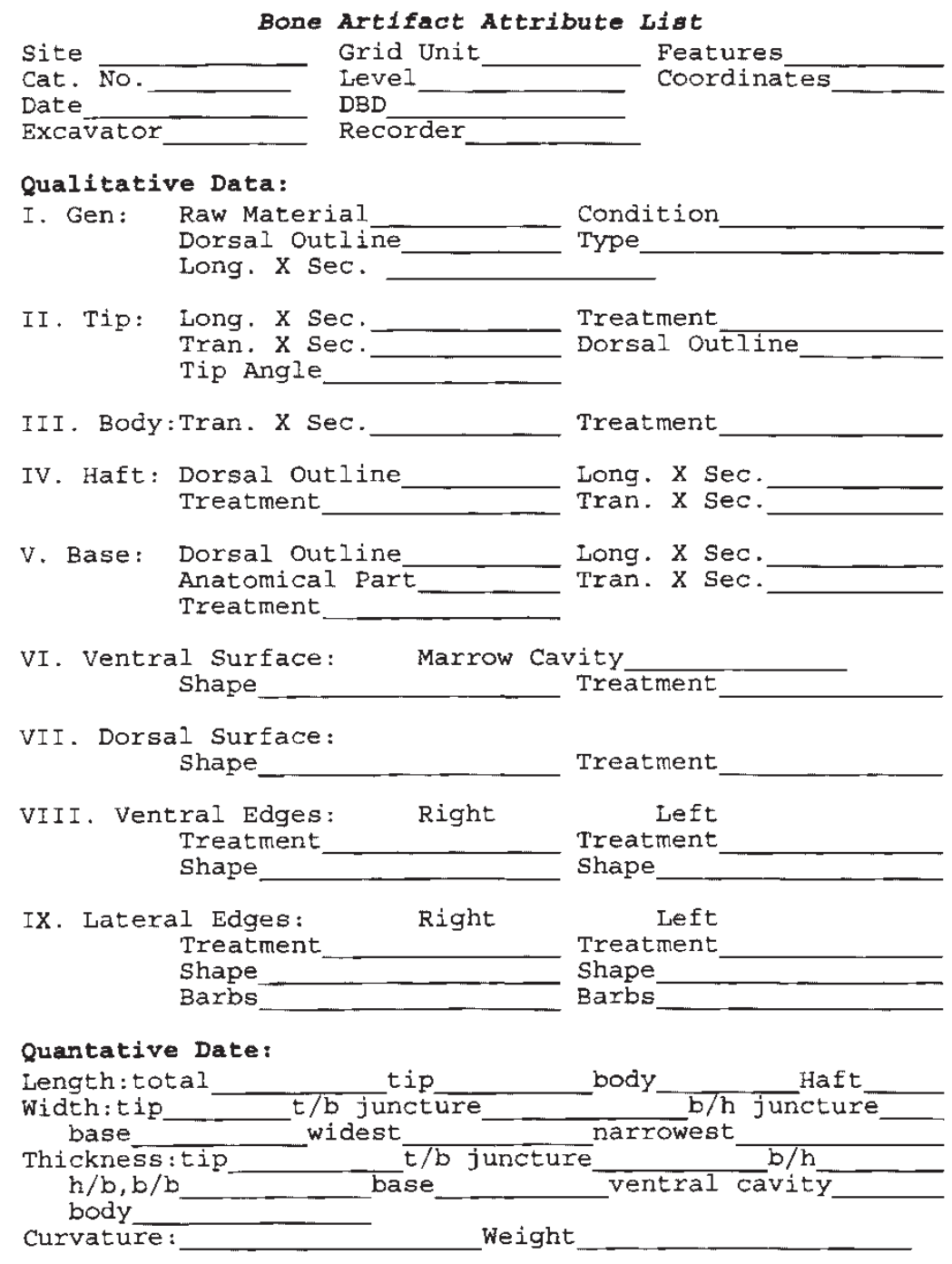

Figure 1. Bone Artifact Attribute List (Davis 1998). 
$\underline{\text { Morphofunctional Classification: Material Culture Type List }}$

\section{Adornment}

A. Beads

1 Bird Bone

2 Canine

3 Decorated

4 Terrestrial Mammal

B. Pendants

1 Bird Bone

2 Beaver Incisor

3 Canine

4 Decorated

5 Fragment

6 Tooth

7 Unknown

C. Pins

1 Decorated

2 Plain

D. Tubes

1 Bird Bone

2 Terrestrial Mammal

3 Decorated

\section{Bipoints}

A. Decorated

3. Bone Blades

4. Crescents

\section{Detritus}

6. Flakers

\section{Handles}

8. Beveled Tools

A. Point Tip (chisels)

1 Haft

2 Fixed

3 Ulna

4 Metapodial

5 Anatomical

6 Worked

7 Splinter

8 Fragment (tip)

B. Incisors

C. Round Tip (wedges)

1 Bird Bone

$2 \mathrm{Haft}$

3 Fixed

4 Ulna

5 Metapodial

6 Worked

7 Fragment 
D. Square Tip (wedges)

1 Bird Bone

2 Haft

3 Fixed

4 Ulna

5 Metapodial

6 Worked

7 Fragment

\section{Worked Fragments}

A Anatomical Part

B Antler

C Barb

D Base

E Bird Bone

F Bone

G Body

H Decorated

I Drilled

J Haft

K Metapodial

L Tip

M Unknown
10. Piercing Tools

A. Awls

1 Worked

2 Splinter

3 Bird Bone

4 Metapodial

5 Ulna

6 Anatomical

7 Decorated

8 Tine

9 Fragment

B. Harpoons

1 Self-Armed

2 Valves

C. Needles

D. Points

$1 \mathrm{Haft}$

2 Fixed (no haft)

3 Socket (hafting bed)

4 Barb

5 Decorated 


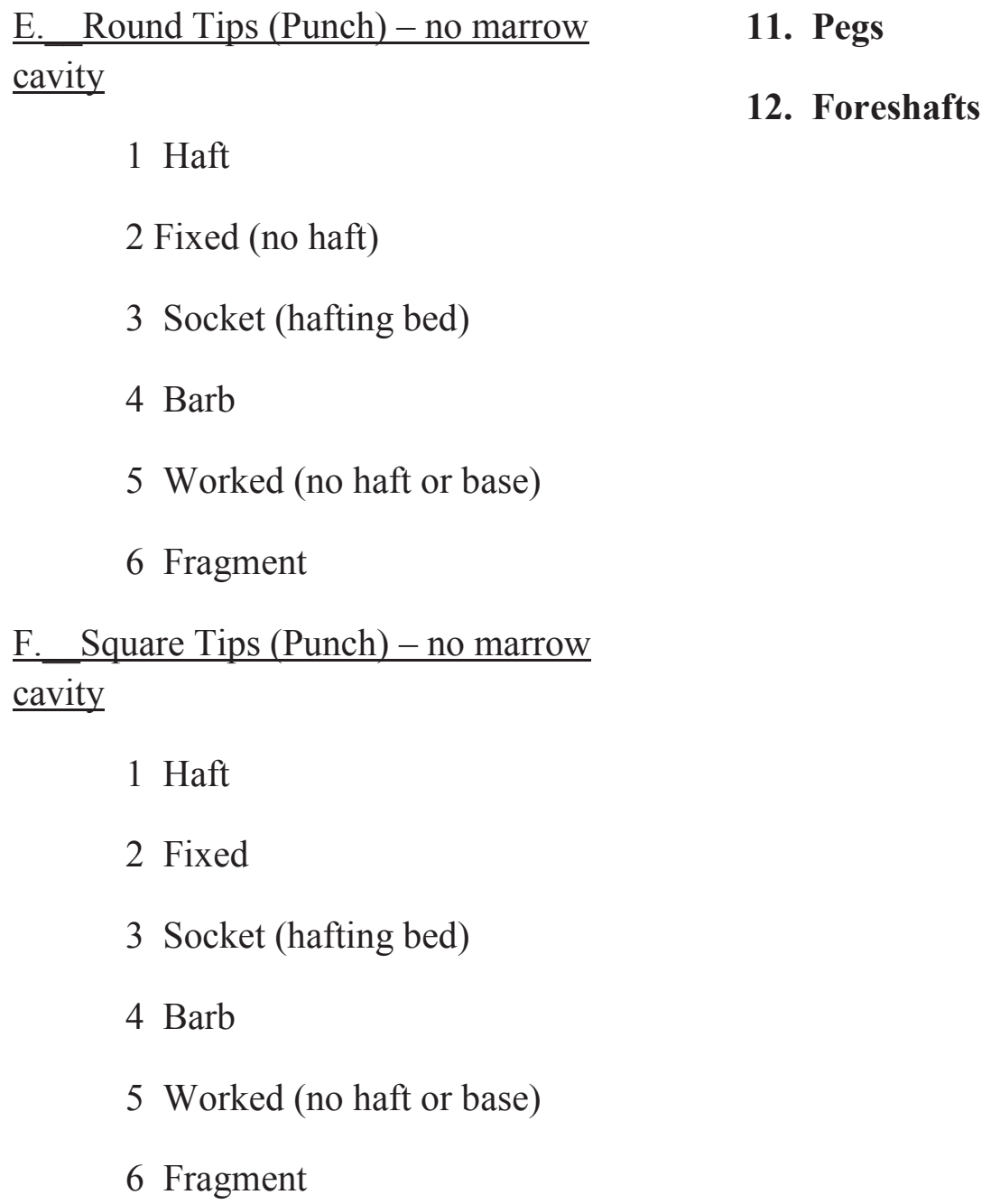

\section{Pegs}

\section{Foreshafts}


Classification:

1. Adornment. Adornment is separated into traditional types: beads, pendants, pins, and tubes. Types are further divided by raw material, decoration, and fragmentation.

A. Beads. Beads are perforated objects, suitable for threading with others (Loy and Powell 1977). Davis (1998) distinguishes beads from tubes in that a bead's length is no more than twice the circumference and both ends exhibit polish. Raetz (1989) suggests items shorter than 3-4 cm are beads, and longer than $3-4 \mathrm{~cm}$ are tubes.

1. Bird Bone $(n=5)$ Beads made from hollow bird bone with both ends polished or ground. Most were biplano/parallel in dorsal view and longitudinal cross section and subelliptical/circular in transverse cross section. All had finished ends with signs of abrasion and/or polish. Some specimens were completely covered in abrasion marks.

Table 1. 1A1 Mean and standard deviation measurements in millimeters and grams.

\begin{tabular}{|c|c|c|c|c|c|c|c|}
\hline & $\mathrm{N}$ & TL LENGTH & MN WIDTH & MAX WIDTH & MIN THICKNESS & MAX THICKNESS & WEIGHT \\
\hline MEAN & 5 & 37.69 & 7.09 & 7.79 & 6.9 & 7.46 & 1.46 \\
\hline ST. DEV. & & 6.74 & 2.48 & 2.59 & 2.9 & 2.66 & 1.2 \\
\hline
\end{tabular}

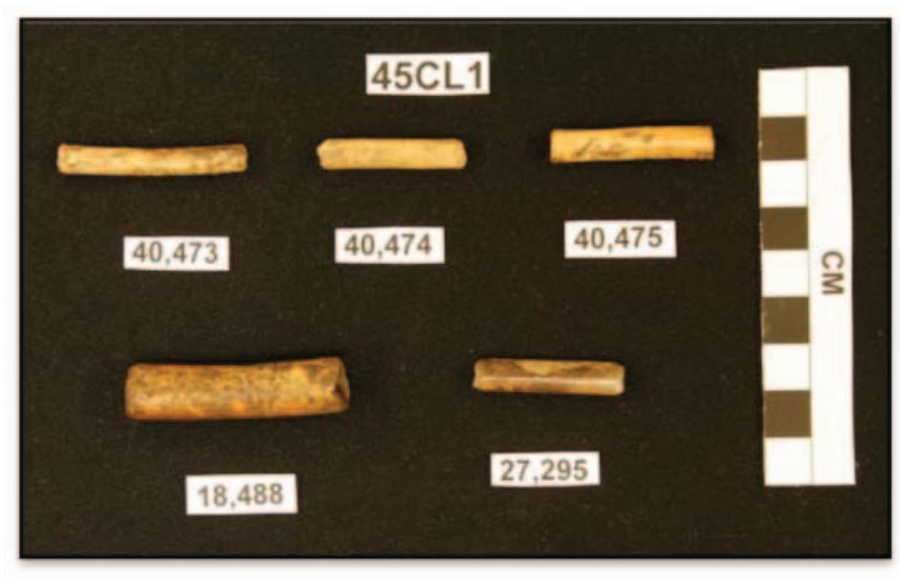

Figure 2. 1A1. Bird bone beads

3. Decorated $(n=2)$ Beads that possess a design. The Cathlapotle specimens displayed incised geometric crisscross patterns. The smaller specimen was fractured on one end. Both were made of bird bone, were parallel in dorsal view and longitudinal cross section, and were circular in transverse cross section. 
Table 2. 1A3.Measurements in millimeters and grams.

\begin{tabular}{|c|c|c|c|c|c|c|c|}
\hline & & TL LENGTH & MIN WIDTH & MAX WIDTH & MIN THICKNESS & MAX THICKNESS & WEIGHT \\
\hline Smaller & & 39.2 & 2.31 & 6.78 & 1.42 & 4.37 & 0.7 \\
\hline Larger & & 41.19 & 5.59 & 5.91 & 5.3 & 5.65 & 0.8 \\
\hline
\end{tabular}

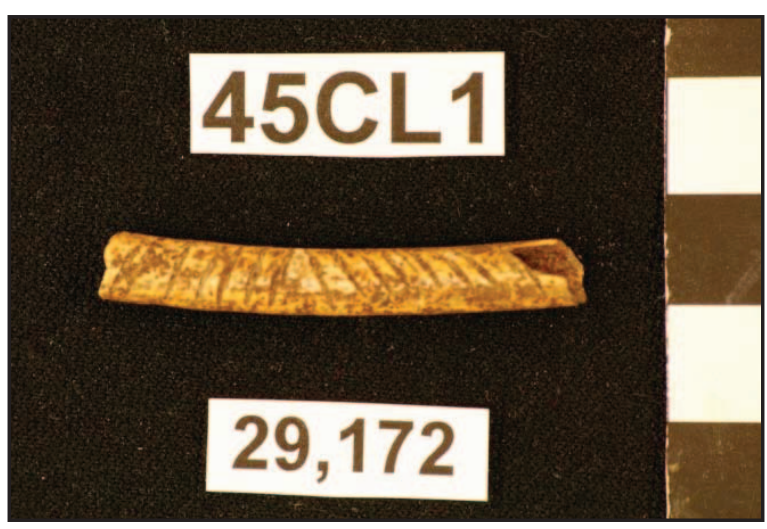

Figure 3. 1A3. Decorated bead.

B. Pendants. Pendants include items that could have been suspended. Pendants were worn as jewelry, or attached to clothing or regalia via a hole, groove, or notch. Pendants are subdivided by raw material, decoration, and fragmentation.

5. Fragment $(n=2)$ The Cathlapotle specimens are both rectangular and flat and made from terrestrial mammal bone. Both are well worked and polished. One of the specimens had one hole drilled in it, and the other has two holes drilled into it.

Table 3. 1B5. Mean and standard deviation measurements in millimeters and grams.

\begin{tabular}{|c|c|c|c|c|c|c|c|}
\hline & & TL LENGTH & MIN WIDTH & MAX WIDTH & MIN THICKNESS & MAX THICKNESS & WEIGHT \\
\hline Smaller & & 24.06 & 15.22 & 12.87 & 3.42 & 2.46 & 1.1 \\
\hline Larger & & 26.99 & 14.93 & 11.77 & 1.54 & 1.66 & 0.8 \\
\hline
\end{tabular}




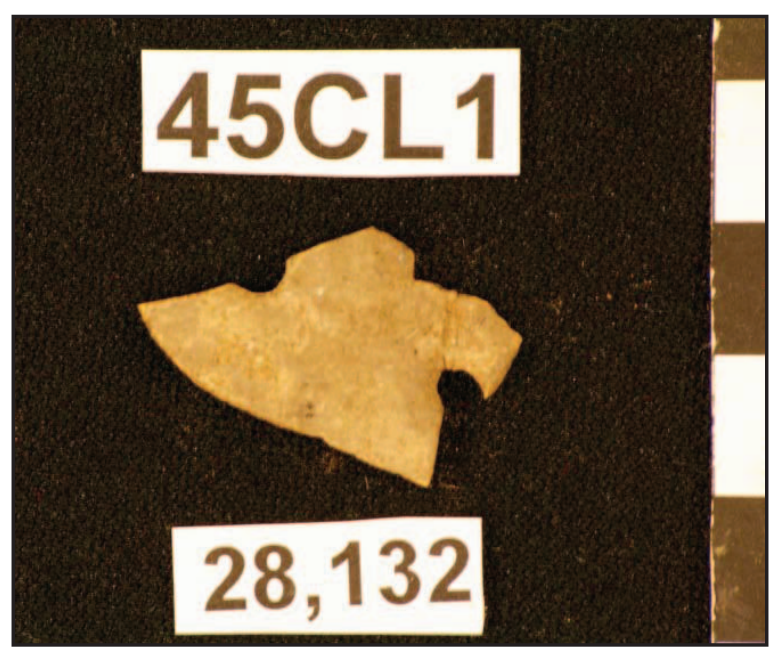

Figure 4. 1B5.Pendant fragment.

6. Tooth $(n=1)$. This artifact is an elk incisor that was polished and ground. A hole had started to be drilled and was never completed.

Table 4. 1B6. Measurements in millimeters and grams.

\begin{tabular}{|c|c|c|c|c|c|c|}
\hline $\mathrm{N}$ & LENGTH & MIN WIDTH & MAX WIDTH & MIN THICKNESS & MAX THICKNESS & WEIGHT \\
\hline 1 & 23.34 & 7.69 & 14.09 & 2.67 & 9.38 & 1.2 \\
\hline
\end{tabular}

C. Pins. Pins are objects resembling ethnographic blanket pins and were used to secure blankets wrapped around shoulders.

1. Decorated $(n=2)$ Pins that possess a design. Two decorated pins were recovered from Cathlapotle. One pin resembles a decorated toggle, and was likely used to fasten clothing or blankets. It is flat ventrally and convex dorsally and ovate in shape. The second pin is anthropomorphic. It is flat both ventrally and dorsally has several protrustions that may represent ears and arms. Two legs split into long splinters where the pin is fragmented. The artifact appears to be a fragmented hair pin, with the head and body of the anthropomorph as the pin head, and the legs splitting into two forks functioning as fasteners.

Table 5. 1C1. Measurements in millimeters and grams.

\begin{tabular}{|c|c|c|c|c|c|c|c|}
\hline & & TL LENGTH & MIN WIDTH & MAX WIDTH & MIN THICKNESS & MAX THICKNESS & WEIGHT \\
\hline Smaller & & 24.39 & 9.24 & 5.93 & 4.71 & 2.25 & 0.6 \\
\hline Larger & & 39.96 & 11.2 & 15.44 & 1.44 & 3.74 & 1.6 \\
\hline
\end{tabular}




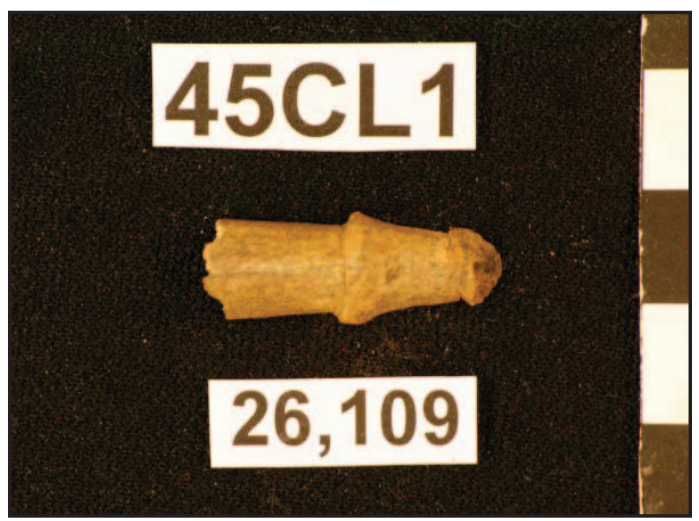

Figure 5. 1C1. Pin fragment.

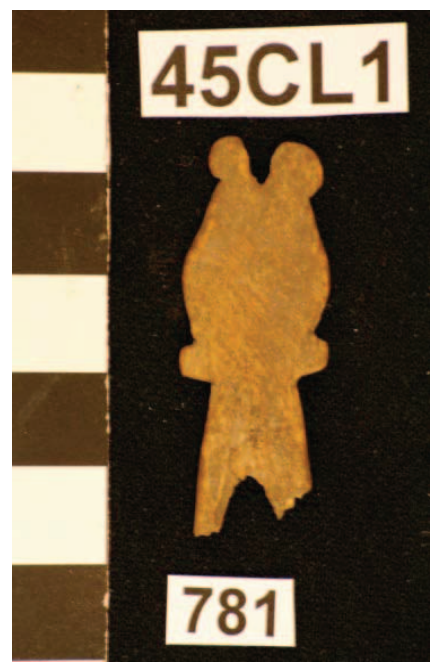

Figure 6. 1C1.Anthropomorphic pin fragment.

2. Bipoints. $(n=5)$ Bipoints are small narrow tools that are pointed at both ends (Raetz 1989). Bipoints are common artifacts in Northwest Coast assemblages and are associated with fishing gear, although their exact function is unknown. They were likely part of complex compound tools such as arming points for composite toggling harpoons, fish rake barbs, fish gorges, or hafted in multiples as part of a leister (Ames 2005, Bennett and Lyman 1989, Drucker 1943, Loy and Powell 1977). Bipoint fragments are likely undercounted, as many were probably classed as tip fragments. All of the bipoints observed at Cathlapotle are composed of terrestrial mammal bone. They are biconvex in dorsal outline and longitudinal cross section and are square to keeled in transverse cross section. Both ends are triangular to ovate in dorsal outline and longitudinal cross section and are generally convex and pointy. Points are circular when viewed in transverse cross section. Four out of five specimens were hafted. Hafts were tapering to parallel when viewed dorsally and longitudinally. Two of the five specimens are fragmented, therefore measurements are reported for the three complete bipoints. 
Cathlapotle bipoints are curated and extremely well worked at both sites exhibiting polish, grinding, and abrasion over the entirety of each artifact.

Table62. Means and standard deviations in millimeters and grams.

\begin{tabular}{|c|c|c|c|c|c|c|c|c|}
\hline & $\mathrm{N}$ & TL LENGTH & MIN WIDTH & MAX WIDTH & MIN THICKNESS & MAX THICKNESS & WEIGHT & TIP ANGLE \\
\hline MEAN & 3 & 51.17 & 1.83 & 6.52 & 1.47 & 5.23 & 1.3 & 23.3 \\
\hline ST. DEV. & & 13.37 & 0.78 & 0.87 & 0.33 & 1.61 & 0.61 & 5.77 \\
\hline
\end{tabular}

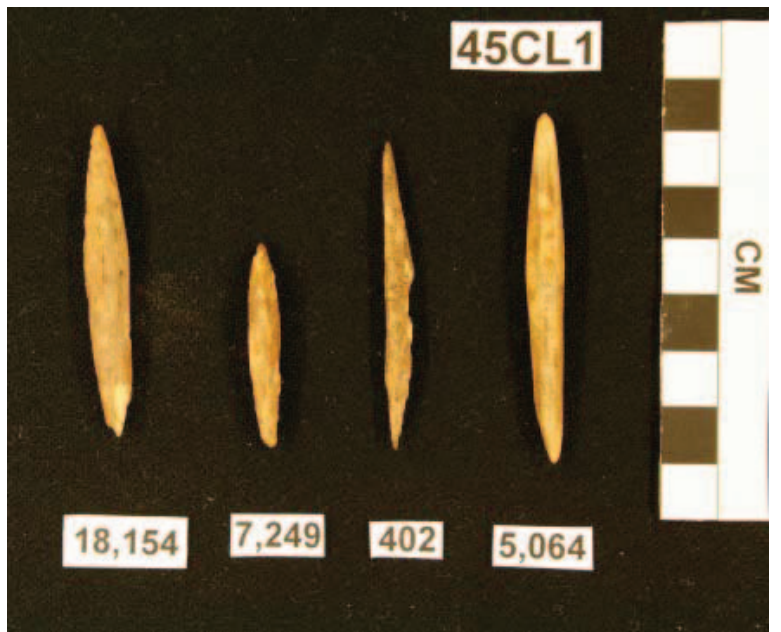

Figure 7. 2. Bipoints.

4. Crescents. $(n=1)$ Crescents are small bipointed bone objects in the shape of a crescent or a bell curve. Crescents are not usually described in Northwest Coast Site Reports, or sometimes are included with bipoints (Ames 2005). Only one specimen was observed at Cathlapotle. It is shaped like a bell curve dorsally, small, flat, and heavily abraded.

Table 7.4. Measurements in millimeters and grams.

\begin{tabular}{|c|c|c|c|c|c|}
\hline TL LENGTH & MIN WIDTH & MAX WIDTH & MIN THICKNESS & MAX THICNKESS & WEIGHT (G) \\
\hline 21.04 & 1.58 & 4.57 & 1.16 & 1.72 & 0.1 \\
\hline
\end{tabular}




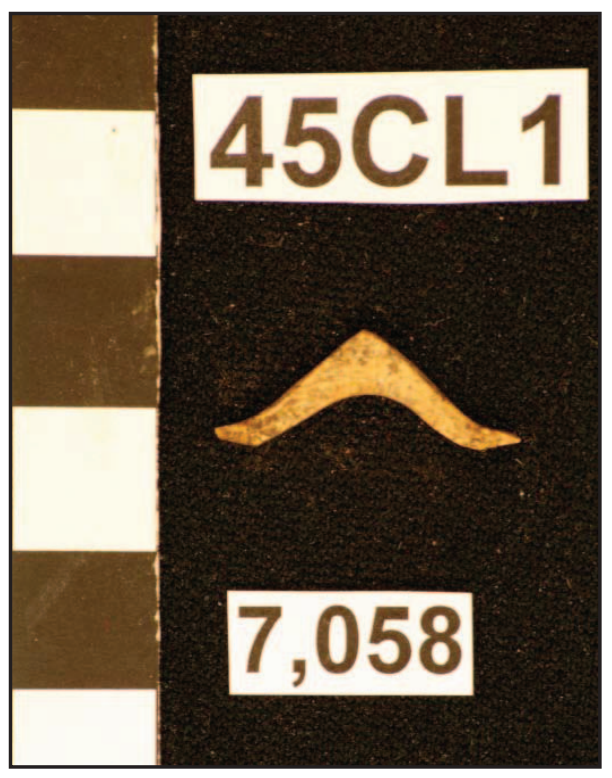

Figure 8. 4. Crescent.

5. Detritus $(n=75)$ Detritus are worked bone or antler which clearly appeared to be waste material from the manufacture of osseous artifacts.

A. Girdled and snapped. ( $n=43)$ Detritus that displays evidence of the girdle and snap (also called saw and snap, or groove and splinter) technique of creating osseous blanks for tool making. All Cathlapotle specimens are comprised of terrestrial mammal bone and most are metapodials. One specimen was the left proximal humerus of canis familiaris-domestic dog. Specimens are excurvate to ovate when viewed dorsally, curved laterally, and excurvate to ovate with some plano-convex when viewed in longitudinal cross section. Most specimens were subelliptical to circular shaped when viewed in transverse cross section, although some were planoconvex and concavo-convex. Specimens displayed signs of girdling, grinding, cut marks, adze marks, flake scars, and saw marks. Typically specimens have one end that is heavily modified with girdling marks surrounded by saw, cut, and adze marks, while the opposite end (the articulatory end) is otherwise unmodified.

Table 8. 5a Means and standard deviations in millimeters and grams.

\begin{tabular}{|c|c|c|c|c|c|c|c|}
\hline & $\mathrm{N}$ & TL LENGTH & MIN WIDTH & MAX WIDTH & MIN THICKNESS & MAX THICKNESS & WEIGHT \\
\hline MEAN & 43 & 61.2 & 22.47 & 33.45 & 17.55 & 23.54 & 18.77 \\
\hline ST. DEV. & & 39.3 & 22.14 & 27.76 & 22.14 & 21.6 & 26.52 \\
\hline
\end{tabular}




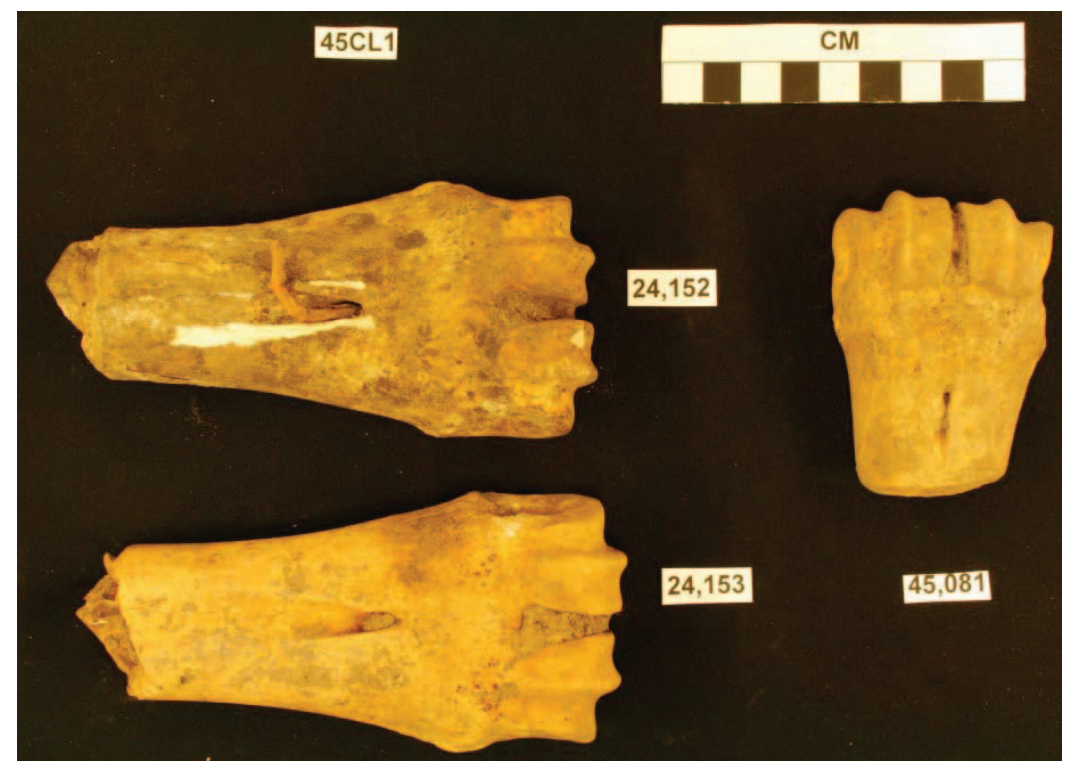

Figure 9. 5a.Girdled and snapped detritus.

B. Scapula. $(n=6)$ Detritus that consists of modified elk scapula. The Cathlapotle specimens are excurvate-incurvate when viewed dorsally and longitudinally and are asymmetrically keeled when viewed in transverse cross section. Most show evidence of abrasion and sawing.

Table 9. 5b Means and standard deviations in millimeters and grams.

\begin{tabular}{|c|c|c|c|c|c|c|c|}
\hline & N & TL LENGTH & MIN WIDTH & MAX WIDTH & MIN THICKNESS & MAX THICKNESS & WEIGHT \\
\hline MEAN & 6 & 209.04 & 22.97 & 57.78 & 13 & 28.64 & 83.67 \\
\hline ST. DEV. & & 103.81 & 11.29 & 17.51 & 4.95 & 21.93 & 43.15 \\
\hline
\end{tabular}




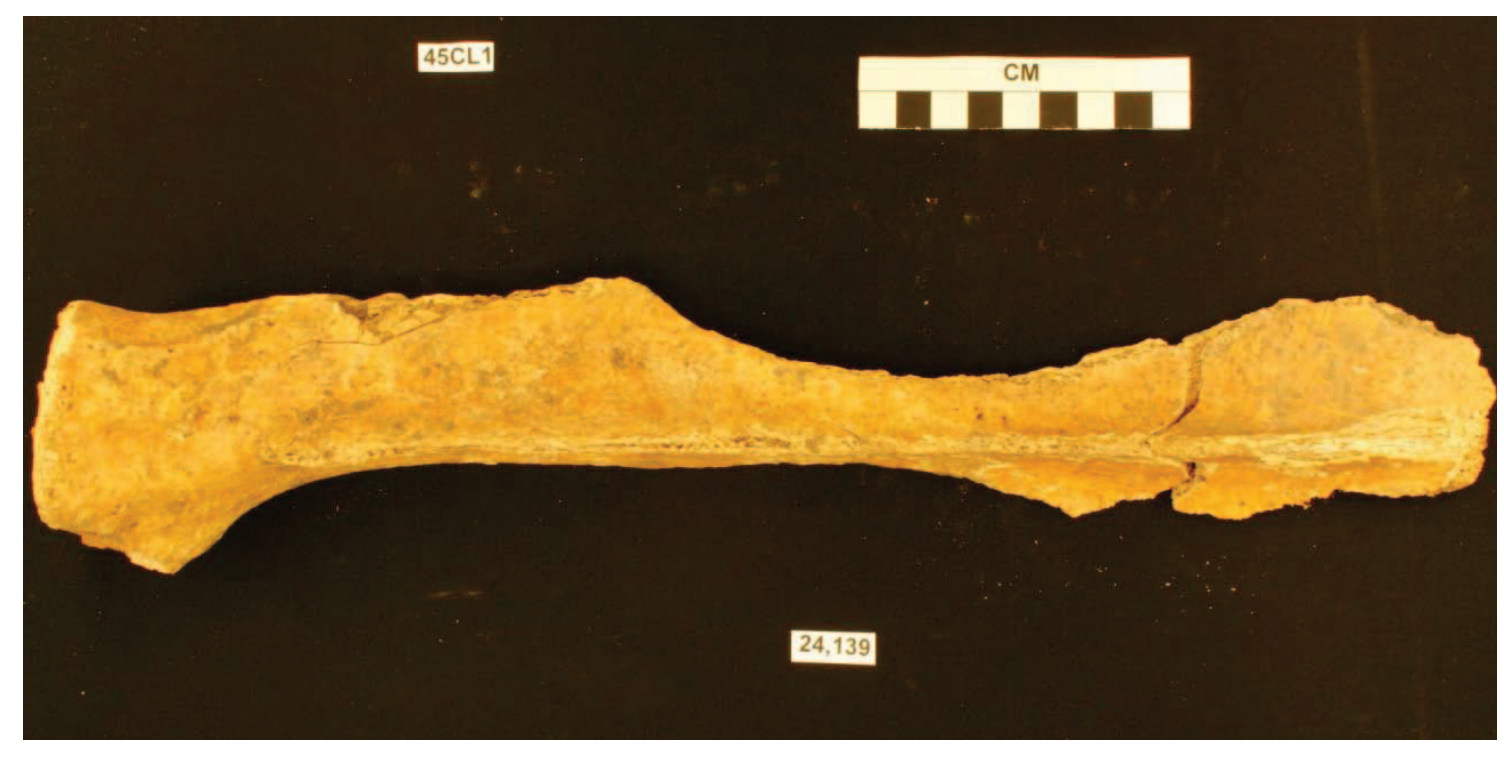

Figure 10. 5b. Worked scapula.

C. Other. $(\mathrm{n}=33)$ All other detritus. The remaining detritus is mostly antler $(\mathrm{n}=20,69 \%)$. Most antler detritus were excurvate, ovate, plano-convex, and expanding when viewed dorsally, excurvate, excurvat-incurvate, and planoconvex when viewed longitudinally, and subelliptical and plano-convex when viewed transversely, although other shapes were represented. Most bone detritus $(n=9,31 \%)$ were ovate when viewed dorsally, convex and excurvate when viewed longitudinally, and subellipitcal and concavoconvex when viewed transversely. Most detritus displayed chop or adze marks and many displayed cut marks and saw marks. Ground and abraded specimens were present but less common.

Table 10. 5c Means and standard deviations in millimeters and grams.

\begin{tabular}{|c|c|c|c|c|c|c|c|}
\hline & $\mathrm{N}$ & TL LENGTH & MIN WIDTH & MAX WIDTH & MIN THICKNESS & MAX THICKNESS & WEIGHT \\
\hline MEAN & 33 & 97.51 & 25.19 & 45.87 & 19.01 & 28.04 & 59.82 \\
\hline ST. DEV. & & 46.18 & 17.39 & 26.66 & 16.18 & 19.66 & 74.18 \\
\hline
\end{tabular}




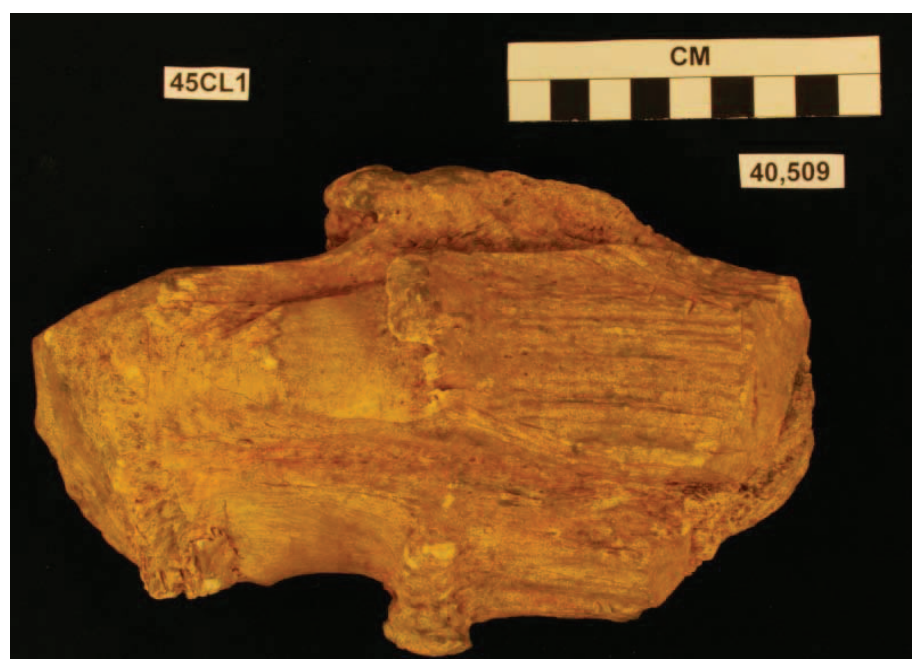

Figure 11. 5c. Detritus

6. Flakers. $(n=4)$ Flakers were used to manufacture stone tools, specifically to remove late stage small pressure flakes. Flakers are most often made of antler tines and display flat crushed tips damaged from use. Many antler flakers are probably classed as worked antler tip fragments (Raetz 1989). Of the four Cathlapotle specimens, 3 are complete and 1 is fractured just past the tip/body juncture, therefore measurements were reported for the 3 complete specimens only. Antler flaker shape is generally representative of the shape of the antler tine blank, ovate and expanding in dorsal and longitudinal views and circular and subelliptical in transverse cross section. Tips are square and ovate in dorsal view and subelliptical and square in transverse cross section. All four flakers have a tip angle of 60 degrees. All show evidence of flaking and crushing at the tip. Two specimens are well worked and are abraded and polished. The same two specimens have flaked or crushed bases, suggesting they may have other functions, perhaps as punches. One flaker seemed expedient and aside from the tip was unmodified.

Table 11. 6 Means and standard deviations in millimeters and grams.

\begin{tabular}{|c|c|c|c|c|c|c|c|}
\hline & $\mathrm{N}$ & TL LENGTH & MIN WIDTH & MAX WIDTH & MIN THICKNESS & MAX THICKNESS & WEIGHT \\
\hline MEAN & 3 & 141.09 & 8.65 & 28.87 & 6.54 & 21.13 & 41.83 \\
\hline ST. DEV. & & 54.5 & 3.45 & 16.83 & 3.65 & 8.66 & 39.06 \\
\hline
\end{tabular}




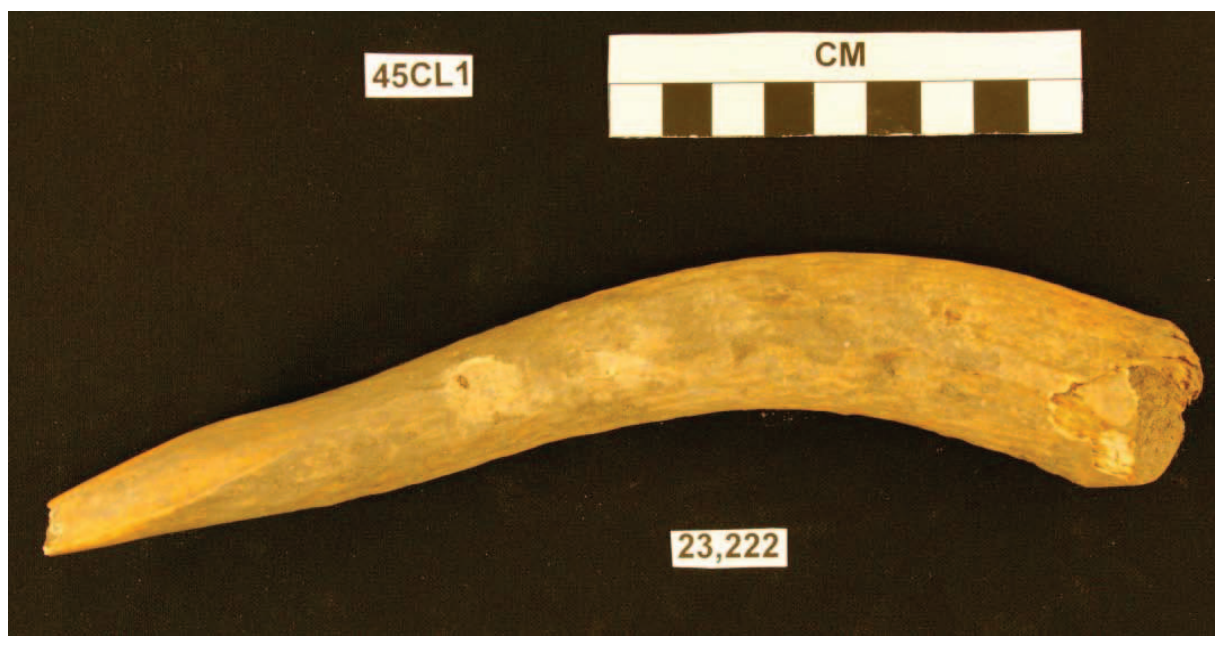

Figure 12.6.Flakers

7. Handles. $(n=7)$ Handles are part of more complex tools and have a hollow slot in the body or at one end to accept a blade or tool. Three of the Cathlapotle specimens were terrestrial mammal bone and four were comprised of antler. There are two distinct types of handle present at Cathlapotle. Five handles (three terrestrial mammal bone and one antler) are very well shaped, slotted handles. Handles are expanding when viewed dorsally and rectangular when viewed transversely. Some were beveled ventrally near the slot opening. One bone specimen was very fractured therefore measurements are reported for the three complete handles. The antler specimen was generally more robust and less finished. Slotted handles do not retain any attributes of the original raw material and are completely shaped artifacts. Two handles are constructed from antler tines and retain tine morphology (Figure 13). The tine tip is held, while the base has a square cut out, forming two lateral barbs. Both specimens are laterally fractured, each missing one barb.

Table 12. 7 Means and standard deviations in millimeters and grams for slotted handles.

\begin{tabular}{|c|c|c|c|c|c|c|c|c|}
\hline & $\mathrm{N}$ & TL LENGTH & MIN WIDTH & MAX WIDTH & MIN THICKNESS & MAX THICKNESS & WEIGHT & SLOT DEPTH \\
\hline MEAN & 5 & 72.09 & 22.65 & 33.2 & 11.5 & 11.34 & 18.46 & 22.83 \\
\hline ST. DEV. & & 31.26 & 5.37 & 5.13 & 4.68 & 4.39 & 15.09 & 17.66 \\
\hline
\end{tabular}




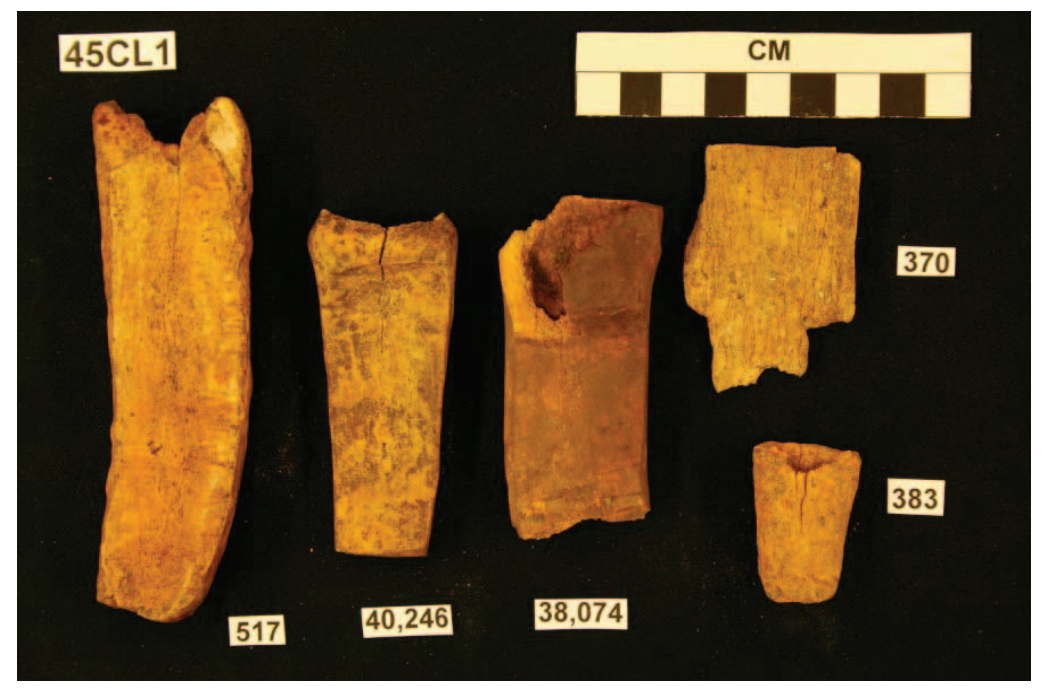

Figure 13. 7. Slotted Handles

Table 13. 7 Measurement $\mathrm{s}$ in millimeters and grams for tine handles.

\begin{tabular}{|c|c|c|c|c|c|c|c|}
\hline & & TL LENGTH & MIN WIDTH & MAX WIDTH & MIN THICKNESS & MAX THICKNESS & WEIGHT \\
\hline Smaller & & 126.61 & 12.17 & 42.01 & 12.77 & 31.82 & 42 \\
\hline Larger & & 195.08 & 10.38 & 39.88 & 9.59 & 28.83 & 75.3 \\
\hline
\end{tabular}

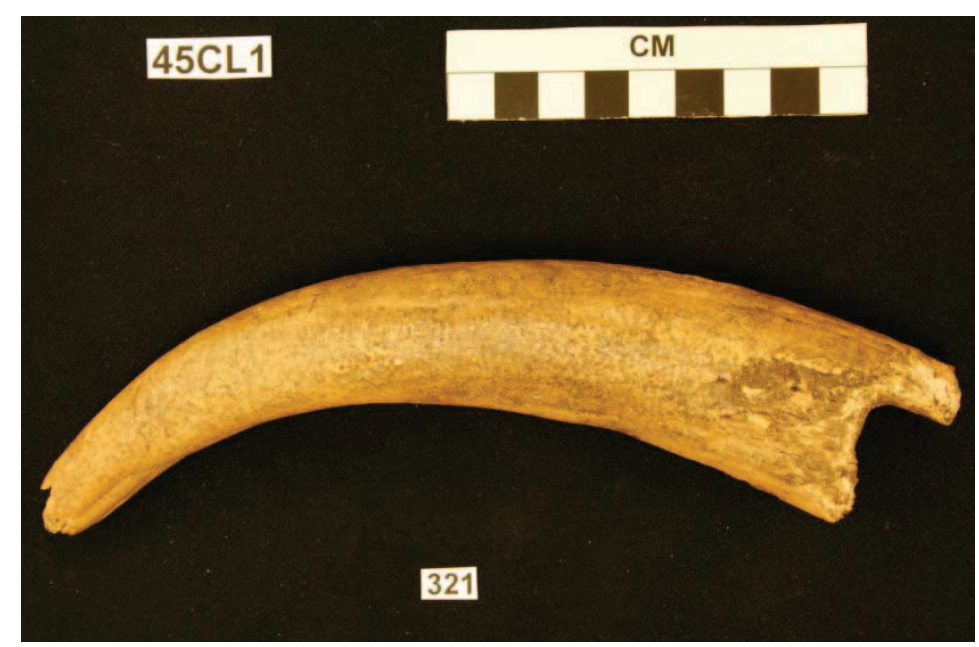

Figure 14.7Tine Handle

8. Beveled tools. Beveled tools include wedges, chisels, adzes, and beaver incisors. Beveled tools have either a bifacially beveled or unifacially beveled tip in transverse and longitudinal cross section. Beveled tools are divided by tip shape, pointed, round, or square. Tip shapes are subdivided by proximal element possession, and fragmentation. 
A. Point Tip. ( $\mathrm{n}=11)$ Beveled tools with pointed tips traditionally known as chisels. Chisels were used in late-stage fine grained work on soft substances such as wood.

2. Fixed. $(n=2)$ Chisels with a worked base and no hafting element. The term fixed implies they were affixed to a handle but lack a haft, or may have been hand held (Ames 2005). The two fixed chisels recovered from Cathlapotle are expanding in dorsal view, triangular/ovate in longitudinal cross section, and circular/elliptical in transverse cross section. Tips are double beveled. One specimen is antler, and one is terrestrial mammal bone. Both are well worked exhibiting abrasion and polish. These artifacts are curated artifacts.

Table 14. 8A2 Measurements in millimeters and grams.

\begin{tabular}{|c|c|c|c|c|c|c|c|c|}
\hline & & TL LENGTH & MIN WIDTH & MAX WIDTH & MIN THICKNESS & MAX THICKNESS & WEIGHT & TIP ANGLE \\
\hline BONE & & 126.39 & 3.51 & 35.67 & 7.3 & 19.2 & 34.5 & 30 \\
\hline ANLTER & & 181.12 & 4.36 & 22.55 & 2.41 & 23.17 & 43.2 & 40 \\
\hline
\end{tabular}

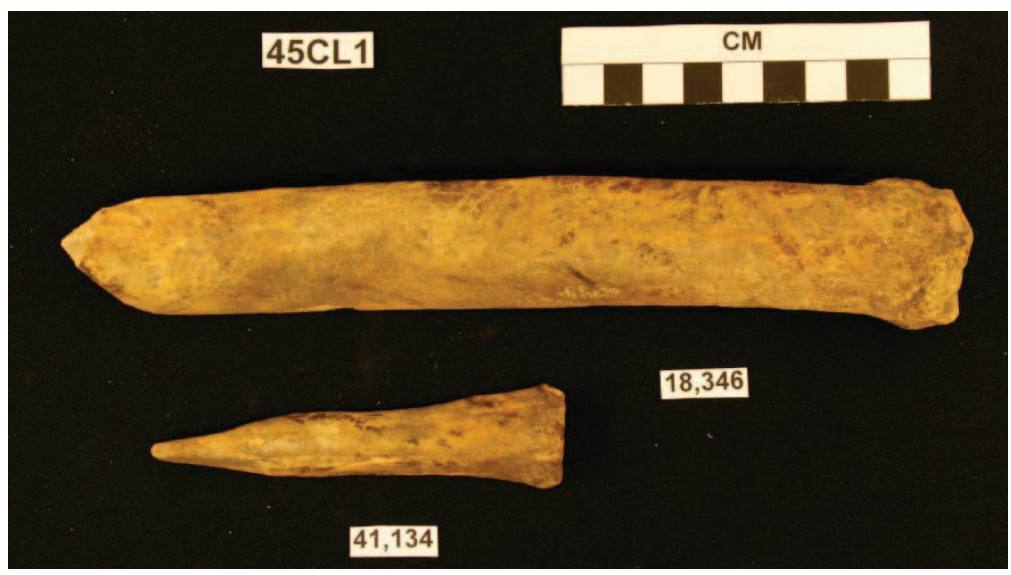

Figure 15. 8A2. Fixed chisels

4. Metapodial. $(n=5)$ Chisels manufactured from a metapodial bone retaining an articulatory end either proximal or distal. Of the five chisels, four were recovered from a cache feature in the Sheet Midden associated with House 1. These chisels were manufactured from split metapodials and have ventrally beveled tips and are concavo-convex in cross section. They are all extremely well worked curated tools. One is a chisel preform (Figure 17). The artifact is well worked exhibiting abrasion, beveling, and polish. The tip is not formed and the artifact still retains a girdled end resulting from the girdle and snap method of bone blank manufacture. A fifth metapodial chisel that was not part of the cache, has a double beveled tip that is well 
worked exhibiting both abrasion and polish. Despite this, working is confined to the tip and the artifact is expedient overall. It is concavo-convex in transverse cross section.

Table 15. 8A4 Means and standard deviations in millimeters and grams.

\begin{tabular}{|c|c|c|c|c|c|c|c|c|}
\hline & $\mathrm{N}$ & TL LENGTH & MIN WIDTH & MAX WIDTH & MIN THICKNESS & MAX THICKNESS & WEIGHT & TIP ANGLE \\
\hline MEAN & 5 & 30.83 & 16.77 & 36.09 & 8.54 & 24.4 & 66.2 & 40 \\
\hline ST. DEV. & & 9.08 & 13.25 & 6.78 & 5.01 & 8.83 & 37.41 & 10 \\
\hline
\end{tabular}

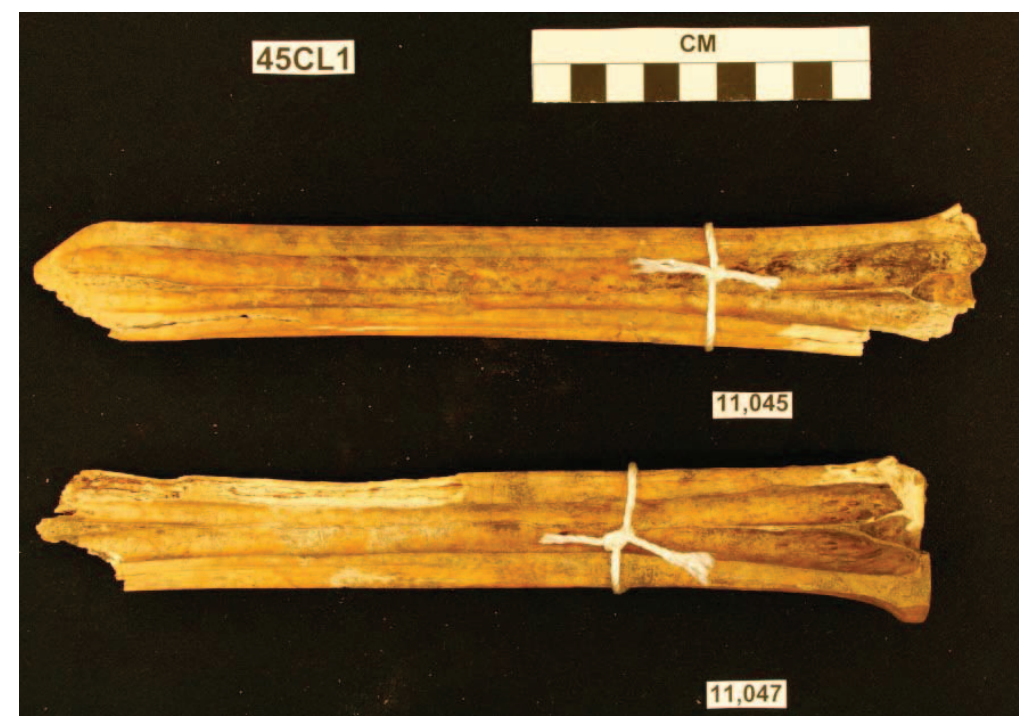

Figure 16.8A4 Metapodial chisels

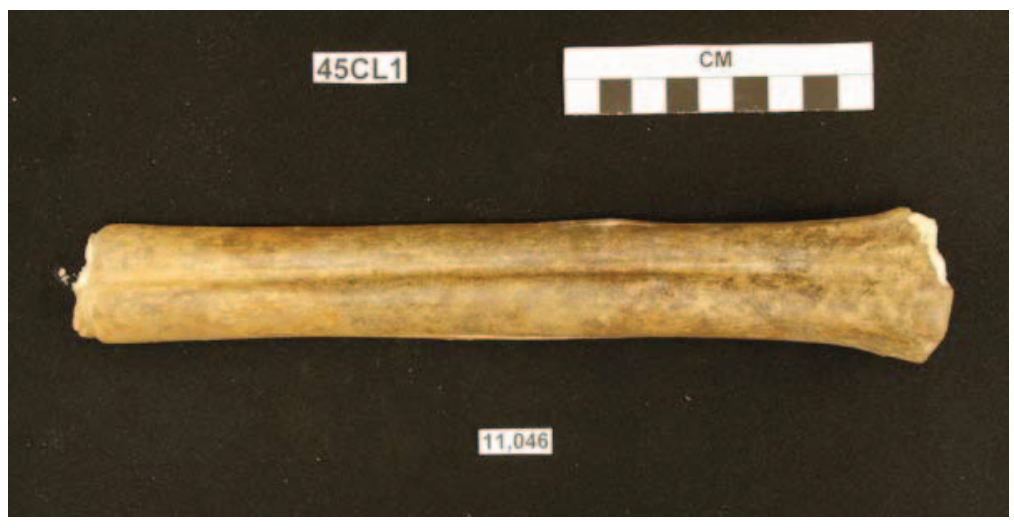

Figure 17. Chisel preform

5. Anatomical. $(n=1)$ Chisels possessing an anatomical end that is neither an ulna nor a metapodial. The base of this anatomical chisel possesses an articulatory end that is unidentifiable. This chisel has a ventrally beveled tip and is concavo-convex in transverse cross section. It is very well worked and is a curated 
chisel. The artifact also exhibits a groove near the base that is $2.7 \mathrm{~cm}$ long.

Table 16. 8A5 Mean in millimeters and grams.

\begin{tabular}{|c|c|c|c|c|c|c|c|c|}
\hline & $\mathrm{N}$ & TL LENGTH & MIN WIDTH & MAX WIDTH & MIN THICKNESS & MAX THICKNESS & WEIGHT & TIP ANGLE \\
\hline MEAN & 1 & 173.48 & 4.8 & 25.48 & 2.22 & 18.94 & 65.9 & 40 \\
\hline
\end{tabular}

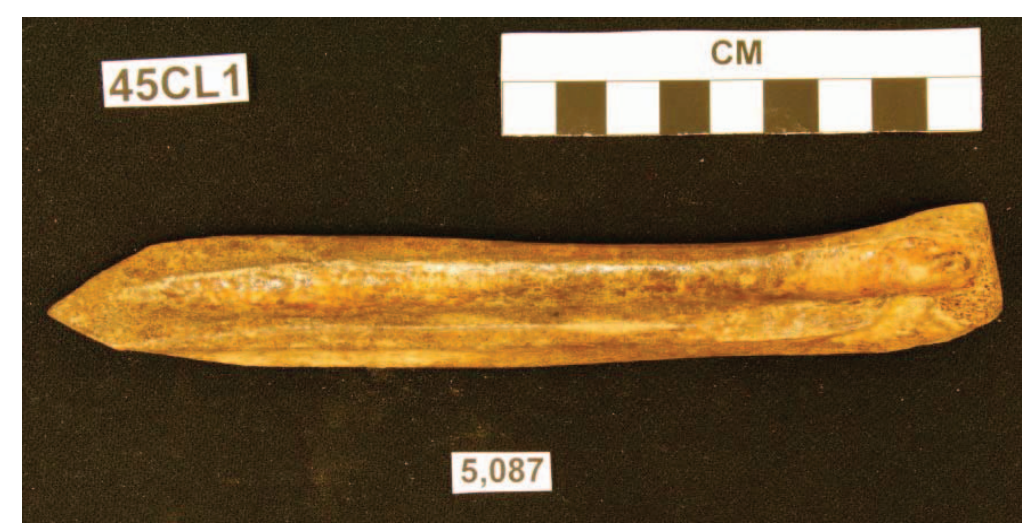

Figure 18.8A5 Anatomical Chisel

8. Fragment (tip) $(n=3)$ Chisel tip fragments. Cathlapotle chisel tip fragments are both tip fragments and tip/body fragments. This class is probably underrepresented, as many chisel tip fragments were likely classed as worked tip fragments. Two are terrestrial mammal bone and one is antler. The antler specimen has a double beveled tip, while the bone specimens are ventrally beveled. All have tip angles of 50 degrees. These artifacts are ovate in dorsal outline, plano-convex in longitudinal cross section, and concavo-convex in transverse cross section. All are well worked with grinding all over as well as some abrasion and a little polish. One bone specimen exhibited crushing and chipping near the tip.

Table 17. 8A8 Means and standard deviations in millimeters and grams.

\begin{tabular}{|c|c|c|c|c|c|c|c|c|}
\hline & $\mathrm{N}$ & TL LENGTH & MIN WIDTH & MAX WIDTH & MIN THICKNESS & MAX THICKNESS & WEIGHT & TIP ANGLE \\
\hline MEAN & 3 & 83.39 & 10.73 & 34.04 & 5.63 & 12.38 & 20.7 & 50 \\
\hline ST. DEV. & & 17.43 & 2.13 & 8.62 & 2.04 & 3.85 & 11.38 & 0 \\
\hline
\end{tabular}




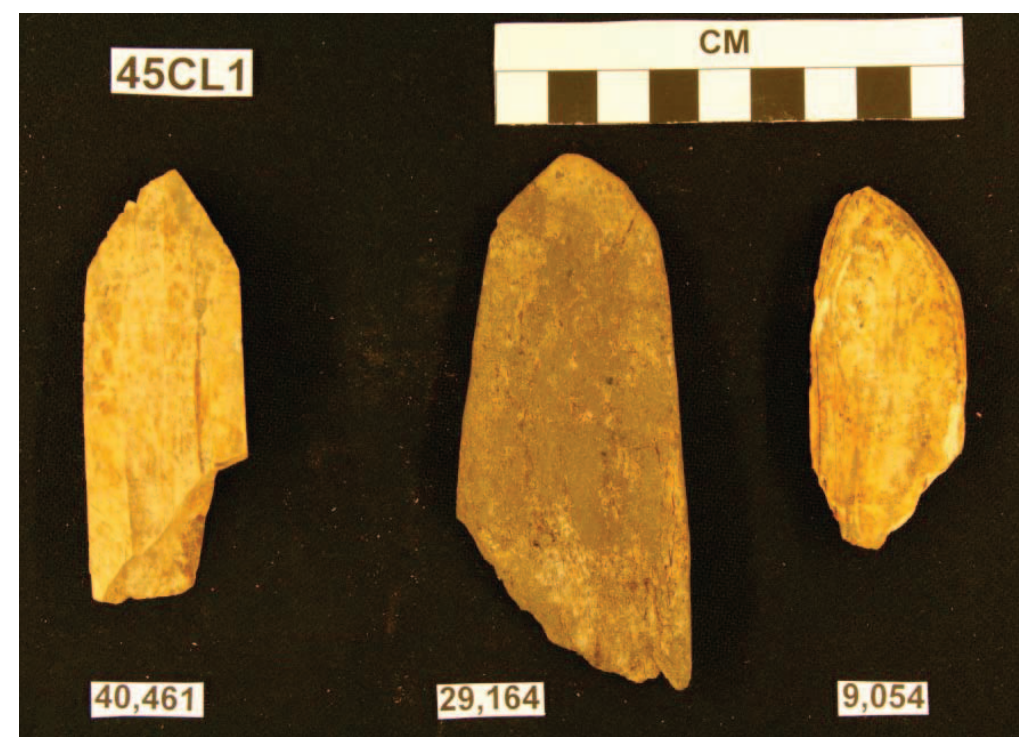

Figure 19.8A8 Chisel fragments

B. Incisors $(n=4)$ Incisor chisels are beaver incisors that have been modified for use or by use. The Cathlapotle specimens are excurvate-incurvate in shape and are ventrally beveled. All exhibit polish, while some exhibit grinding and abrasion.

Table 18. 8B Means and standard deviations in millimeters and grams.

\begin{tabular}{|c|c|c|c|c|c|c|c|}
\hline & $\mathrm{N}$ & TL LENGTH & MIN WIDTH & MAX WIDTH & MIN THICKNESS & MAX THICKNESS & WEIGHT \\
\hline MEAN & 4 & 40.45 & 6.2 & 6.9 & 3.19 & 5.84 & 1.33 \\
\hline ST. DEV. & & 18.92 & 1.23 & 0.81 & 1.03 & 0.39 & 0.89 \\
\hline
\end{tabular}

\section{$45 \mathrm{CL} 1$}
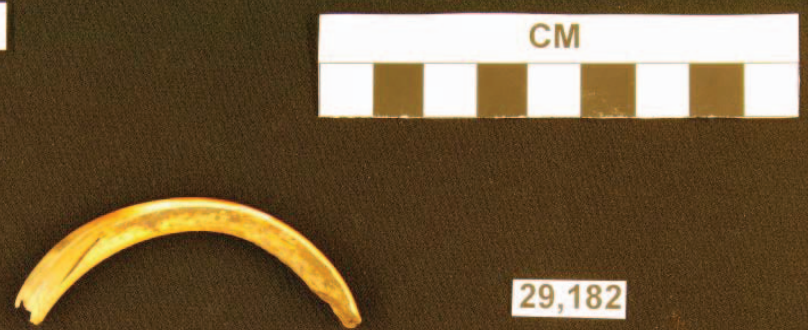

\section{9,182}

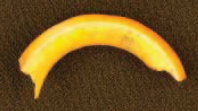

Figure 20.8B Incisor chisels 
C. Round Tip (Wedges) $(n=20)$ Beveled tools with round tips are traditionally known as wedges or adzes. Round tip wedges/adzes have beveled tips and round (curved) tips in dorsal view.

2. Haft $(n=4)$ Round tipped wedges/adzes that possess a hafting element. Cathlapotle hafted round tip wedges are ovate in dorsal outline, plano-convex in longitudinal and transverse cross section. Hafts are tapering. Two specimens are made of antler and two are made of terrestrial mammal bone. The antler specimen is double beveled, while one bone specimen is ventrally beveled and one is dorsally beveled. These are very well made, well-shaped, curated tools and exhibit polish, grinding, and abrasion.

Table 19. 8c2 Means and standard deviations in millimeters and grams.

\begin{tabular}{|c|c|c|c|c|c|c|c|c|}
\hline & $\mathrm{N}$ & TL LENGTH & MIN WIDTH & MAX WIDTH & MIN THICKNESS & MAX THICKNESS & WEIGHT & TIP ANGLE \\
\hline MEAN & 4 & 117.45 & 19.34 & 39.05 & 5.9 & 12.7 & 0 & 50 \\
\hline ST. DEV. & & 58.51 & 7.13 & 9.9 & 1.82 & 3.9 & 35.1 & 0 \\
\hline
\end{tabular}

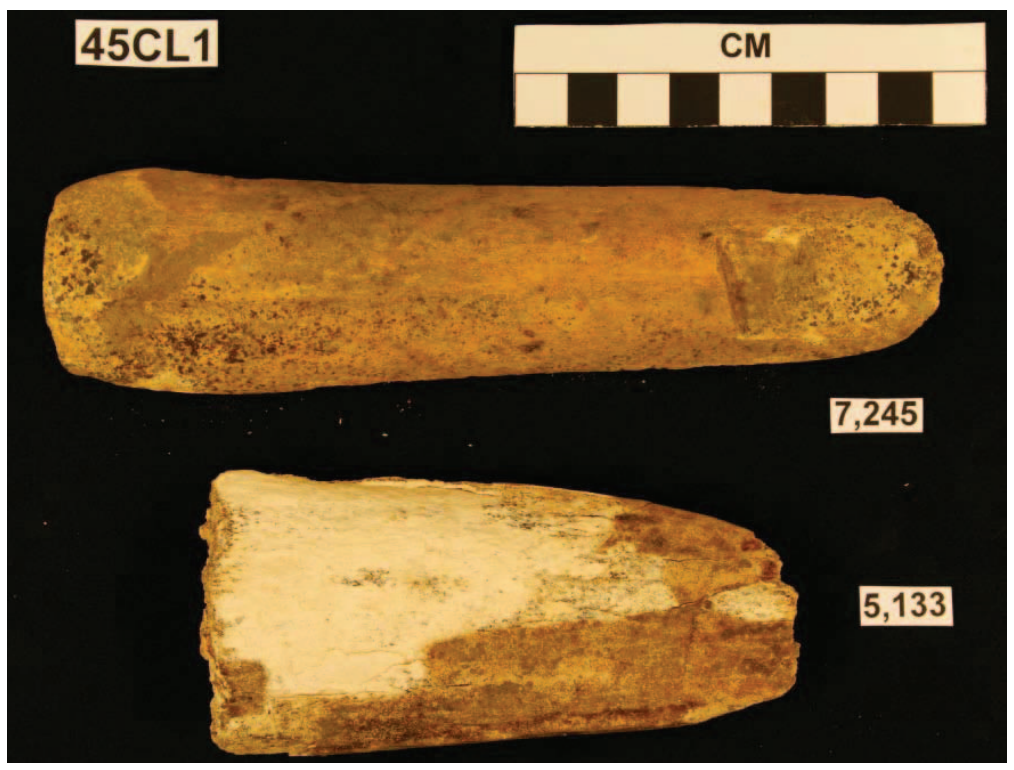

Figure $21.8 \mathrm{C} 2$. Round tipped hafted wedges.

3. Fixed $(n=3)$ Round tipped wedges/adzes with a worked base and no hafting element. Two of the Cathlapotle fixed round tipped wedges are comprised of antler and one is comprised of terrestrial mammal bone. They are ovate in dorsal outline and subelliptical in transverse cross section. The antler specimens have double beveled tips and the bone specimen is ventrally beveled only. These are all very nice well-made curated tools and exhibit polish, grinding, and abrasion. 
Table 20. 8c3 Means and standard deviations in millimeters and grams.

\begin{tabular}{|c|c|c|c|c|c|c|c|c|}
\hline & $\mathrm{N}$ & TL LENGTH & MIN WIDTH & MAX WIDTH & MIN THICKNESS & MAX THICKNESS & WEIGHT & TIP ANGLE \\
\hline MEAN & 3 & 74.19 & 22.43 & 38.17 & 5.06 & 11.27 & 18.63 & 50 \\
\hline ST. DEV. & & 33.12 & 9.33 & 9.54 & 1.03 & 4.28 & 9.89 & 5 \\
\hline
\end{tabular}

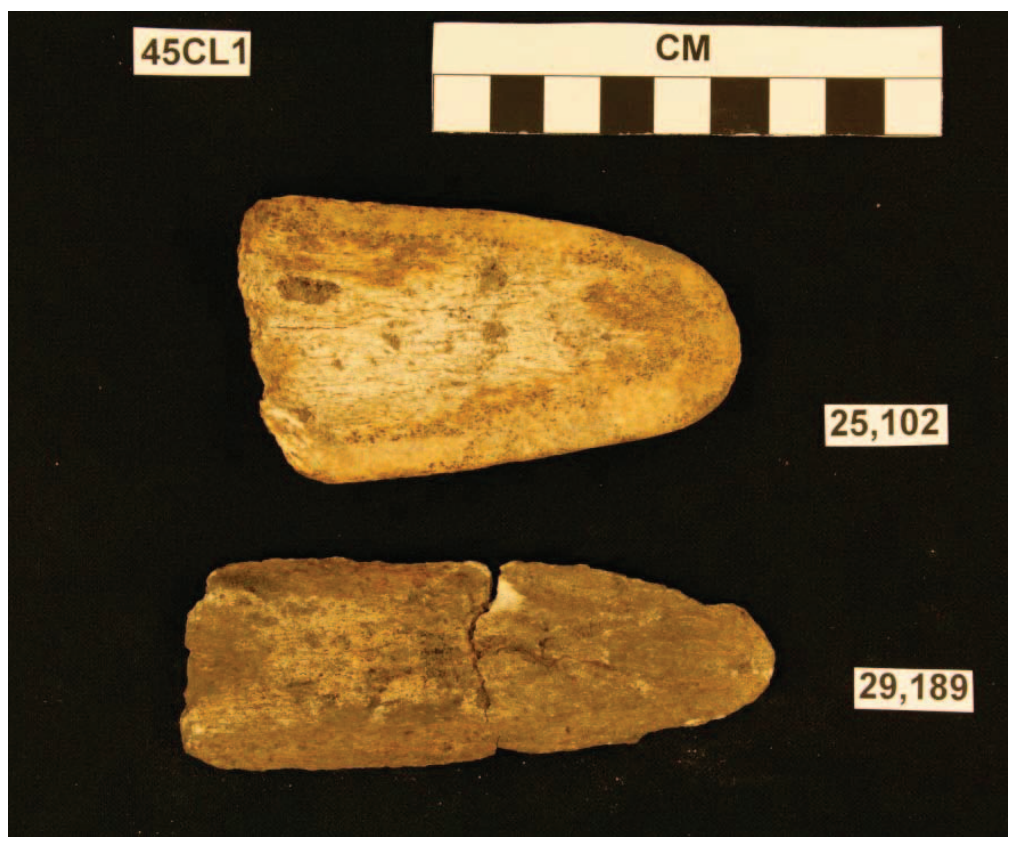

Figure 22. 8C3 Round tipped fixed wedges.

6. Worked $(n=3)$ Round tipped wedges/adzes that do not possess a haft or base element, and are worked on the tip and body only. Two worked round tipped wedges are comprised of antler, while one is terrestrial mammal bone. Worked wedges are ovate in dorsal outline and concavo-convex in transverse crosssection. The bone specimens and one antler specimen are dorsally beveled, while one antler specimen is double beveled. The doubly beveled antler specimen is worked near the tip and less so elsewhere and appears to be a fairly expedient woodworking tool. The other two artifacts are nicely worked and exhibits polish, grinding, and abrasion. They appear to be curated worked round tipped wedges.

Table 21. 8C6 Means and standard deviations in millimeters and grams.

\begin{tabular}{|c|c|c|c|c|c|c|c|c|}
\hline & N & TL LENGTH & MIN WIDTH & MAX WIDTH & MIN THICKNESS & MAX THICKNESS & WEIGHT & TIP ANGLE \\
\hline MEAN & 3 & 105.31 & 20.53 & 25.75 & 4.71 & 21.48 & 25.4 & 53.3 \\
\hline ST. DEV. & & 32.05 & 7.3 & 4.64 & 2.39 & 6.9 & 13.27 & 11.5 \\
\hline
\end{tabular}




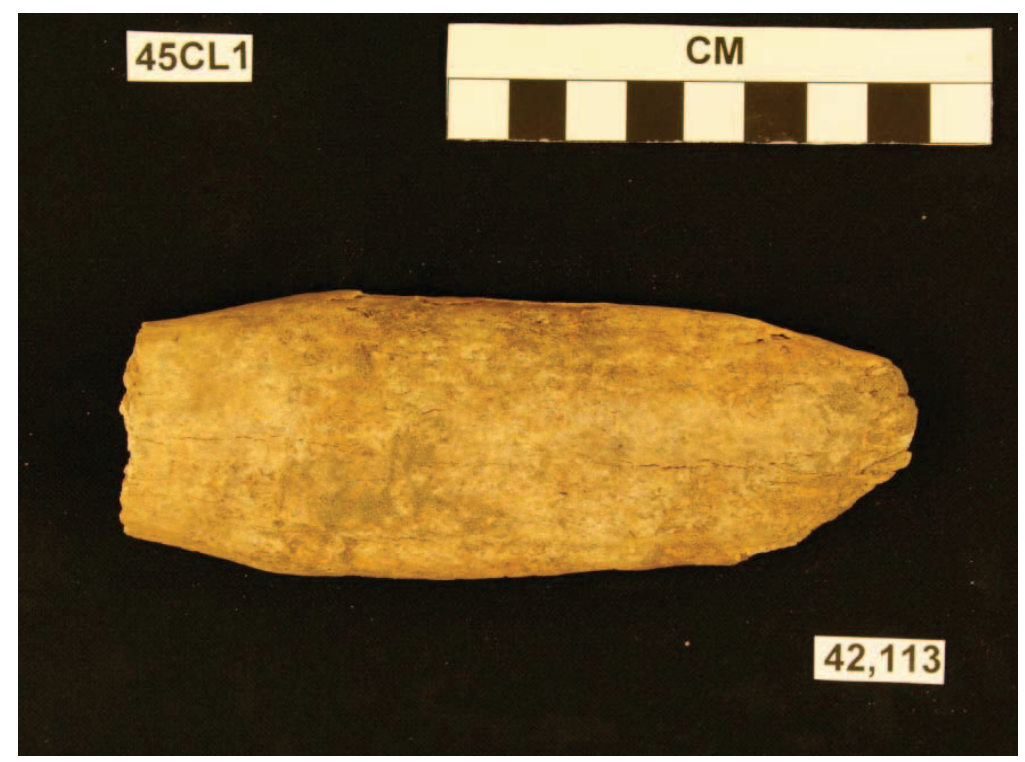

Figure 23. 8C6Round tipped worked wedge.

7. Fragment $(n=10)$ Tip and body fragments of round tipped wedge/adzes. Eight of the round tipped wedge fragments recovered from Cathlapotle is made of antler, and two are made of terrestrial mammal bone. These wedge fragments are excuravte/ovate in dorsal outline and triangular/ovate in longitudinal cross section. Six of the ten are ventrally beveled, three are double beveled, and one is dorsally beveled. These are well worked artifacts that are broken. Many look like small wedge bits.

Table 22. 8c7 Means and standard deviations in millimeters and grams.

\begin{tabular}{|c|c|c|c|c|c|c|c|c|}
\hline & $\mathrm{N}$ & TL LENGTH & MIN WIDTH & MAX WIDTH & MIN THICKNESS & MAX THICKNESS & WEIGHT & TIP ANGLE \\
\hline MEAN & 10 & 65.8 & 14.78 & 26.82 & 4.9 & 12.76 & 16.76 & 53.6 \\
\hline ST. DEV. & & 56.16 & 6.83 & 6.43 & 1.77 & 8.28 & 27.15 & 6.9 \\
\hline
\end{tabular}




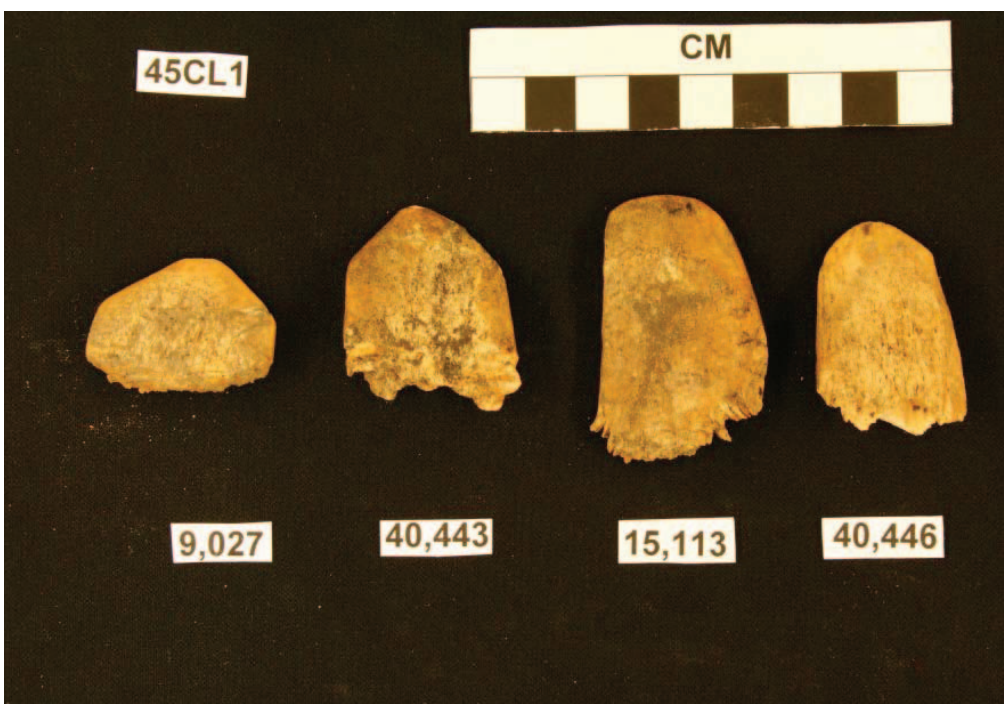

Figure 24. 8C7. Round tipped wedge fragments

D. Square Tip (Wedges) $(n=6)$ Square tipped beveled tools are traditionally known as wedges or adzes. Square tipped wedges have beveled tips and square (straight) tips in dorsal view.

2. Haft $(n=1)$ Square tipped wedges that possess a hafting element. This specimen is an antler wedge with a double beveled tip. It is excurvate/ovate in dorsal outline, parallel in longitudinal cross section, and subelliptical in transverse cross section. The haft is rectangular in shape. This artifact is well made and was likely curated. It is abraded and polished.

Table 23. 8D2 Measurements in millimeters and grams.

\begin{tabular}{|c|c|c|c|c|c|c|}
\hline TL LENGTH & MIN WIDTH & MAX WIDTH & MIN THICKNESS & MAX THICKNESS & WEIGHT & TIP ANGLE \\
\hline 125.02 & 45.75 & 25.82 & 4.75 & 27.45 & 69.6 & 55 \\
\hline
\end{tabular}

3. Fixed $(n=3)$ Square tipped wedges with a worked base and no hafting element. Fixed square tipped wedges at Cathlapotle are all constructed of antler. These artifacts are excurvate/ovate in dorsal outline and concavo-convex in longitudinal and transverse cross sections. Bases are square and convex. Two of the specimens are double beveled, while one is dorsally beveled. These artifacts are well worked and show signs of abrasion and polish.

Table 24. 8D3 Means and standard deviations in millimeters and grams.

\begin{tabular}{|c|c|c|c|c|c|c|c|c|}
\hline & $\mathrm{N}$ & TL LENGTH & MIN WIDTH & MAX WIDTH & MIN THICKNESS & MAX THICKNESS & WEIGHT & TIP ANGLE \\
\hline MEAN & 3 & 128.76 & 20.45 & 40.87 & 5.27 & 29.93 & 58.8 & 51.67 \\
\hline ST. DEV. & & 28.84 & 10.99 & 13.13 & 1.2 & 3.46 & 33.58 & 2.89 \\
\hline
\end{tabular}




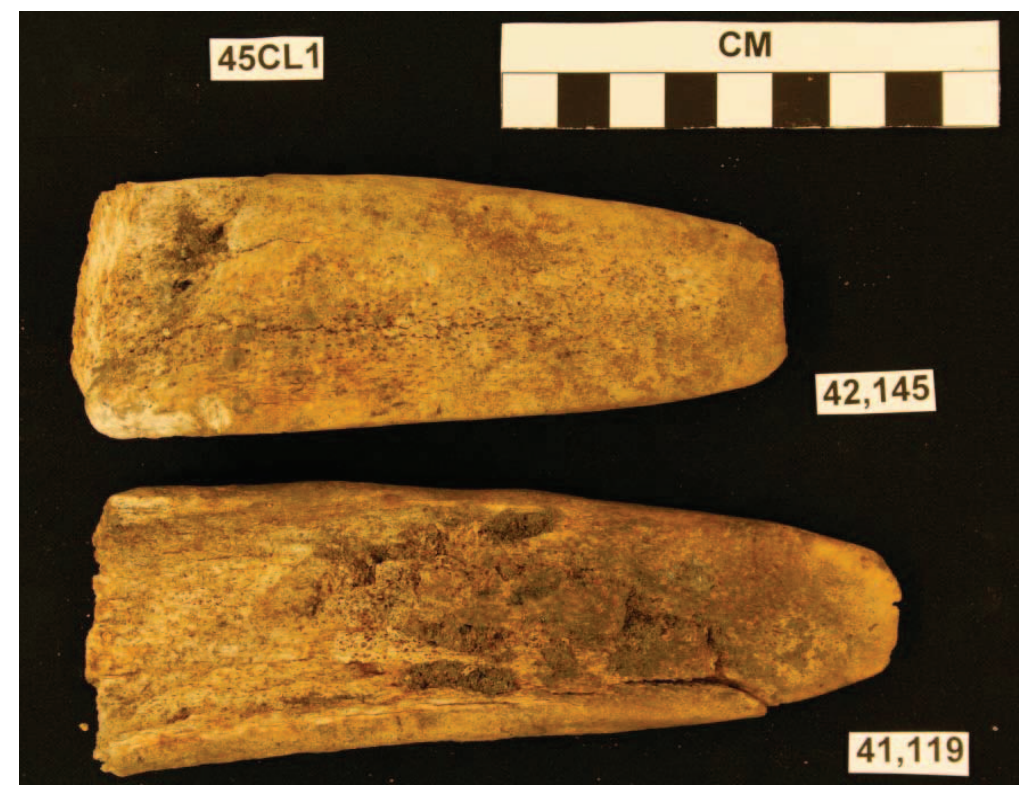

Figure 25.8D3 Square tipped fixed wedges

7. Fragment $(n=2)$ Tip and body fragments of square tipped wedges. The two Cathlapotle specimens are both antler, one is double beveled, while the other is ventrally beveled. The artifacts are triangular in shape and exhibit grinding and abrasion.

Table 25. 8D7 Measurements in millimeters and grams.

\begin{tabular}{|c|c|c|c|c|c|c|c|c|}
\hline & & TL LENGTH & MIN WIDTH & MAX WIDTH & MIN THICKNESS & MAX THICKNESS & WEIGHT & TIP ANGLE \\
\hline Smaller & & 80.1 & 15.13 & 28.13 & 2.67 & 10.55 & 16.5 & 60 \\
\hline Larger & & 186.5 & 21.76 & 42.89 & 3.46 & 27.7 & 82.7 & 60 \\
\hline
\end{tabular}

E. Beveled body/base fragments. $(n=14)$ Base/ body fragments that exhibit beveling. The tip is either missing or tip shape is indiscernible. In some cases wedges were too fragmentary to measure and were recorded as body/base fragments. Specimens from Cathlapotle were all constructed from antler. Measurable artifacts were expanding in dorsal view and excurvate in longitudinal view. Most were ventrally beveled and many were heavily polished.

Table 26. 8e Means and standard deviations in millimeters and grams.

\begin{tabular}{|c|c|c|c|c|c|c|c|}
\hline & $\mathrm{N}$ & TL LENGTH & MIN WIDTH & MAX WIDTH & MIN THICKNESS & MAX THICKNESS & WEIGHT \\
\hline MEAN & 12 & 115.42 & 20.58 & 40.94 & 11.29 & 21.23 & 49.42 \\
\hline ST. DEV. & & 42.58 & 12.79 & 12.41 & 4.26 & 13.69 & 41.65 \\
\hline
\end{tabular}

9. Worked fragments. $(n=)$ These items are too fragmentary to be classed in any other category. They are divided by identifiable characteristics including 
material, element, or treatment. Some may be detritus from tool manufacture or butchery, and some may be broken tools.

A. Anatomical Part $(n=7)$ Worked bone fragments retaining an articulatory end. Two are ribs, two are femur heads, one is a femur shaft, and others are unidentifiable anatomical worked fragments.

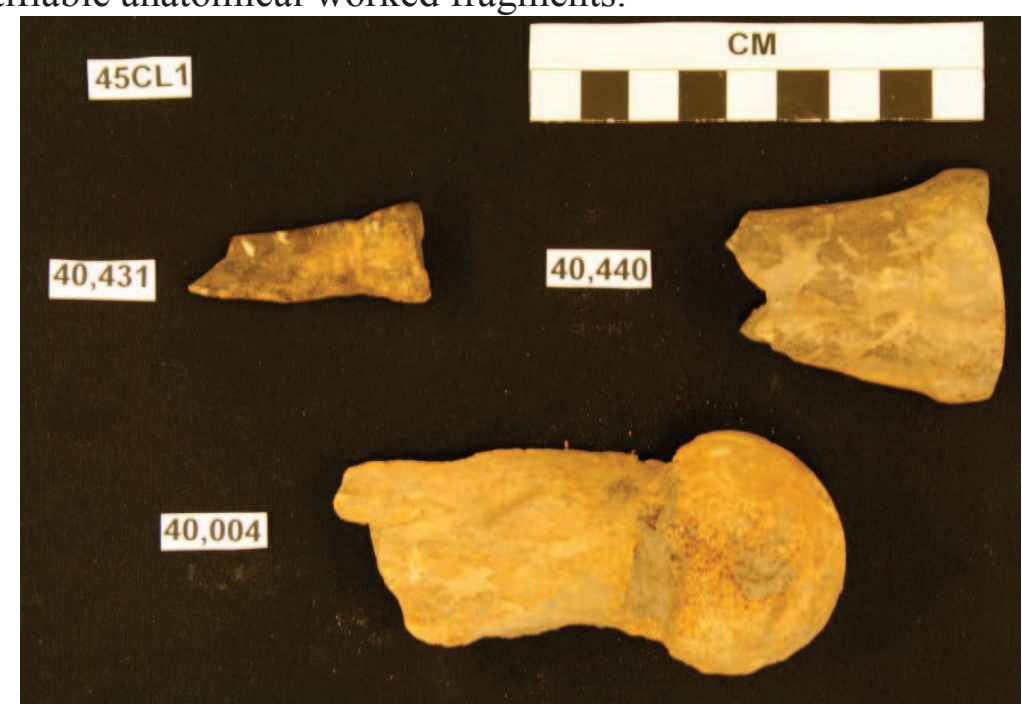

Figure 26.9A.Anatomical worked fragments

B. Antler $(n=42)$ Worked antler fragments with no other identifiable characteristics. Many exhibit chopping and adze marks and may be detritus. Others may be flakers that did not display enough wear to warrant their designation.

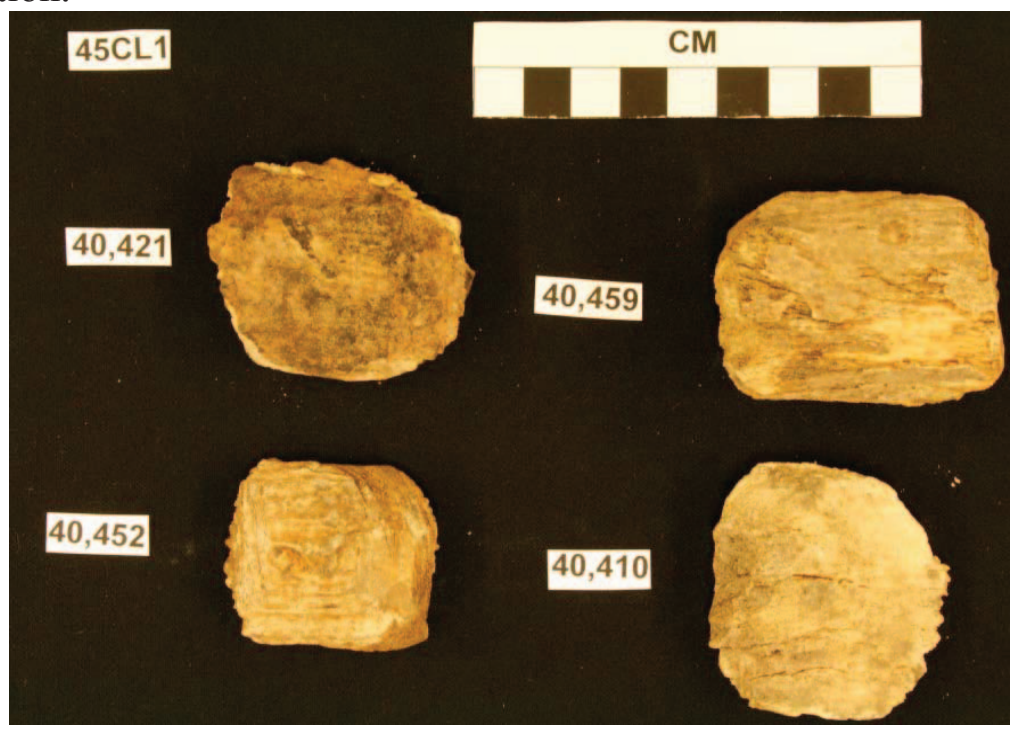

Figure 27.9B. Worked antler fragments 


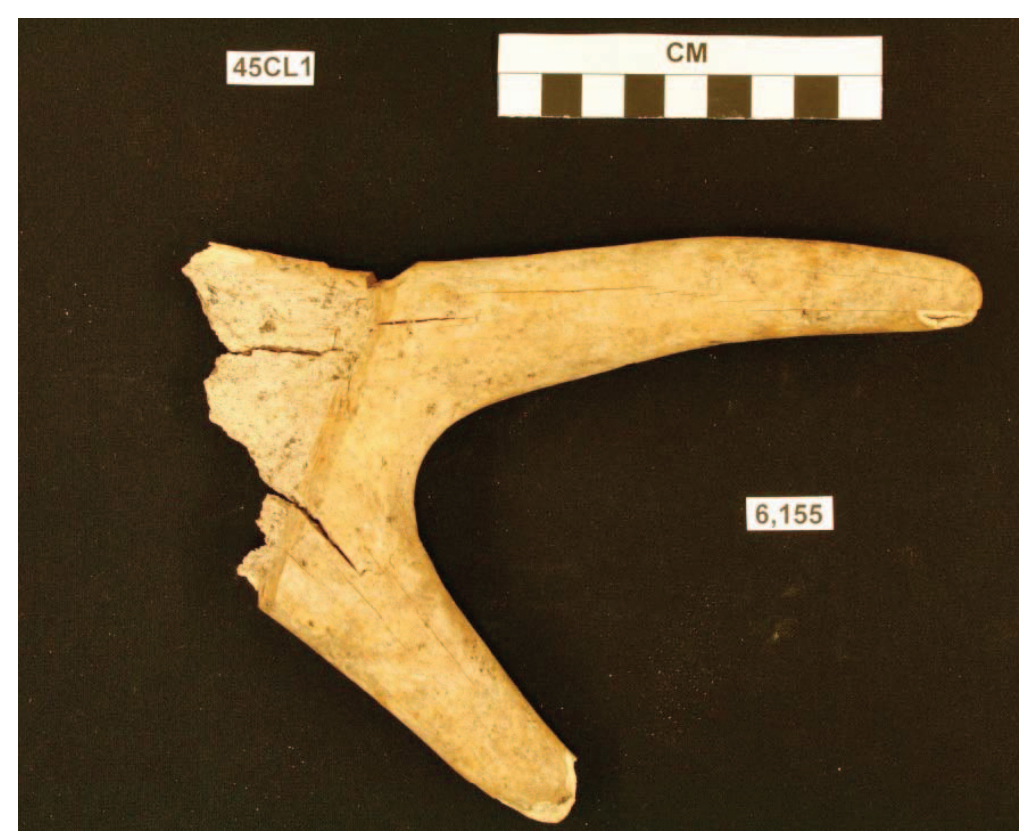

Figure 28.9BWorked antler fragment

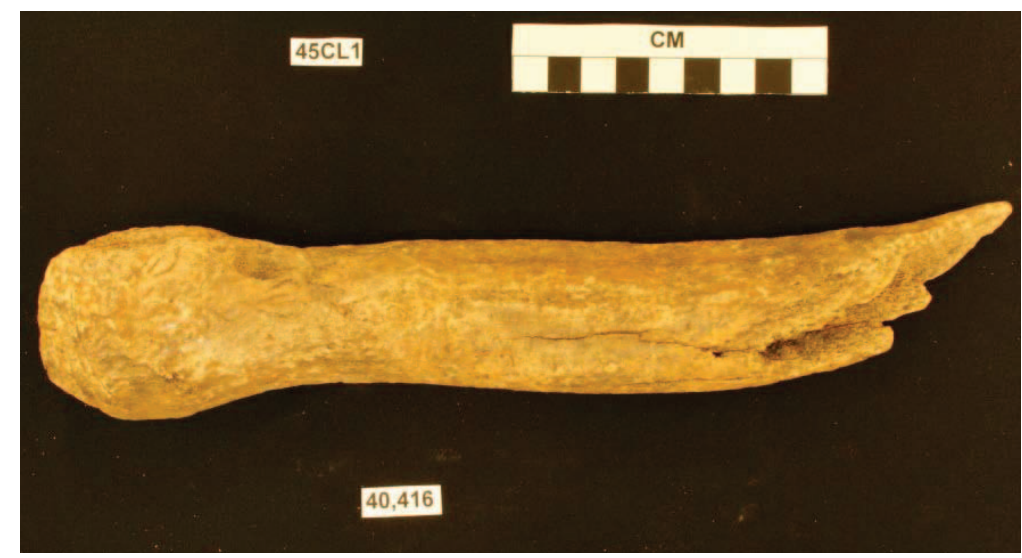

Figure 29. 9BWorked antler fragment with a carved eye D. Base $(n=10)$ Worked base fragments with no evidence of a hafting element. 


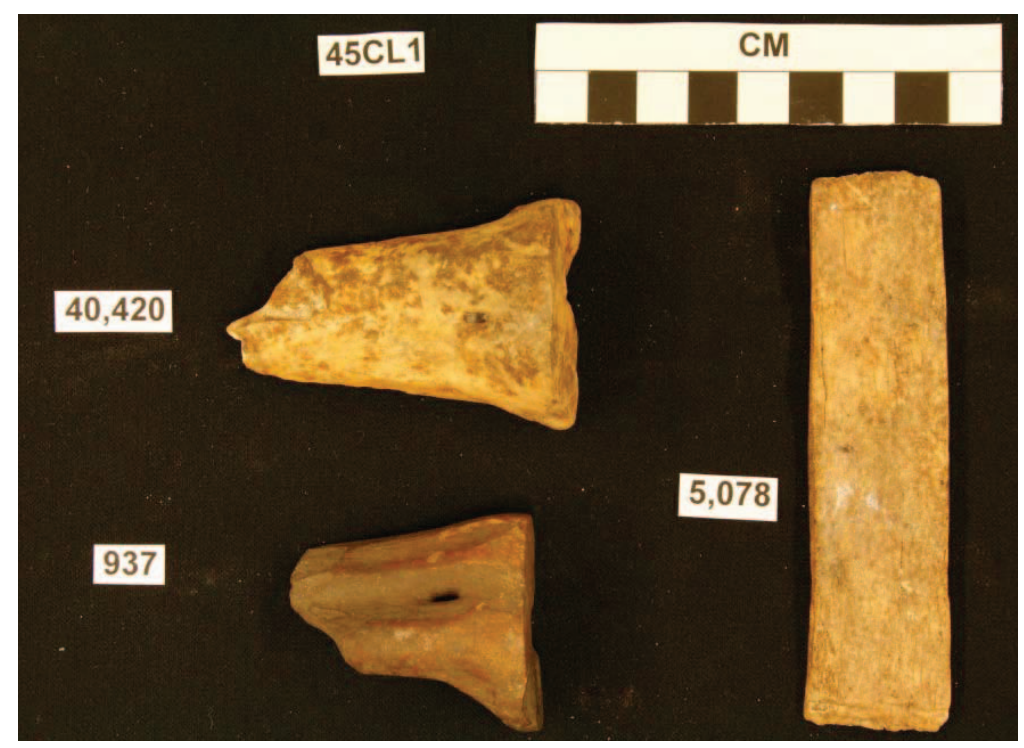

Figure 30. 9D.Worked base fragments

E. Bird Bone $(n=3)$ Worked bird bone fragments.

F. Bone $(n=59)$ Worked bone fragments with no other identifiable characteristics. Many fragments are calcined.

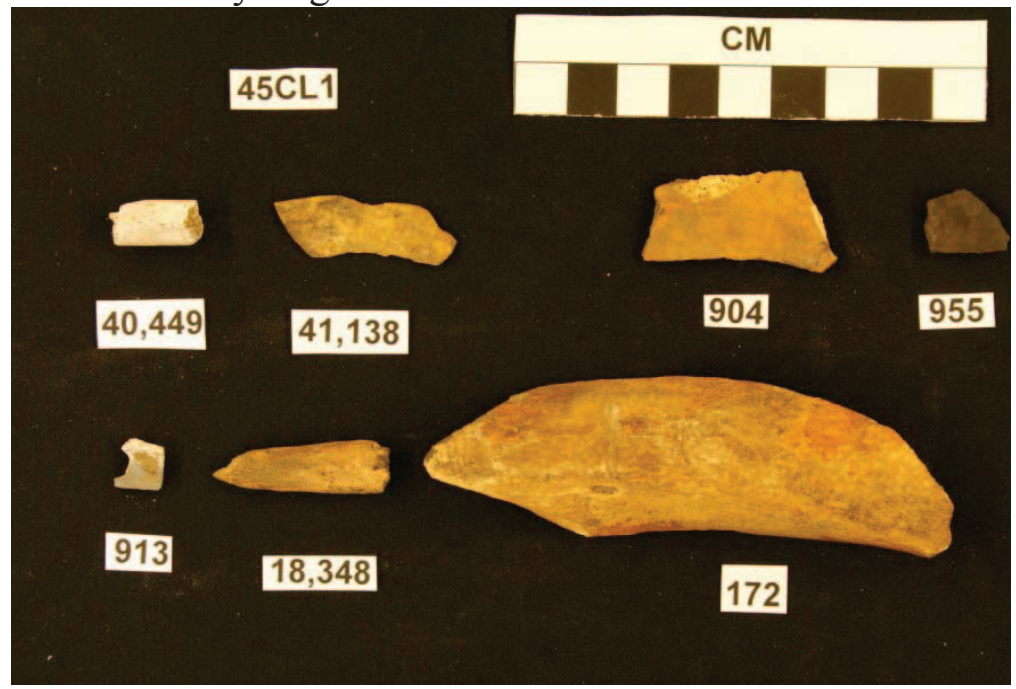

Figure 31. 9F.Worked bone fragments

G. Body $(n=22)$ Worked body fragments. Many are rectangular and "rodlike." These may be foreshaft fragments. 


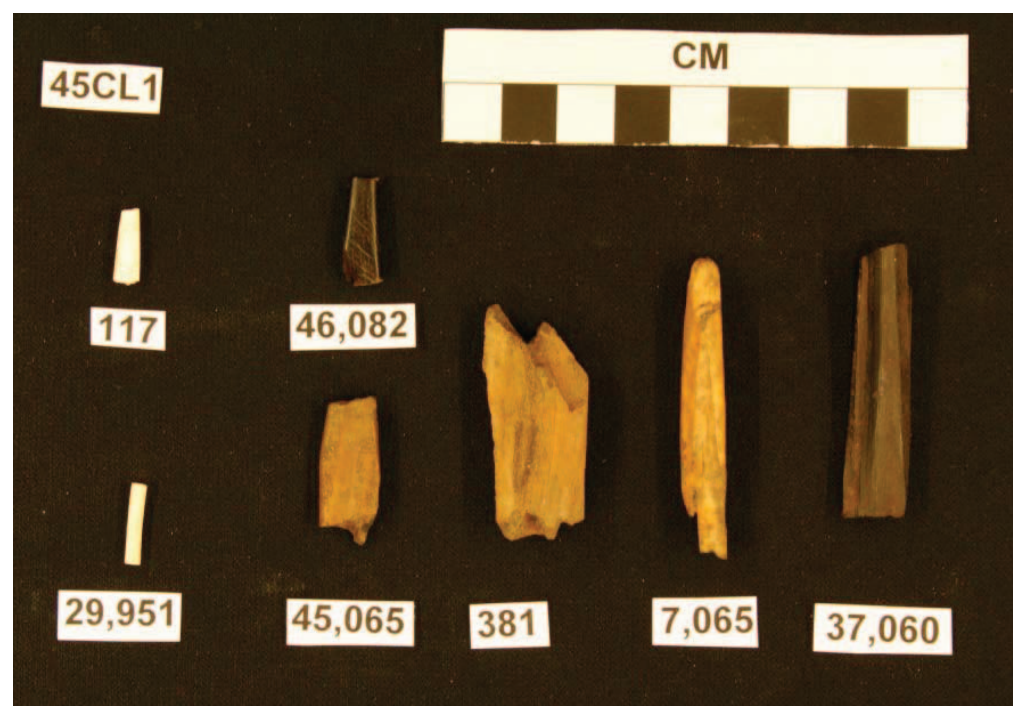

Figure 32.9G.Worked body fragments.

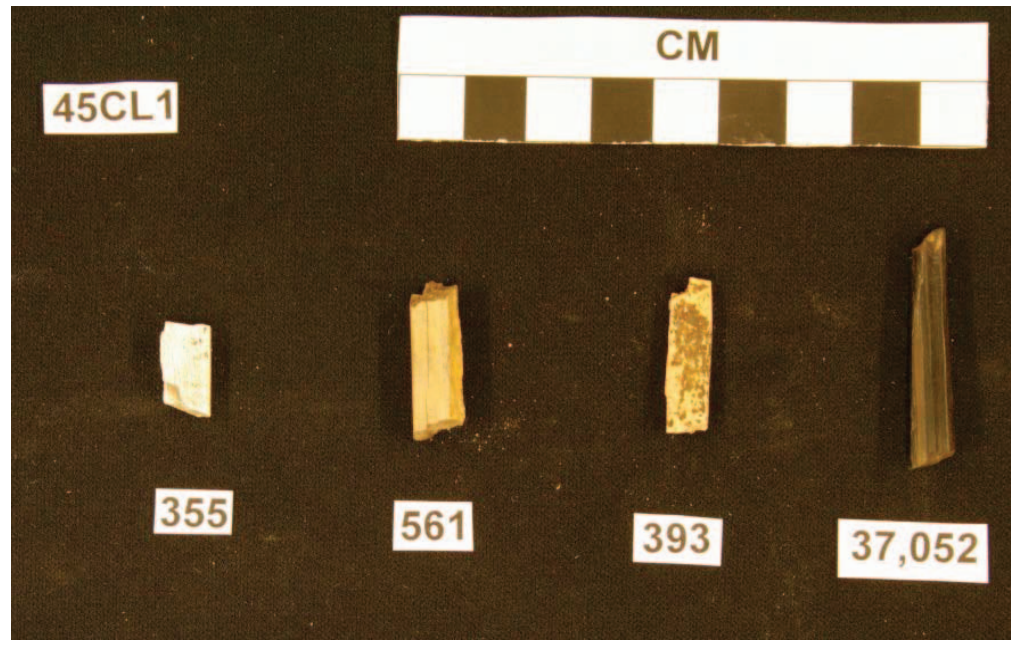

Figure 33. 9G.Worked body fragments that are "rod-like"

H. Decorated $(n=7)$ Fragments that possess a design. Two of these are carved bone (Figure 34). These are similar to the anthropomorphic hair pin (1C1, Figure 6) but do not display anything diagnostic of a hair pin. These very well may be hair pin head fragments. One decorated worked fragment is a beaver incisor. Some decorated fragments are calcined. 


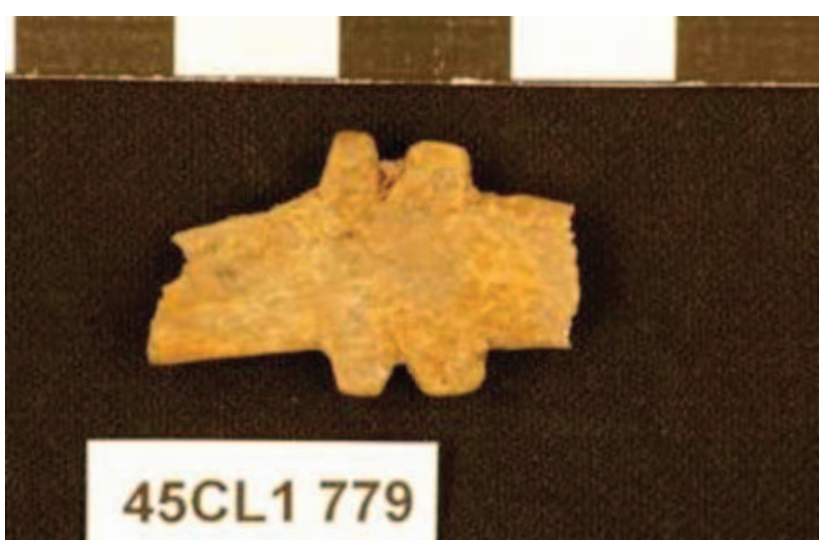

Figure 34. 9H. Decorated bone fragment.

I. Drilled $(n=1)$ Worked fragment with a hole drilled in it.

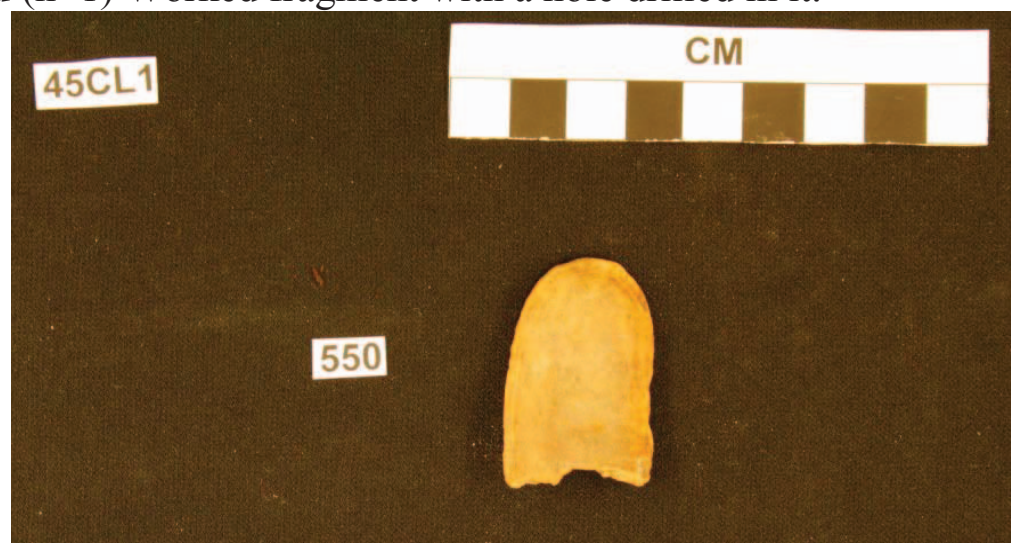

Figure 35. 9I. Drilled fragment

J. Haft $(n=1)$ Haft element fragments.

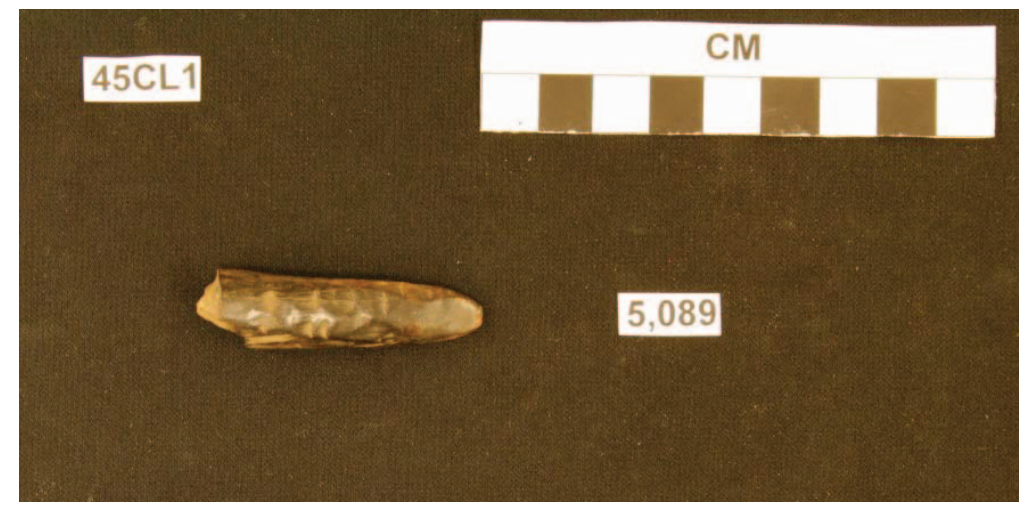

Figure 36. 9J. Worked haft fragment

K. Metapodial $(n=1)$ Worked metapodial fragments.

L. Tip $(n=19)$ Worked tip fragments. 
M. Unknown $(n=5)$ Worked fragments of an unknown raw material or unknown type. This category is also a catchall for other raw materials such as shell, or teeth.

10. Piercing Tools. Piercing tools are artifacts which possess a pointed tip that is not beveled. Categories are based on tip shape and are divided by element possession, raw material, decoration, and fragmentation. Piercing tools include awls, needles, barbs, points, or harpoons.

A. Awls. $(n=25)$ Awls are pointed tipped tools that are worked on the tip and body but possess no worked base or haft. Many awls are manufactured from splinters of long bone. Loy and Powell (1977) define awls as long thin pointed objects that differ from needles as awls lack a fiber attachment. Awls were used to perforate organic materials, such as hides, wood, and bark. Awls were also used to weave baskets, nets, and other fibrous materials (Larson 1995). Awls possess pointed tips and may have been multifunctional tools serving as projectile points or fishhooks (Roll 1974). Awls are frequently interpreted as expedient tools. Splinter awls are literally pointed bone splinters that exhibit polish on the tip area only. When tasks necessitating an awl arise, a readily available bone splinter is used once or twice and discarded. Splinter awls are the most common type of awl at Cathlapotle. Anatomical awls, such as ulna awls, are similar to splinter awls as the distal end of a bone is quickly sharpened to a point, used a few times and discarded. Anatomical awls are easy to recognize and frequently only exhibit wear near the tip. Both sites contain anatomical awls, but in relatively small numbers. Splinter awls and anatomical awls are classic examples of expedient tools as they are quickly made by simply sharpening the tip of the bone, used a few times, and discarded. Splinter awls are often irregularly shaped and exhibit no working other than on the tip. Anatomical ends provide suitable handles for anatomical awls but also exhibit no working other than on the tip. Although expedient awls are frequently present in osseous assemblages, curated hafted awls are not uncommon.

1. Worked $(n=6)$ A worked awl that possess no hafting element or base element. Cathlapotle worked awls are all made of terrestrial mammal bone. They are triangular/expanding in shape with circular tips and rectangular convex bases. Three specimens are well worked, two is seemingly expedient, and one is heavily eroded.

Table 27. 10A1 Means and standard deviations in millimeters and grams.

\begin{tabular}{|c|c|c|c|c|c|c|c|c|}
\hline & $\mathrm{N}$ & TL LENGTH & MIN WIDTH & MAX WIDTH & MIN THICKNESS & MAX THICKNESS & WEIGHT & TIP ANGLE \\
\hline MEAN & 6 & 98.51 & 1.95 & 9.99 & 2.23 & 4.32 & 5.85 & 25 \\
\hline ST. DEV. & & 32.04 & 0.72 & 3.08 & 0.56 & 2.45 & 4.09 & 7.75 \\
\hline
\end{tabular}




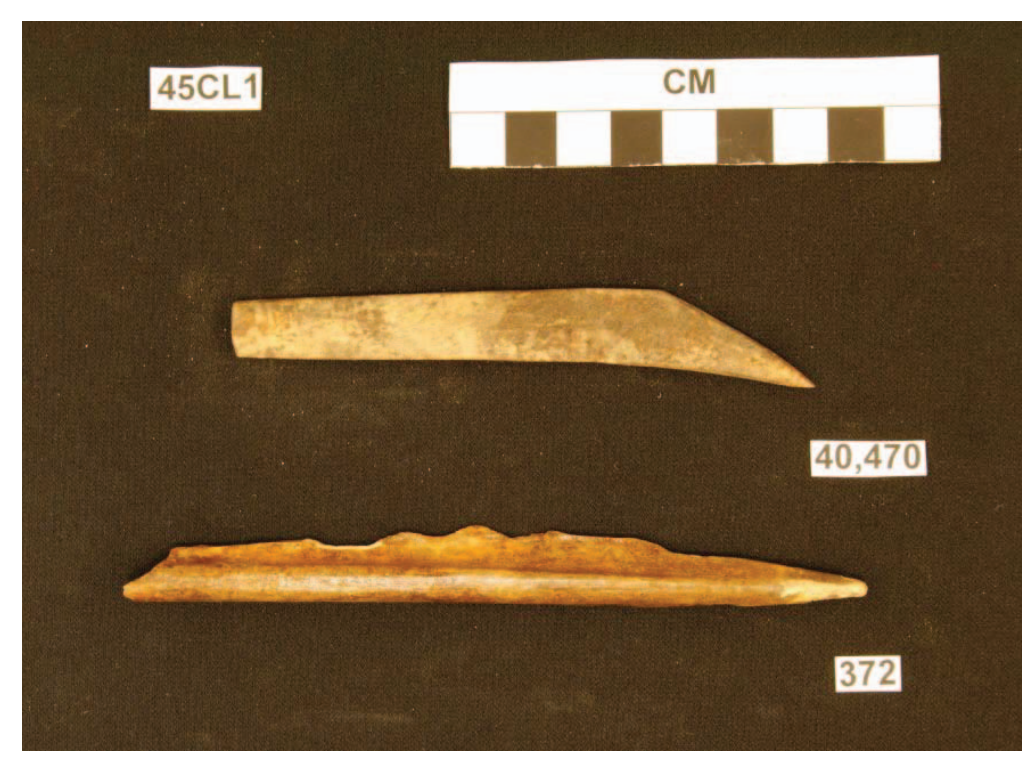

Figure 37.10A1Worked awls

2. Splinter $(n=16)$ Splinter awls are expedient tools that have been manufactured from bone fragments (splinters). Working is usually confined to the tip area only. All Cathlapotle splinter awls are made of terrestrial mammal bone. They are triangular/expanding in shape with circular/elliptical tips. Polish is the most common treatment on splinter awls, and when present polish is confined to the tip area. These are expedient tools.

Table 28. 10A2 Means and standard deviations in millimeters and grams.

\begin{tabular}{|c|c|c|c|c|c|c|c|c|}
\hline & N & TL LENGTH & MIN WIDTH & MAX WIDTH & MIN THICKNESS & MAX THICKNESS & WEIGHT & TIP ANGLE \\
\hline MEAN & 16 & 86.42 & 1.94 & 11.62 & 2 & 3.72 & 4.53 & 21.56 \\
\hline ST. DEV. & & 26.13 & 1.02 & 4.6 & 1.04 & 2.22 & 2.71 & 8.7 \\
\hline
\end{tabular}




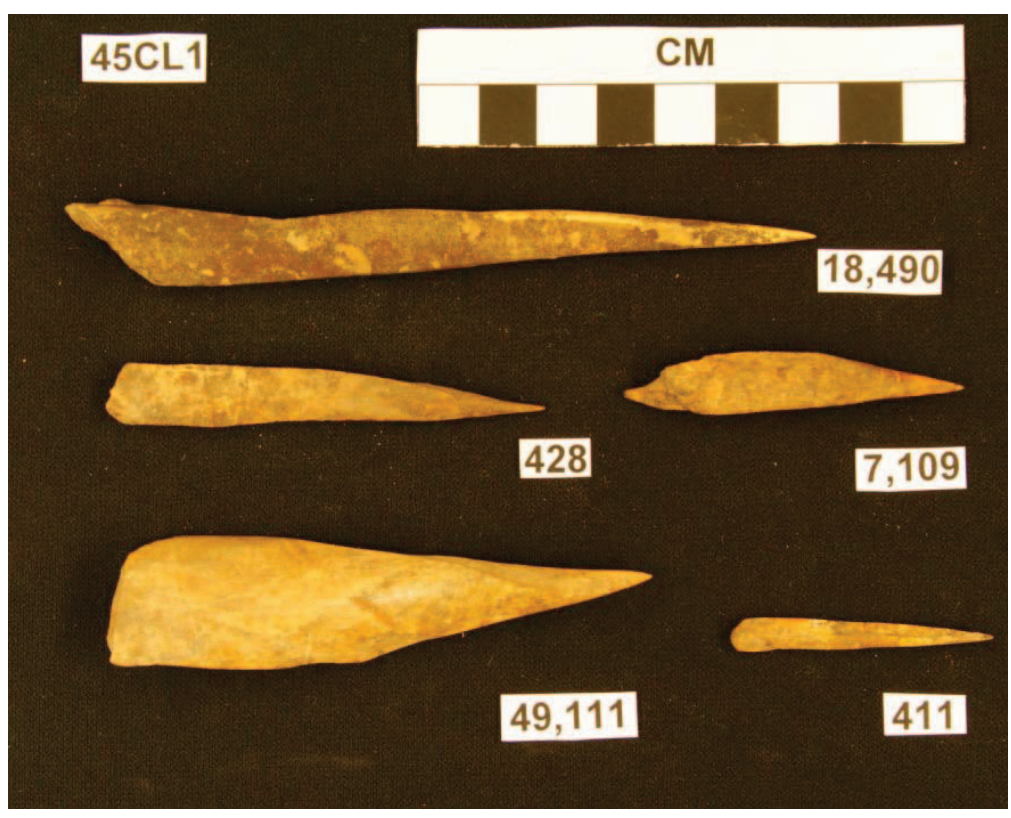

Figure 38.10A2 Splinter awls.

4. Metapodial $(n=1)$. Metapodial awls are manufactured by working the distal end of a metapodial into a sharp tip.

Table 29. 10A4 Measurement in millimeters and grams.

\begin{tabular}{|c|c|c|c|c|c|c|c|c|}
\hline & $\mathrm{N}$ & TL LENGTH & MIN WIDTH & MAX WIDTH & MIN THICKNESS & MAX THICKNESS & WEIGHT & TIP ANGLE \\
\hline & 1 & 111.63 & 1.67 & 9.93 & 2.11 & 9.37 & 5.1 & 10 \\
\hline
\end{tabular}

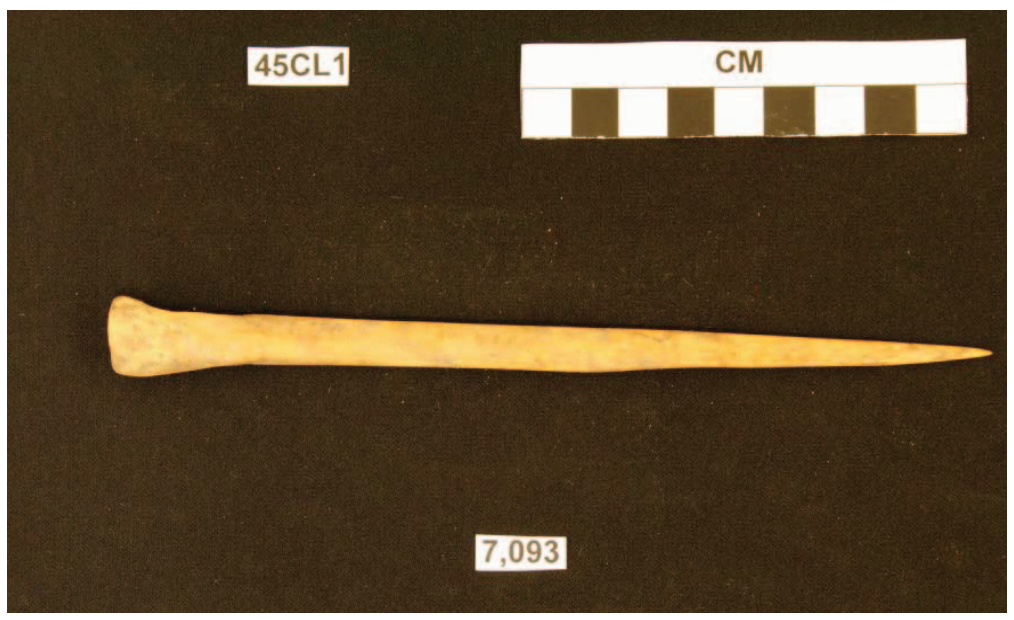

Figure 39.10A4Metapodial Awl

5. Ulna $(n=3)$ Ulna awls are manufactured by working the distal end of the ulna into a sharp tip. The proximal end retains the articulatory surface. Cathlapotle ulna awls are 
excurvate/expanding in shape. Working is confined to the tip. Both specimens are abraded and polished near the tip and unmodified elsewhere.

Table 30. 10A5 Means and standard deviations in millimeters and grams.

\begin{tabular}{|c|c|c|c|c|c|c|c|c|}
\hline & $\mathrm{N}$ & TL LENGTH & MIN WIDTH & MAX WIDTH & MIN THICKNESS & MAX THICKNESS & WEIGHT & TIP ANGLE \\
\hline MEAN & 3 & 129.07 & 2.23 & 22.45 & 2.18 & 8.49 & 9.1 & 15 \\
\hline ST. DEV. & & 41.65 & 1.28 & 15.15 & 0.74 & 3.87 & 5.37 & 8.66 \\
\hline
\end{tabular}

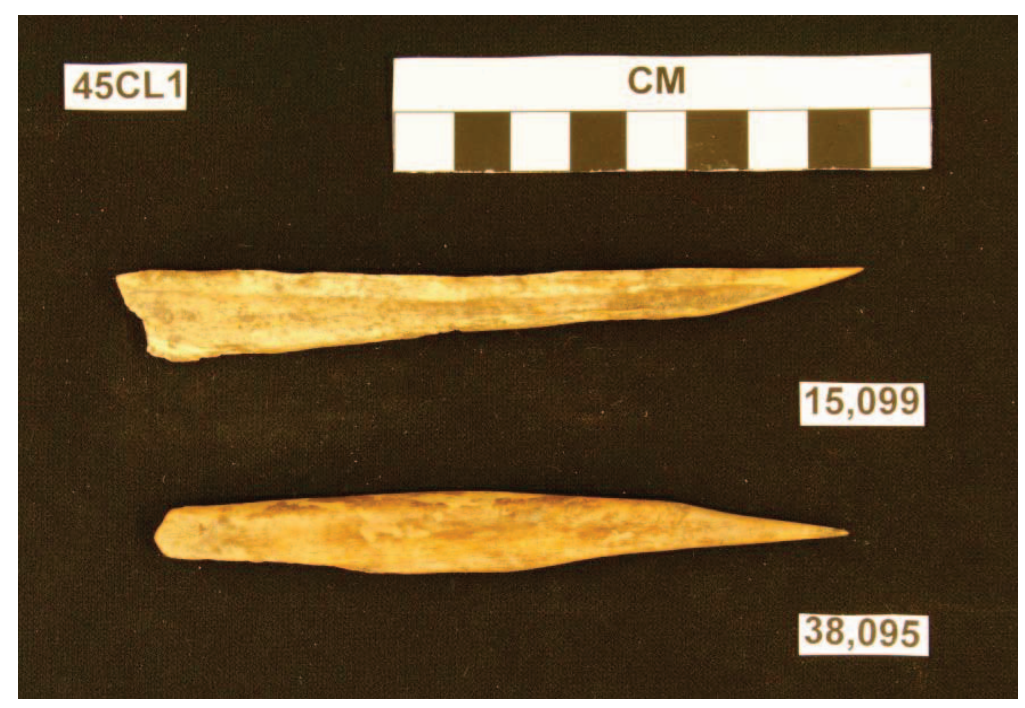

Figure 40.10A5 Ulna awls

6. Anatomical $(n=1)$ Anatomical awls are manufactured by working one end of a bone that is not an ulna or metapodial. This awl is an expedient tool. It is triangular in shape.

Table 31. 10A6 Measurements in millimeters and grams.

\begin{tabular}{|c|c|c|c|c|c|c|}
\hline TL LENGTH & MIN WIDTH & MAX WIDTH & MIN THICKNESS & MAX THICKNESS & WEIGHT & TIP ANGLE \\
\hline 114.09 & 1.75 & 15.27 & 1.74 & 10.34 & 8.1 & 10 \\
\hline
\end{tabular}

9. Fragment $(n=3)$ These artifacts possess a worked tip and body, and are fragmented in some way. Cathalpotle awls fragments are triangular in dorsal outline and longitudinal cross section and are keeled in transverse cross section. These all seem to be fragments of expedient awls. 
Table 32. 10A9 Means and standard deviations in millimeters and grams.

\begin{tabular}{|c|c|c|c|c|c|c|c|c|}
\hline & $\mathrm{N}$ & TL LENGTH & MIN WIDTH & MAX WIDTH & MIN THICKNESS & MAX THICKNESS & WEIGHT & TIP ANGLE \\
\hline MEAN & 3 & 70.02 & 1.49 & 10.15 & 1.73 & 4.99 & 2.87 & 11.67 \\
\hline ST. DEV. & & 13.1 & 0.12 & 1.8 & 0.4 & 1.31 & 1.31 & 7.67 \\
\hline
\end{tabular}

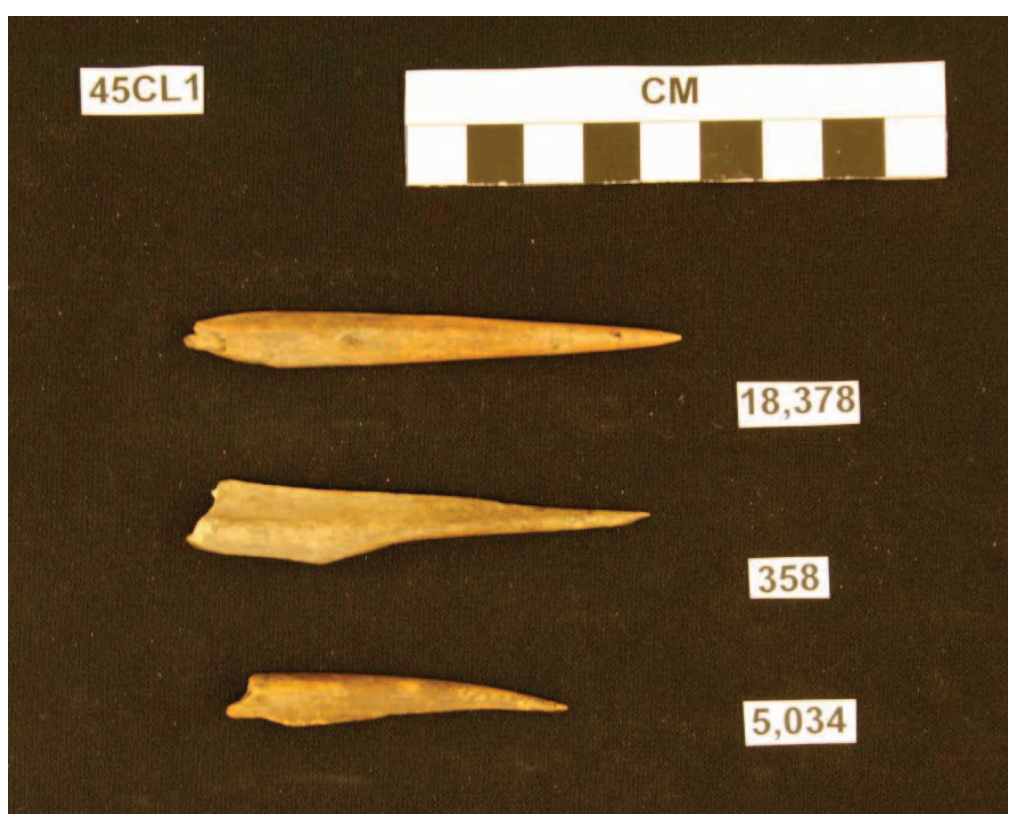

Figure 41. 10A9Awl fragments

B. Harpoons ( $\mathrm{n}=11)$ Harpoons are compound weapons used to capture aquatic prey. Harpoons are defined by their ability to detach from a shaft or foreshaft, so when prey is truck the harpoon head detaches and remains inside the prey (Raetz 1989). Harpoon heads are attached to a line that is held by the harpooner. Harpooning prey is generally not fatal. Prey are attached to the harpooner and then typically killed with a club or lance. Harpoons are essential for sea fishing or sea mammal hunting. Archaeologically, harpoons are represented by harpoon heads, valves, foreshafts/rods, and arming points. Harpoon heads and valves are diagnostic evidence of harpoons, as points had many functions and foreshafts/rods are not always recognized archaeologically. Harpoons are classed by whether they are composite or barbed. Composite toggling harpoons are constructed of two valves that are lashed together. Each valve has a distal hafting bed and when the two valves are lashed together they form a socketed base that fits on a foreshaft. Drucker (1943) distinguishes two types of composite toggling harpoons. Type I valves form a socket and were armed with bipoints or points. Type II valves form a slot to hold a bone, slate, or shell blade versus a Type I socket. Type I valves were the only type observed at both Meier and Cathlapotle. Barbed harpoon heads can be unilaterally or bilaterally barbed and have holes, guards, grooves, notches, or shoulders to hold the retrieving line in place. 
1. Self-Armed( $(n=1)$. One barbed self-arming harpoon head was recovered from Cathlapotle. It is plano-convex in both dorsal outline and transverse cross section and is rectangular in longitudinal cross section. The left lateral edge is flat, while the right lateral edge possesses two barbs that have been broken into stumps. This harpoon head is fractured at both barbs as well as transversely fractured proximal to the second barb where the hafting element would presumably be located. The artifact displays both abrasion and erosion. This artifact is clearly exhausted but was likely curated at one time.

Table 33. 10B1 Measurements in millimeters and grams.

\begin{tabular}{|c|c|c|c|c|c|c|}
\hline TL LENGTH & MIN WIDTH & MAX WIDTH & MIN THICKNESS & MAX THICKNESS & WEIGHT & TIP ANGLE \\
\hline 118.29 & 11.19 & 24.67 & 8.55 & 8.29 & 28.1 & 50 \\
\hline
\end{tabular}

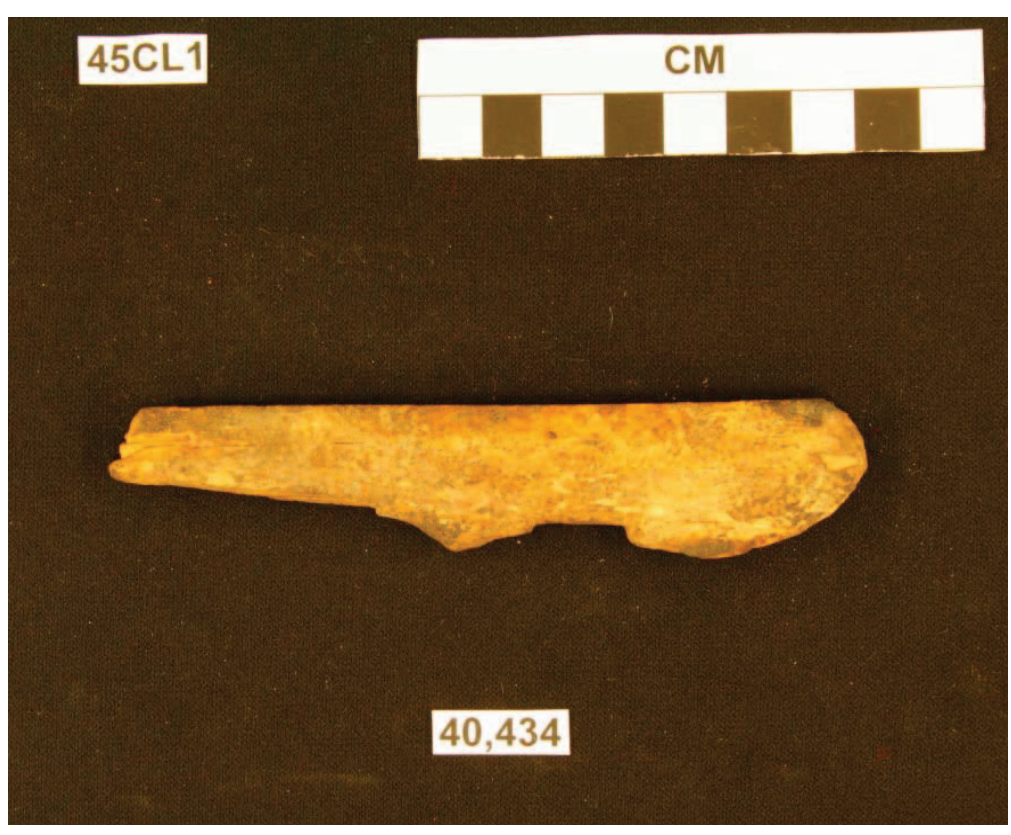

Figure 42.10B1Barbed harpoon

2. Composite $(n=10)$. Ten composite toggling harpoon valves were recovered from Cathlapotle. They are excurvate in dorsal outline, plano-convex in longitudinal cross section, and concavo-convex in transverse cross section. Hafts are rectangular to tapering in shape. All valves are made of terrestrial mammal bone. Of the ten valves, six are fragments and one is a valve blank. Two complete specimens were a pair of valves and were observed together in situ during excavations. Many specimens are extremely well worked while others less so. Although the sample size is small $(n=10)$ the Cathlapotle valve assemblage reflects various stages in the life cycle of a valve. There is a blank, a shaped valve that is not abraded, valves that are moderately worked, valves that are extremely well worked and finished, the in situ pair, as well as 
valve fragments at the end of their life cycle that are broken and eroded. Measurements are reported for the four complete specimens only.

Table 34. 10B2 Means and standard deviations in millimeters and grams.

\begin{tabular}{|c|c|c|c|c|c|c|c|}
\hline & $\mathrm{N}$ & TL LENGTH & MIN WIDTH & MAX WIDTH & MIN THICKNESS & MAX THICKNESS & WEIGHT \\
\hline MEAN & 4 & 52.01 & 6.11 & 11.5 & 3.62 & 6.82 & 2.58 \\
\hline ST. DEV. & & 6.13 & 2.5 & 2.33 & 0.17 & 0.27 & 0.87 \\
\hline
\end{tabular}

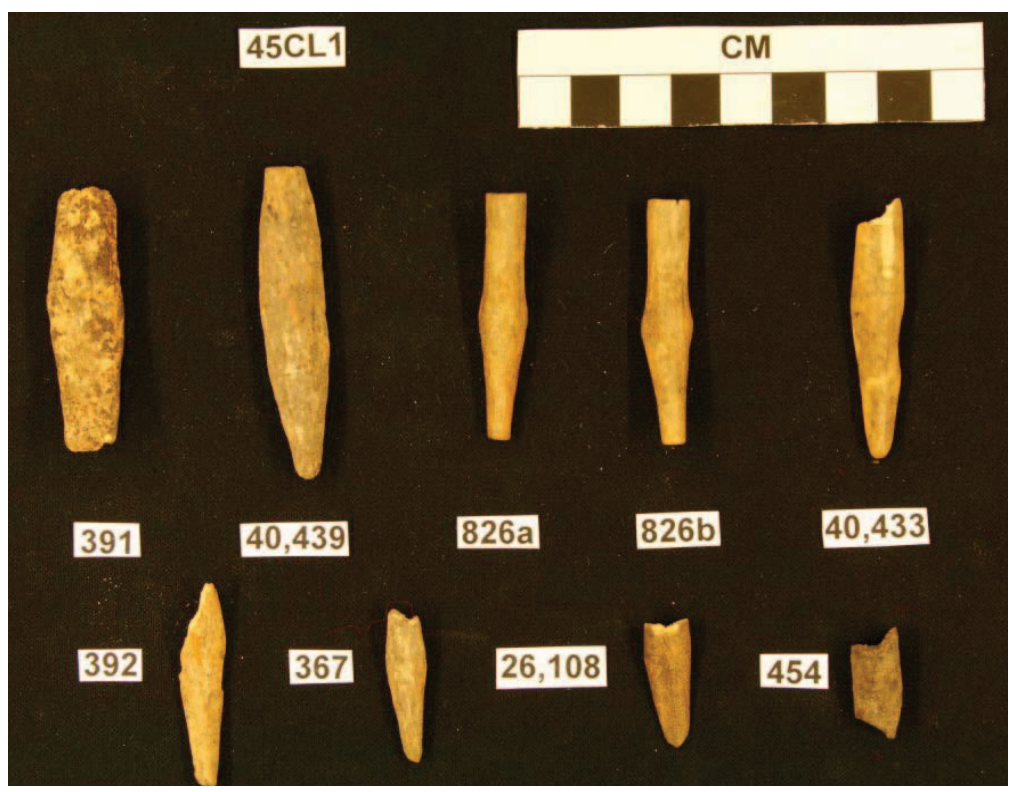

Figure 43. 10B2 Harpoon valves.

D. Points $(n=22)$ Points have a pointed tip and a haft or base element. Points include barbs and what Drucker (1943) terms "fixed bone points" (Ames 2005). Northwest Coast osseous points are variable in morphology and function. Point morphology ranges from simple fixed points to stemmed points and unilaterally and bilaterally barbed points. Lyman (1989) deals with variability in osseous points by grouping bone points into three size classes. Small needle like points are less than $4 \mathrm{~cm}$ long and less than 0.5 $\mathrm{cm}$ in diameter. Medium points are equal to $4 \mathrm{~cm}$ in length and $0.5 \mathrm{~cm}$ in diameter and large points are greater than $4 \mathrm{~cm}$ in length and $0.5 \mathrm{~cm}$ in diameter. Small points may have functioned as fish rake teeth, or arming points of small composite toggling harpoons (Roll 1974, Larson 1995). Multiple hafted points with rectangular bases armed leisters and lances. Larger points probably served as projectiles or arming points for composite toggling harpoons. Points were also part of composite fish hooks. A small sharp barb or point was tied to one end of a shank and covered with pitch. The other end of the shank was tied to the fishing line (Raetz 1989). For this thesis I recognize three types of points, hafted, fixed, and fragments. Hafted points have a pointed tip and evidence of a haft, fixed points have a 
pointed tip and a worked base, while point fragments have pointed tips and are worked over much more than awls and are clearly distinct from awls. All points including fragments are extremely well worked and are heavily abraded and polished. A variety of morphological types are represented and include small delicate points that were probably hafted in multiples to arm leister spears, as well as larger points with internal hafts or line notches that probably armed composite harpoons. There are more hafted points at both sites than any other type of point, followed by fixed points. All of the points from Cathlapotle are curated tools with a lot of time invested in their manufacture. The Cathlapotle point assemblage, although small $(n=22)$, represents multiple types of complex weapons.

1. Haft $(\mathrm{n}=12)$ Hafted points have a pointed tip and a hafting element with or without a base. All hafted points recovered from Cathlapotle are constructed of terrestrial mammal bone. Hafted points at Cathlapotle are variable in shape. In general, most are excurvate in dorsal outline, biconvex in longitudinal cross section, and either circular or rectangular in transverse cross section. Point tips are circular and elliptical in transverse cross section. Five hafted points have tapering hafts, two have internal hafts, one has a line notch, one has a line guard, one is stemmed, one has a parallel haft and one a rectangular haft. The two specimens with internal hafts also have beveled bases, one is double beveled and one is ventrally beveled. Two other points (one with a tapering haft and one with a parallel haft) have beveled bases as well. All hafted points are extremely well worked and are heavily abraded and polished. Two hafted points with tapering hafts are small and delicate and likely were one of multiple hafted points that armed a leister spear. Hafted points with internal hafts and a line notch likely armed composite harpoons. In short, all of the hafted bone points recovered from Cathlapotle are curated tools with a lot of time invested in their manufacture. The hafted bone point assemblage, although small, represents more than one type of complex weapon system.

Table 35. 10D1 Means and standard deviations in millimeters and grams.

\begin{tabular}{|c|c|c|c|c|c|c|c|c|}
\hline & $\mathrm{N}$ & TL LENGTH & MIN WIDTH & MAX WIDTH & MIN THICKNESS & MAX THICKNESS & WEIGHT & TIP ANGLE \\
\hline MEAN & 12 & 48.67 & 1.97 & 5.91 & 2.34 & 3.9 & 1.3 & 30.56 \\
\hline ST. DEV. & & 28.47 & 0.86 & 2.09 & 1.23 & 1.73 & 1.4 & 11.02 \\
\hline
\end{tabular}




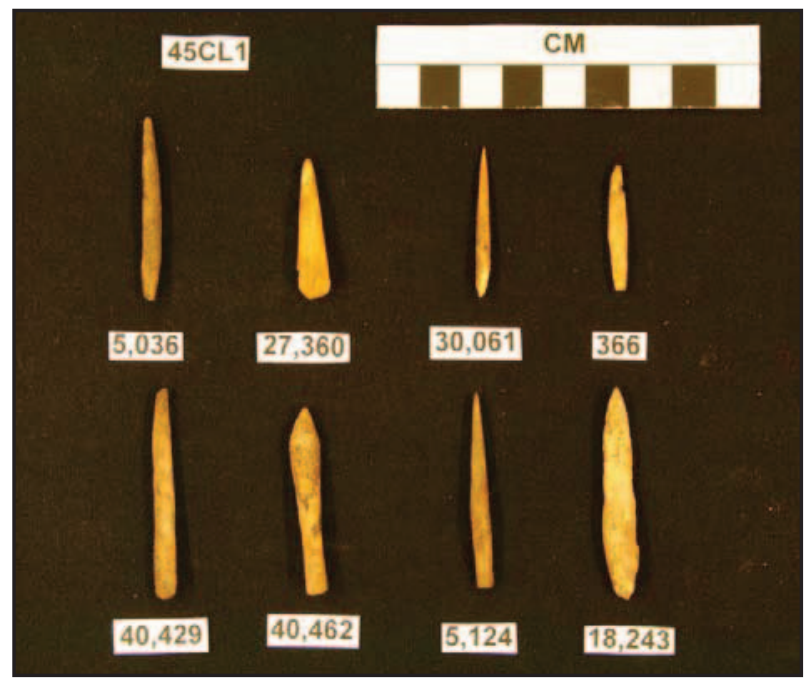

Figure 44. 10D1 Hafted points

2. Fixed $(n=7)$ Fixed points have a pointed tip and worked base without a hafting element. Fixed points from Cathlapotle are excurvate in dorsal outline and concavo-convex and rectangular in transverse cross section. Six of the seven fixed points recovered from the site are made of terrestrial mammal bone; one is made of bird bone. Fixed point bases are generally convex and two are ventrally beveled. All are extremely well worked curated tools and exhibit heavy abrasion and polish.

Table 36. 10D2 Means and standard deviations in millimeters and grams.

\begin{tabular}{|c|c|c|c|c|c|c|c|c|}
\hline & $\mathrm{N}$ & TL LENGTH & MIN WIDTH & MAX WIDTH & MIN THICKNESS & MAX THICKNESS & WEIGHT & TIP ANGLE \\
\hline MEAN & 7 & 47.54 & 3.29 & 8.68 & 1.95 & 4.72 & 2.03 & 21.7 \\
\hline ST. DEV. & & 15.91 & 2.37 & 2.59 & 1.32 & 1.75 & 1.14 & 2.9 \\
\hline
\end{tabular}




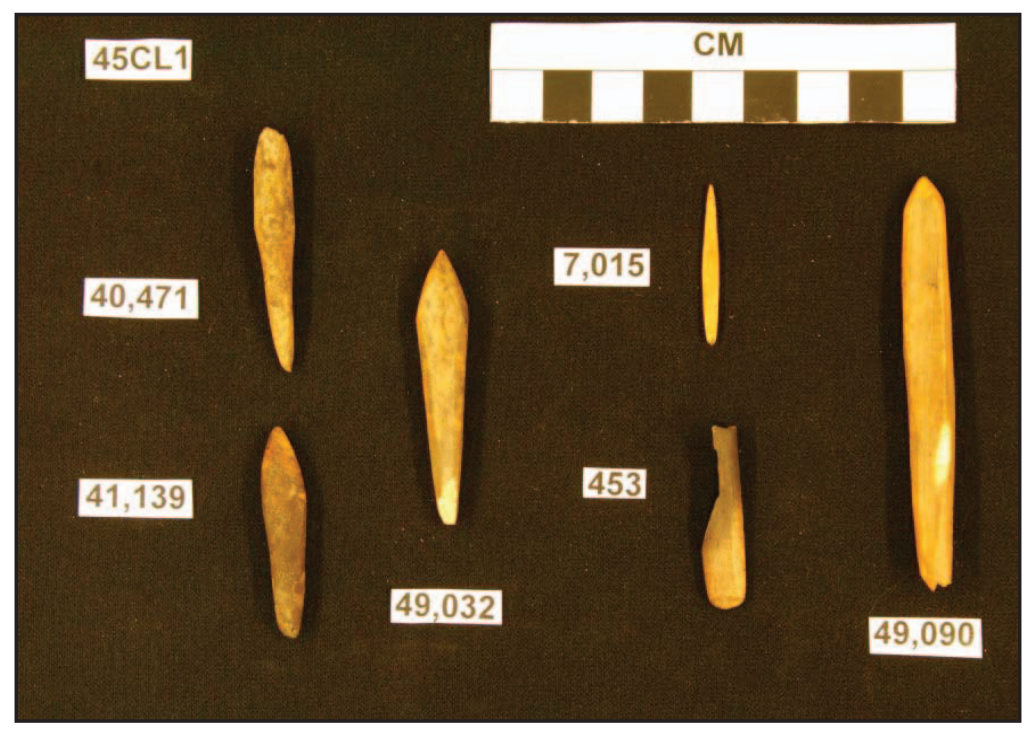

Figure 45. 10D2Fixed points.

6. Fragment $(n=3)$ These artifacts have a pointed tip and are worked moreso over the tip and body than awls. Point fragments are clearly not awls. The three Cathlapotle specimens are all made of terrestrial mammal bone. They are ovate in dorsal and longitudinal views and keeled in transverse cross section.

Table 37. 10D6 Means and standard deviations in millimeters and grams.

\begin{tabular}{|c|c|c|c|c|c|c|c|c|}
\hline & $\mathrm{N}$ & TL LENGTH & MIN WIDTH & MAX WIDTH & MIN THICKNESS & MAX THICKNESS & WEIGHT & TIP ANGLE \\
\hline MEAN & 3 & 26.08 & 2.4 & 6.91 & 1.98 & 5.17 & 0.77 & 25 \\
\hline ST. DEV. & & 8.74 & 0.77 & 1.34 & 0.74 & 1.45 & 0.21 & 13.28 \\
\hline
\end{tabular}

11. Peg $(n=1)$ Pegs resemble wooden pegs.. The peg recovered from Cathlapotle is rectangular in dorsal outline, excurvate in longitudinal cross section, and square in transverse cross section. The base is convex and ventrally beveled. This artifact is flat on all four sides.

Table 38. 11 Measurements in millimeters and grams.

\begin{tabular}{|c|c|c|c|c|c|}
\hline TL LENGTH & MIN WIDTH & MAX WIDTH & MIN THICKNESS & MAX THICKNESS & WEIGHT \\
\hline 51.53 & 9.74 & 13.24 & 7.47 & 9.13 & 8.1 \\
\hline
\end{tabular}




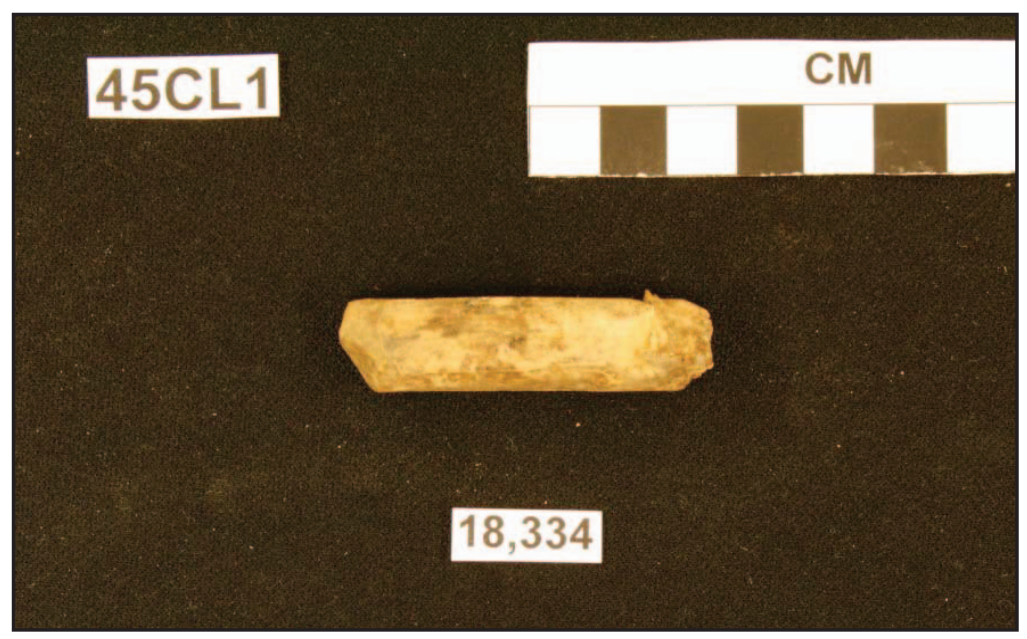

Figure $46.11 \mathrm{Peg}$.

12. Foreshaft/Rod $(n=4)$ Foreshafts/Rods are square to cylindrical rods with blunt tips and bases. They function as shock absorbers between a harpoon head and shaft (Raetz 1989). Rods purposely breakaway from the head and shaft, preventing damage to the entire the weapon system. Often hafting elements are indiscernible. Foreshaft/Rods are commonly fragmented. They are likely undercounted as many fragments were probably recorded as worked bone body fragments. The category $9 \mathrm{G}$ represents worked bone body fragments that are square or rectangular in transverse cross section that appear to be foreshaft/rod fragments. As it is impossible to tell whether or not these worked bone fragments are in fact foreshaft/rod fragments, they are recorded as worked bone and noted here. The foreshaft/rods recovered from Cathlapotle are all constructed of terrestrial mammal bone. They are biplano in dorsal and longitudinal views and are square and subelliptical in transverse cross section. Two are fragmented and two are complete. One complete specimen has a tapering haft and the other a stemmed haft. Bases are convex and rounded. Foreshaft/rods are flat to slightly curved on all four sides. These specimens showed evidence of grinding and some polish. They were likely curated artifacts as they were part of larger more complex weapon systems.

Table 39. 12 Means and standard deviations in millimeters and grams.

\begin{tabular}{|c|c|c|c|c|c|c|c|}
\hline & $\mathrm{N}$ & TL LENGTH & MIN WIDTH & MAX WIDTH & MIN THICKNESS & MAX THICKNESS & WEIGHT \\
\hline MEAN & 4 & 89.2 & 6.58 & 9.24 & 4.36 & 4.83 & 6.93 \\
\hline ST. DEV. & & 35.8 & 2.69 & 2.96 & 0.66 & 2.19 & 4.6 \\
\hline
\end{tabular}




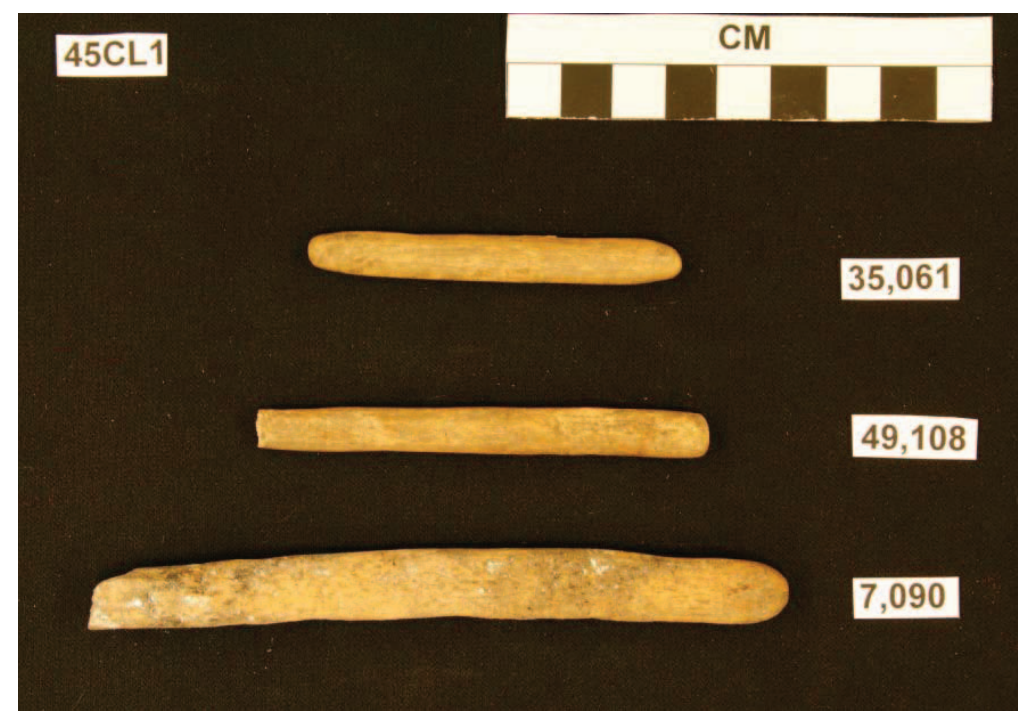

Figure 47.12Foreshafts 
Appendix B:

Observed and Expected Artifact Counts for Significant Chi Square Tests 
Table 40. Observed and expected counts for complete procurement artifacts at Cathlapotle.

\begin{tabular}{|c|c|c|}
\hline \multicolumn{3}{|c|}{ Cathlapotle } \\
\hline \multicolumn{3}{|c|}{$\overline{\text { Complete Procurement Artifacts }}$} \\
\hline & & Expected \\
\hline In & 6 & 12 \\
\hline Out & 12 & 6 \\
\hline
\end{tabular}

Table 41. Observed and expected counts for all procurement artifacts at Cathlapotle.

\begin{tabular}{|lrr|}
\hline \multicolumn{3}{|l|}{ Cathlapotle } \\
\multicolumn{4}{|l|}{ All Procurement Artifacts } \\
In & Observed & Expected \\
Out & 10 & 24 \\
\hline
\end{tabular}

Table 42. Observed and expected counts for complete modification artifacts at Cathlapotle

\begin{tabular}{|c|c|c|}
\hline \multicolumn{3}{|c|}{ Cathlapotle } \\
\hline \multicolumn{3}{|c|}{ Complete Modification Artifacts } \\
\hline & & Expected \\
\hline In & 7 & 16 \\
\hline Out & 17 & 8 \\
\hline
\end{tabular}

Table 43. Observed and expected counts for all modification artifacts at Cathlapotle.

\begin{tabular}{|lrr|}
\hline \multicolumn{2}{|l|}{ Cathlapotle } \\
\multicolumn{2}{|l|}{ All Modification Artifacts } \\
In & $\frac{\text { Observed }}{26}$ & Expected \\
Out & 34 & 39 \\
\hline
\end{tabular}


Table 44. Observed and expected counts for all awls at Cathlapotle.

\begin{tabular}{|c|c|c|}
\hline \\
\hline \multicolumn{3}{|c|}{$\begin{array}{l}\text { Cathlapotle } \\
\text { All Awls }\end{array}$} \\
\hline & Observed & Expected \\
\hline $\ln$ & 8 & 21 \\
\hline Out & 25 & 12 \\
\hline
\end{tabular}

Table 45. Observed and expected counts for broken other artifacts at Cathlapotle.

\begin{tabular}{|c|c|c|}
\hline \multicolumn{3}{|c|}{ Cathlapotle } \\
\hline \multicolumn{3}{|c|}{ Broken Other Artifacts } \\
\hline & & Expected \\
\hline In & 26 & 37 \\
\hline Out & 31 & 20 \\
\hline
\end{tabular}

Table 46. Observed and expected counts for all other artifacts at Cathlapotle.

\begin{tabular}{|c|c|c|}
\hline \multicolumn{3}{|c|}{ Cathlapotle } \\
\hline \multicolumn{3}{|c|}{ All Other Artifacts } \\
\hline & Observed & Expected \\
\hline In & 116 & 151 \\
\hline Out & 118 & 82 \\
\hline
\end{tabular}

Table 47. Observed and expected counts for all other artifacts at Cathlapotle

\begin{tabular}{|lrr|}
\hline Cathlapotle & & \\
\cline { 1 - 2 } All Other Artifacts & & \\
\cline { 1 - 2 } Facility & Observed & Expected \\
Bench/Cellar & 25 & 19 \\
Hearth Periphery & 18 & 38 \\
Wall & 23 & 21 \\
Wall/Bench/Cellar & 36 & 42 \\
Midden Lobe A & 6 & 9 \\
Midden Lobe B & 20 & 9 \\
Sheet Midden & & \\
(H1) & 40 & 38 \\
Sheet Midden & & \\
(H2) & 37 & 13 \\
Sheet Midden & & \\
(H6) & 15 & 7 \\
\hline
\end{tabular}


Table 48. Observed and expected counts for all complete artifacts at Cathlapotle.

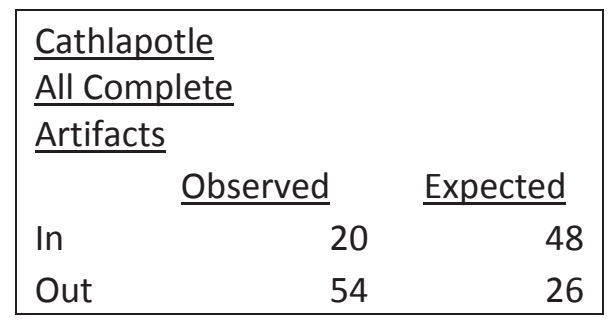

Table 49. Observed and expected counts for all broken artifacts at Cathlapotle.

\begin{tabular}{|lrr|}
\hline \multicolumn{2}{|l|}{ Cathlapotle } \\
\multicolumn{2}{|l|}{ All Broken Artifacts } \\
In & $\frac{\text { Observed }}{2}$ & Expected \\
Out & 55 & 79 \\
\hline
\end{tabular}

Table 50. Observed and expected counts for detritus at Cathlapotle.

\begin{tabular}{|lrr|}
\hline \multicolumn{2}{|l|}{$\begin{array}{l}\text { Cathlapotle } \\
\text { Detritus }\end{array}$} & \\
& $\frac{\text { Observed }}{43}$ & Expected \\
In & 36 & 51 \\
Out & 36 & 27 \\
\hline
\end{tabular}

Table 51. Observed and expected counts for all artifacts at Cathlapotle.

\begin{tabular}{|llr|}
\hline \multicolumn{2}{l|}{ Cathlapotle } \\
\multicolumn{2}{l|}{ All Artifacts } \\
In & $\frac{\text { Observed }}{164}$ & Expected \\
Out & 164 & 239 \\
\hline
\end{tabular}

Table 52. Observed and expected counts for broken modification artifacts at Meier.

\begin{tabular}{|lrr|}
\hline \multicolumn{3}{|l|}{ Meier } \\
Broken Modification Artifacts \\
In & $\frac{\text { Observed }}{2}$ & Expected \\
Out & 97 & 109 \\
\hline
\end{tabular}


Table 53. Observed and expected counts for ornaments at Meier.

\begin{tabular}{|llr|}
\hline \multicolumn{2}{|l|}{ Meier } \\
\multicolumn{2}{|l|}{ All Ornaments } \\
\\
In & $\frac{\text { Observed }}{66}$ & Expected \\
Out & 15 & 58 \\
\hline
\end{tabular}

Table 54. Observed and expected counts for ornaments at Meier

\begin{tabular}{|c|c|c|}
\hline \multicolumn{3}{|l|}{ Meier } \\
\hline \multicolumn{3}{|c|}{ All Ornaments } \\
\hline Location & $\underline{\text { Observed }}$ & Expected \\
\hline North & 25 & 15 \\
\hline Center & 14 & 11 \\
\hline South & 29 & 33 \\
\hline Midden & 8 & 13 \\
\hline Exterior & 7 & 11 \\
\hline
\end{tabular}

Table 55. Observed and expected counts for ornaments at Meier.

\begin{tabular}{|lrr|}
\hline Meier & & \\
All Ornaments & & \\
Facility & Observed & Expected \\
\cline { 2 - 3 } Bench & 8 & 13 \\
Cellar & 31 & 21 \\
Cellar/Bench & 11 & 6 \\
Hearth Periphery & 13 & 12 \\
Wall & 5 & 7 \\
Midden & 8 & 13 \\
Exterior & 7 & 11 \\
\hline
\end{tabular}

Table 56. Observed and expected counts for broken other artifacts at Meier.

\begin{tabular}{|lrr|}
\hline \multicolumn{2}{|l|}{ Meier } & \\
\multicolumn{3}{|l|}{ Broken Other Artifacts } \\
In & $\frac{\text { Observed }}{387}$ & Expected \\
Out & 184 & 408 \\
\hline
\end{tabular}


Table 57. Observed and expected counts for broken other artifacts at Meier.

\begin{tabular}{|c|c|c|}
\hline Meier & & \\
\hline Broken & her Artifact & \\
\hline Location & Observed & Expected \\
\hline North & 109 & 106 \\
\hline Center & 63 & 77 \\
\hline South & 215 & 224 \\
\hline Midden & 121 & 90 \\
\hline Exterior & 63 & 75 \\
\hline
\end{tabular}

Table 58. Observed and expected counts for broken other artifacts at Meier.

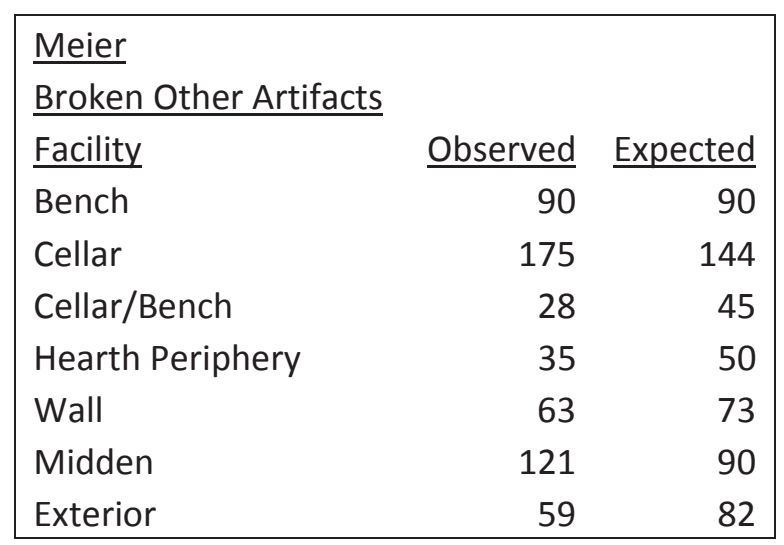

Table 59. Observed and expected counts for all other artifacts at Meier.

\begin{tabular}{|lrr|}
\hline \multicolumn{2}{|l|}{ Meier } & \\
\multicolumn{2}{|l|}{ All Other Artifacts } \\
In & $\frac{\text { Observed }}{432}$ & Expected \\
Out & 212 & 183 \\
\hline
\end{tabular}


Table 60. Observed and expected counts for all other artifacts at Meier.

\begin{tabular}{|c|c|c|}
\hline \multicolumn{3}{|c|}{$\begin{array}{l}\text { Meier } \\
\text { All Other Artifacts }\end{array}$} \\
\hline Location & Observed & Expected \\
\hline North & 120 & 120 \\
\hline Center & 68 & 87 \\
\hline South & 244 & 252 \\
\hline Midden & 145 & 101 \\
\hline Exterior & 67 & 84 \\
\hline
\end{tabular}

Table 61. Observed and expected counts for all other artifacts at Meier.

\begin{tabular}{|c|c|c|}
\hline \multicolumn{3}{|l|}{$\underline{\text { Meier }}$} \\
\hline All Other Artifacts & & \\
\hline$\underline{\text { Facility }}$ & Observed & Expected \\
\hline Bench & 97 & 101 \\
\hline Cellar & 196 & 162 \\
\hline Cellar/Bench & 30 & 50 \\
\hline Hearth Periphery & 41 & 56 \\
\hline Wall & 67 & 82 \\
\hline Midden & 145 & 101 \\
\hline Exterior & 68 & 92 \\
\hline
\end{tabular}

Table 62. Observed and expected counts for all complete artifacts at Meier

\begin{tabular}{|lrr|}
\hline \multicolumn{2}{|l|}{ Meier } & \\
\multicolumn{2}{|l|}{ All Complete Artifacts } & \\
In & $\frac{\text { Observed }}{\text { Expected }}$ & 142 \\
Out & 36 & 51 \\
\hline
\end{tabular}


Table 63. Observed and expected counts for all complete artifacts at Meier.

\begin{tabular}{|lrr|}
\hline \multicolumn{2}{l}{ Meier } \\
\multicolumn{2}{ll}{ All Complete Artifacts } & \\
\cline { 1 - 1 } Location & Observed & Expected \\
\cline { 1 - 2 } North & 36 & 33 \\
Center & 34 & 24 \\
South & 72 & 70 \\
Midden & 24 & 28 \\
Exterior & 12 & 23 \\
\hline
\end{tabular}

Table 64. Observed and expected counts for all complete artifacts at Meier.

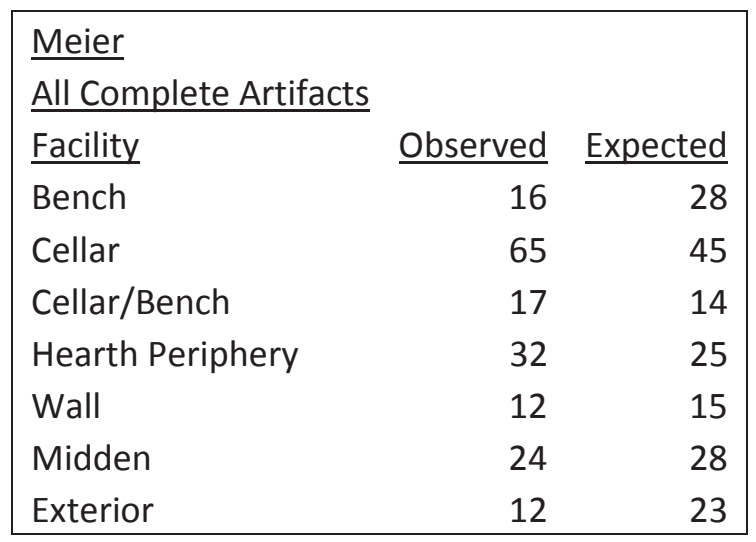

Table 65. Observed and expected counts for all broken artifacts at Meier.

\begin{tabular}{|lrr|}
\hline \multicolumn{2}{|l|}{ Meier } \\
\multicolumn{2}{|l|}{ All Broken Artifacts } \\
\\
In & $\frac{\text { Observed }}{641}$ & \\
Out & 304 & 269 \\
\hline
\end{tabular}


Table 66. Observed and expected counts for all broken artifacts at Meier.

\begin{tabular}{|c|c|c|}
\hline Meier & & \\
\hline All Broke & Artifacts & \\
\hline Location & Observed & Expectec \\
\hline North & 175 & $17 \epsilon$ \\
\hline Center & 105 & 127 \\
\hline South & 361 & 370 \\
\hline Midden & 199 & 148 \\
\hline Exterior & 105 & 123 \\
\hline
\end{tabular}

Table 67. Observed and expected counts for all broken artifacts at Meier.

\begin{tabular}{|c|c|c|}
\hline \multicolumn{3}{|l|}{ Meier } \\
\hline \multicolumn{3}{|l|}{ All Broken Artifacts } \\
\hline Facility & Observed & Expected \\
\hline Bench & 143 & 148 \\
\hline Cellar & 281 & 238 \\
\hline Cellar/Bench & 51 & 73 \\
\hline Hearth Periphery & 107 & 135 \\
\hline Wall & 59 & 82 \\
\hline Midden & 199 & 148 \\
\hline Exterior & 105 & 121 \\
\hline
\end{tabular}

Table 68. Observed and expected counts for all artifacts at Meier.

\begin{tabular}{|c|c|c|}
\hline \multicolumn{3}{|l|}{$\underline{\text { Meier }}$} \\
\hline Location & Observed & Expected \\
\hline North & 224 & 224 \\
\hline Center & 145 & 162 \\
\hline South & 468 & 472 \\
\hline Midden & 247 & 189 \\
\hline Exterior & 121 & 157 \\
\hline
\end{tabular}


Table 69. Observed and expected counts for all artifacts at Meier.

\begin{tabular}{|lrr|}
\hline Meier & & \\
\cline { 1 - 1 } All Artifacts & & \\
Facility & Observed & Expected \\
\cline { 2 - 3 } Bench & 168 & 189 \\
Cellar & 373 & 304 \\
Cellar/Bench & 71 & 93 \\
Hearth Periphery & 148 & 172 \\
Wall & 77 & 105 \\
Midden & 247 & 189 \\
Exterior & 121 & 154 \\
\hline
\end{tabular}

